\title{
Eco-town: An integrated modeling framework for simulating the effects of urban morphology on sustainable development
}

\author{
Ali Abutalebpur
}

Follow this and additional works at: https://researchrepository.wvu.edu/etd

\section{Recommended Citation}

Abutalebpur, Ali, "Eco-town: An integrated modeling framework for simulating the effects of urban morphology on sustainable development" (2015). Graduate Theses, Dissertations, and Problem Reports. 5024.

https://researchrepository.wvu.edu/etd/5024

This Dissertation is protected by copyright and/or related rights. It has been brought to you by the The Research Repository @ WVU with permission from the rights-holder(s). You are free to use this Dissertation in any way that is permitted by the copyright and related rights legislation that applies to your use. For other uses you must obtain permission from the rights-holder(s) directly, unless additional rights are indicated by a Creative Commons license in the record and/ or on the work itself. This Dissertation has been accepted for inclusion in WVU Graduate Theses, Dissertations, and Problem Reports collection by an authorized administrator of The Research Repository @ WVU.

For more information, please contact researchrepository@mail.wvu.edu. 
Eco-town: An integrated modeling framework for simulating the effects of urban morphology on sustainable development

\author{
Ali Abutalebpur \\ Dissertation Submitted \\ to the Davis College of Agriculture, Natural Resources and Design \\ at West Virginia University \\ in partial fulfillment of the requirements for the degree of \\ Doctor of Philosophy in \\ Human and Community Development
}

\author{
Hodjat Ghadimi, Ph.D., Chair \\ Randall W. Jackson, Ph.D. \\ Peter V. Schaeffer, Ph.D. \\ Barbara McFall, Ph.D. \\ Michael P. Strager, Ph.D. \\ Chris Haddox, Ph.D.
}

School of Design and Community Development

Morgantown, West Virginia
2015

Keywords: Sustainable Development, Urban Morphology, Genuine Progress Indicator, Eco-town

Copyright 2015 Ali Abutalebpur 


\begin{abstract}
Eco-town: An integrated modeling framework for simulating the effects of urban morphology on sustainable development
\end{abstract}

\begin{abstract}
Ali Abutalebpur
Spatial structure of a city is a key determinant of its socioeconomic well-being and there is a growing interest in models that investigate the relation between spatial structure and sustainable urban development. This dissertation aims to examine the role of urban spatial structure on social, economic, and environmental dimensions of sustainability through developing an integrated modeling framework. In particular, this modeling framework bridges "design of urban built environment" and "sustainable development" at the city-region level through simulation and measuring the effect of changes in urban spatial structure on the stock of various asset forms including natural, human, and physical capital.

The proposed methodology consists of an integrated modeling framework through which various spatial configurations of the selected urban facilities are simulated and simulation outputs are evaluated in terms of sustainability. This framework consists of four components: i. a spatial database, ii. a land suitability analysis, iii. a spatial optimization model which is a combination of optimal facility location and optimal shopping frequency models and iv. a sustainability assessment. The sustainability metrics of Genuine Progress Indicator (GPI) is employed to evaluate simulation results and reveal the direction and magnitude of effects.

The modeling framework was applied to the study area of Morgantown, West Virginia for a case of locating food and beverage stores. The simulation results were generalized into a set of monocentric, polycentric and decentralized scenarios in order to measure the GPI level's change due to the changes in the spatial configuration of food and beverage stores. The results show that even a modest change in the spatial configuration of an urban facility (food and beverage store) can significantly change the urban sustainability level as measured by GPI.
\end{abstract}




\section{DEDICATION}

I would like to dedicate my dissertation to my family 


\section{ACKNOWLEDGEMENTS}

I would never have been able to finish my dissertation without the guidance of my committee members, help from friends, and support from my family.

I would like to express my deepest appreciation to my advisor, Dr. Hodjat Ghadimi, for his excellent guidance, patience, and providing me with an excellent atmosphere for doing research. I would like to thank my committee members Dr. Randall W. Jackson, Dr. Peter V. Schaeffer, Dr. Michael P. Strager, Dr. Barbara McFall, and Dr. Chris Haddox for their valuable time, helpful suggestions, and great support for the past several years. I would also like to thank Dr. Kerry Odell who as division director was always willing to help and give his best suggestions.

I would also like to thank my family. They were always supporting me and encouraging me with their best wishes. Finally, special thanks go to my mom for her love and care. 


\section{TABLE OF CONTENTS}

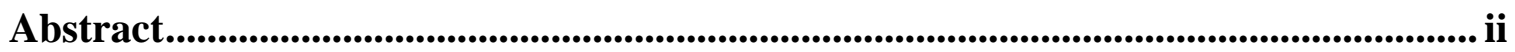

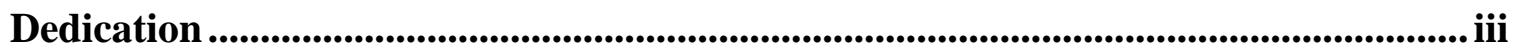

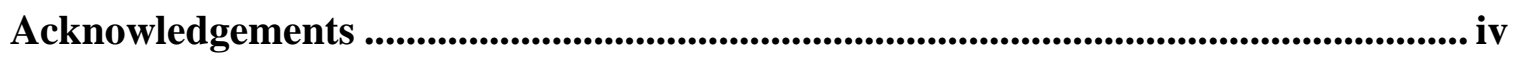

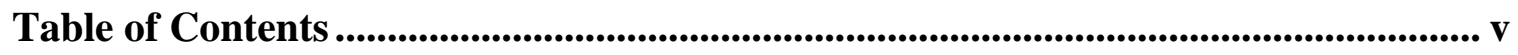

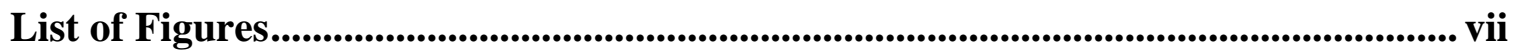

List of Tables ................................................................................................................................... $\mathrm{x}$

Chapter I.............................................................................................................................................. 1

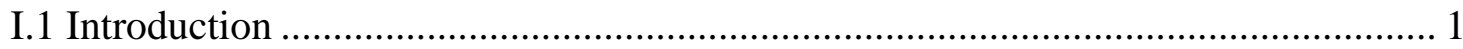

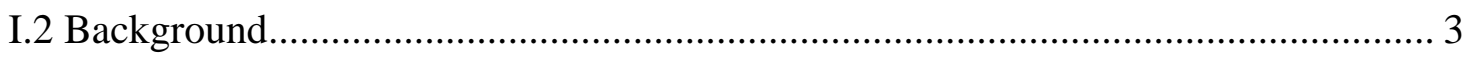

I.3 Main goals and objectives of the research...................................................... 12

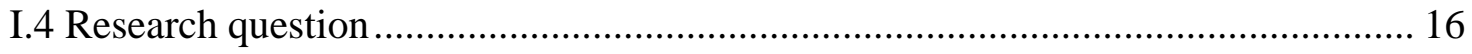

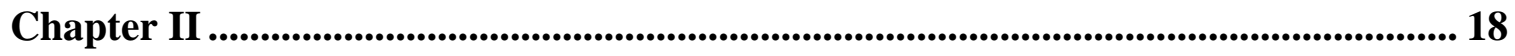

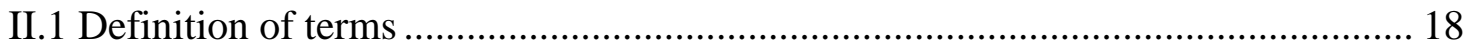

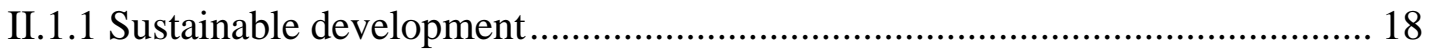

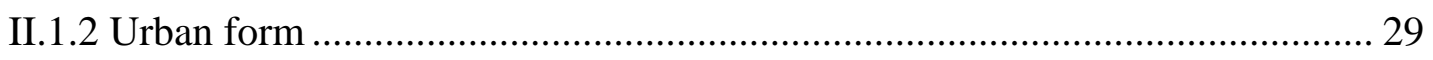

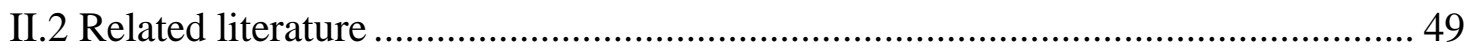

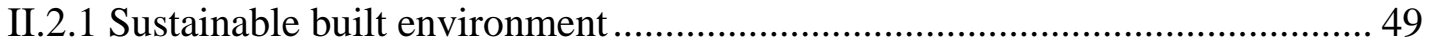

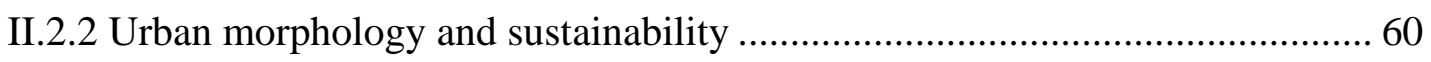

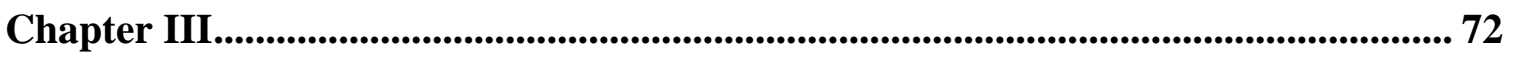

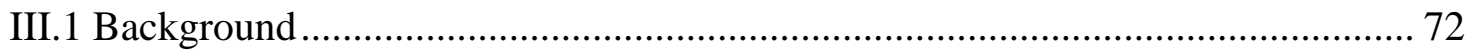

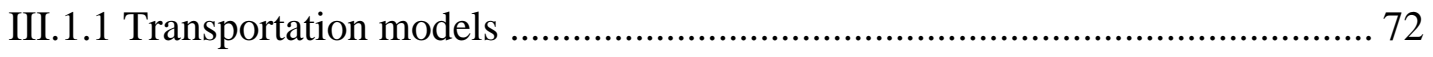

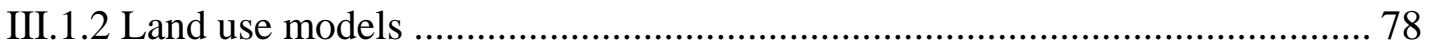

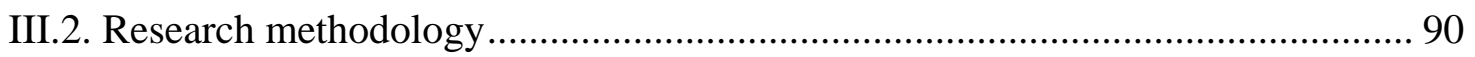




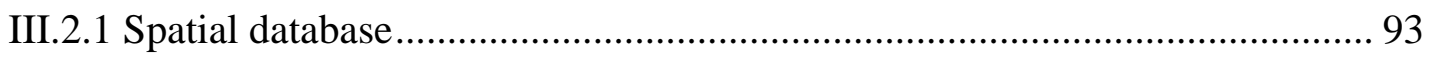

III.2.2 Land Suitability Analysis........................................................................ 93

III.2.3 Spatial optimization model ...................................................................... 96

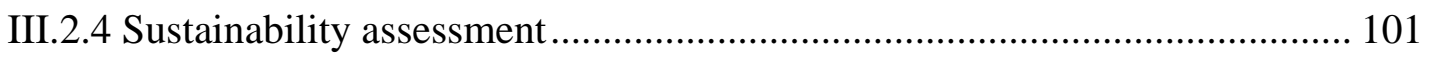

Chapter IV .......................................................................................................................... 112

IV.1 Case study area: The city of Morgantown, WV ............................................ 112

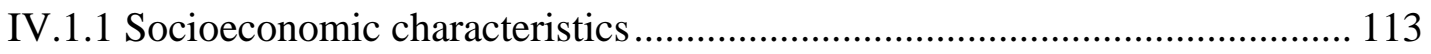

IV.1.2 Physical characteristics and spatial structure attributes ............................... 114

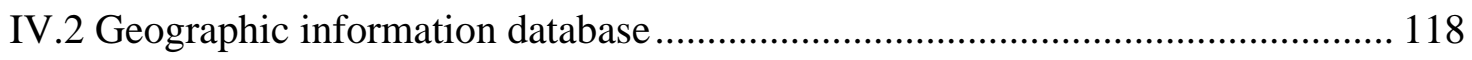

IV.2.1 Morgantown boundary ......................................................................... 118

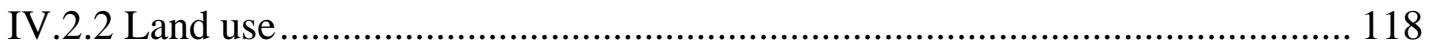

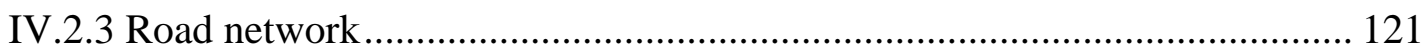

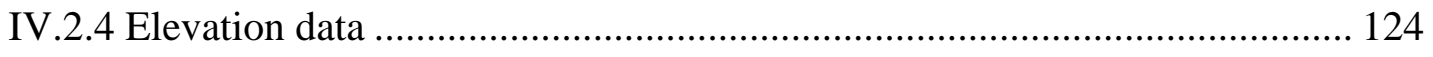

IV.3 Subject of modeling (selected urban facility) ................................................... 127

IV.4 Application of Land Suitability Analysis (LSA) .............................................. 128

IV.5 Application of spatial optimization model .................................................... 136

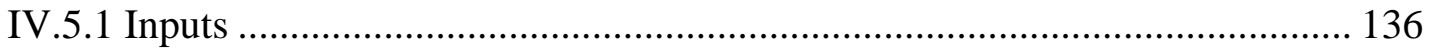

IV.5.2 Results of computer simulation (outputs) ................................................ 142

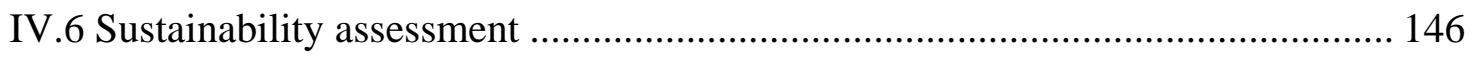

Chapter V ........................................................................................................................... 150

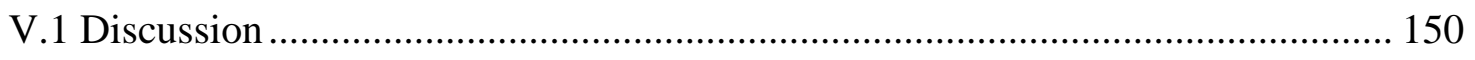

V.2 Limitations and future works ....................................................................... 154

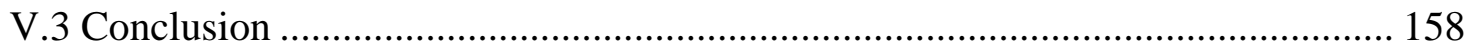

Refrences............................................................................................................................................. 162 


\section{LIST OF FIGURES}

Figure 1.1 Direct and indirect effects of built environment................................................... 2

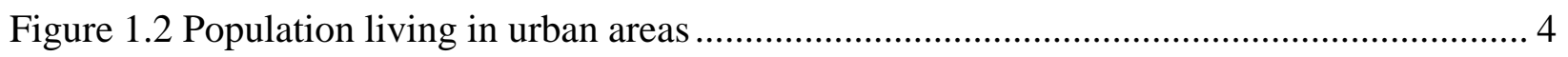

Figure 1.3 Visibility of Hong Kong's skyline in March and June ........................................ 6

Figure 1.4 Consumption and replacement of natural land cover with man-made surface ............ 7

Figure 1.5 Trends in fatalities due to road traffic injuries ................................................. 8

Figure 1.6 Energy consumption versus population density in selected countries ..................... 10

Figure 1.7 Urban built up area in selected cities........................................................... 11

Figure 2.1 Pressure-state-response (PSR) sustainability framework .................................... 24

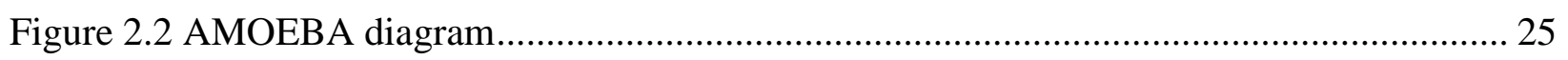

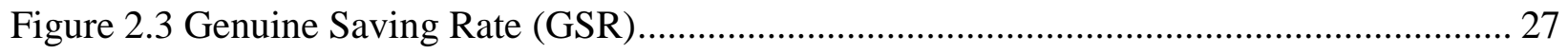

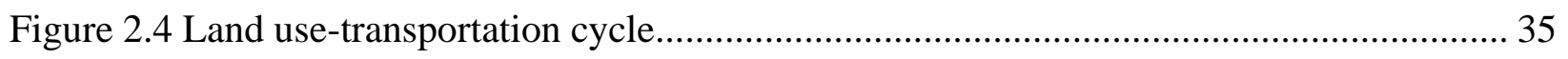

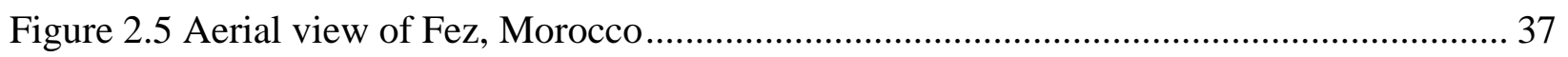

Figure 2.6 (a) Aerial view of Palmanova, Italy ..................................................................... 38

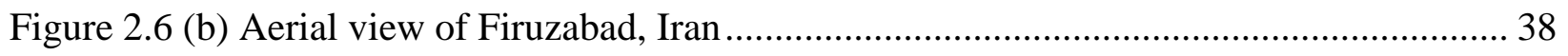

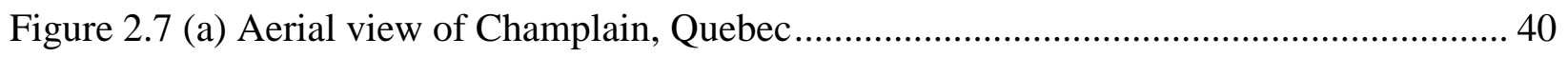

Figure 2.7 (b) Aerial view of Volgograd, Russia................................................................... 40

Figure 2.8 Aerial view of New York, USA .................................................................. 41

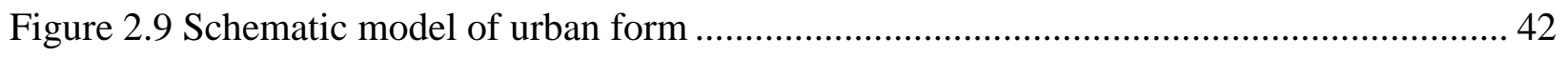

Figure 2.10 Example of urban visualization using density profile ...................................... 43

Figure 2.11 Tsai's approach for quantifying urban form...................................................... 46

Figure 2.12 (a) Aerial view of Curitiba, Brazil.................................................................... 52

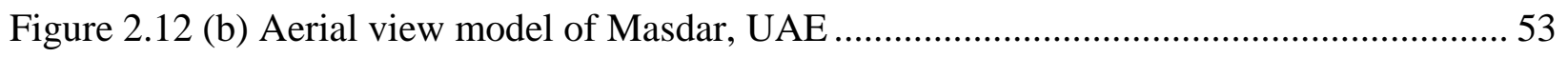

Figure 2.13 (a) Aerial view of Vauban, Germany ............................................................. 55

Figure 2.13 (b) Aerial view of Hammarby Sjöstad, Sweden ................................................. 56

Figure 2.14 (a) Architectural model of Arcosanti. Arizona..................................................... 59

Figure 2.14 (b) Aerial view of Ecovillage in Ithaca, NY ................................................... 59

Figure 2.15 Bertaud's imaginary city and various scenarios of urban spatial structure ............. 62

Figure 2.16 Role of small blocks in diversity of a city or neighborhood ................................ 67 
Figure 2.17 Effect of street layout design on travel pattern.................................................. 70

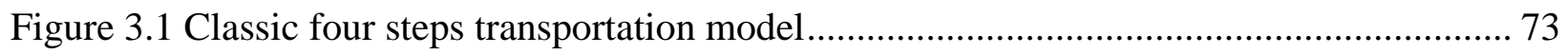

Figure 3.2 Utility function curves for transportation modal split ................................................ 76

Figure 3.3 Schematic model of Reilly's Law of Retail Gravitation........................................... 80

Figure 3.4 Lowry's land use model ........................................................................................ 81

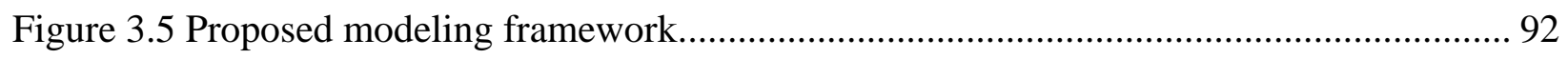

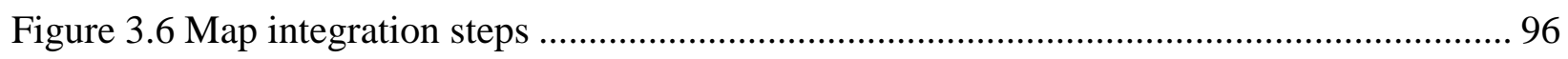

Figure 3.7 Good's demand versus good's price (demand curve) ….......................................... 100

Figure 3.8 Monetized estimates of transportation costs for passengers of an average car in urban

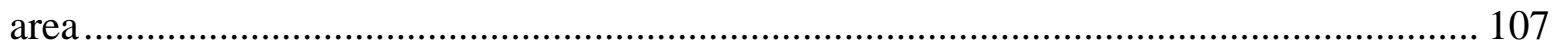

Figure 3.9 Relationship between supply, demand, price and consumer's surplus (welfare)...... 110

Figure 4.1 Official Municipal map of Morgantown .................................................................. 113

Figure 4.2 Parcel-based Land Use map of Morgantown ....................................................... 120

Figure 4.3 Percentage of land covered by each type of land use .............................................. 121

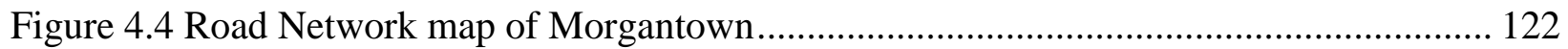

Figure 4.5 Distance to streets (left) and distance to highways (right) ....................................... 123

Figure 4.6 Morgantown's digital elevation map................................................................... 124

Figure 4.7 Slope (left) and visibility (right) ..................................................................... 125

Figure 4.8 Morgantown's population by each census block (year 2010) ……......................... 126

Figure 4.9 Reclassified distance to streets (left) and distance to highways (right)..................... 130

Figure 4.10 Reclassified slope (left) and visibility (right) ........................................................ 130

Figure 4.11 GIS model builder for land suitability analysis ..................................................... 133

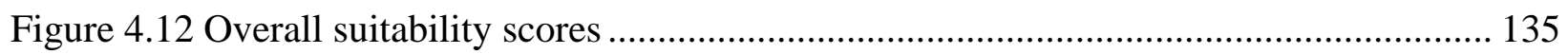

Figure 4.13 Proposed zoning map ........................................................................................ 137

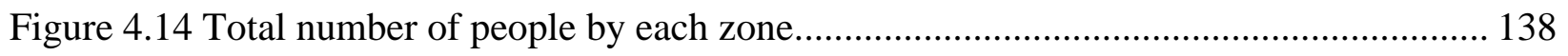

Figure 4.15 Estimated demand curve for food and beverage basket ........................................ 142

Figure 4.16 Interpolated ranking map of monocentric scenario ............................................... 144

Figure 4.17 Value of objective function for different spatial configurations ............................. 146

Figure 4.18 Comparison of negative effects (best and worst cases) ......................................... 147

Figure 4.19 Changes in GPI and GPI components (best and worst cases) ................................ 148 
Figure 4.20 Changes in depletion/decline of capital stock and addition to consumer surplus-Unit:

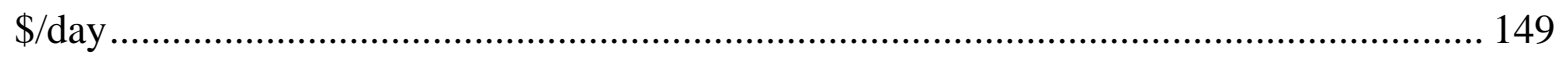

Figure 5.1 Conceptual models of urban spatial structure and simulation result...................... 153 


\section{LIST OF TABLES}

Table 1.1 International road space comparison ............................................................ 9

Table 2.1 Strong and Weak sustainability ................................................................ 21

Table 2.2 Correlation between urban density, activity intensity, private transport, and energy usage 61

Table 2.3 Drive alone share at worksites based on land use ............................................... 65

Table 2.4 Travel pattern in Asian, European and American cities ......................................... 71

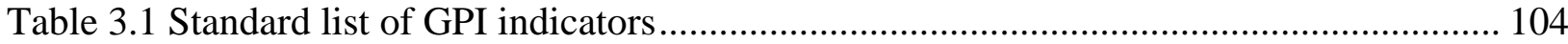

Table 3.2 Linking Litman's transportation costs estimation and standard GPI indicators ......... 108

Table 4.1 Utility scores matrix used for reclassification ................................................. 129

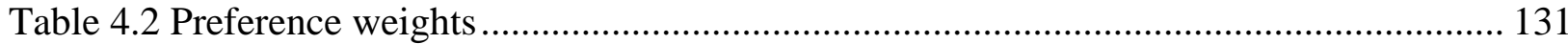

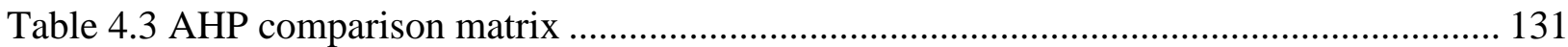

Table 4.4 Minimum distance matrix - Unit: Miles ...................................................... 138

Table 4.5 Estimated U.S. Per Capita Retail Sales by Kind of Business-Year 2012 ................. 140

Table 4.6 US price elasticity estimates, by food and beverage category, from $1938-2007 \ldots . .141$

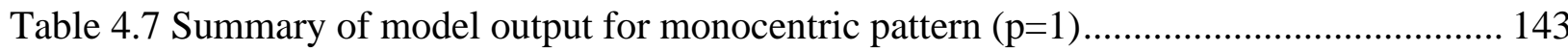

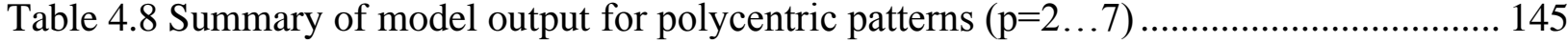




\section{CHAPTER I}

\section{Introduction}

\section{I.1 Introduction}

The concept of sustainable development popularized by the publication of the Brundtland Commission Report (Brundtland \& World Commission on Environment and Development, 1987) has been widely investigated by scholars across various fields of study including those interested in community and urban development. Sustainable development is multidimensional in nature - simultaneously considers the social, economic and environmental aspects of development (P. Newman, 2006). In dealing with sustainable cities the concept is even more complicated due to the fact that cities are simultaneously a complex amalgamation of dynamic human and physical systems (S Salat, 2007). As such, it requires a multidisciplinary approach, drawing on the expertise of urban planners and designers, transportation planners, and economists, among others.

A large and expanding volume of literature investigates the role of the urban built environment and urban spatial structure on sustainable development and yet considerable disagreements and gaps remain. Design of the urban built environment directly affects environmental quality through the consumption and replacement of natural land cover with manmade surface. It also indirectly affects environmental quality through travel behavior (U.S. EPA, 2001). Figure 1.1 shows how, land use patterns, transportation infrastructure and building orientation and design as the three main components of the built environment, directly and indirectly affect environmental quality. 


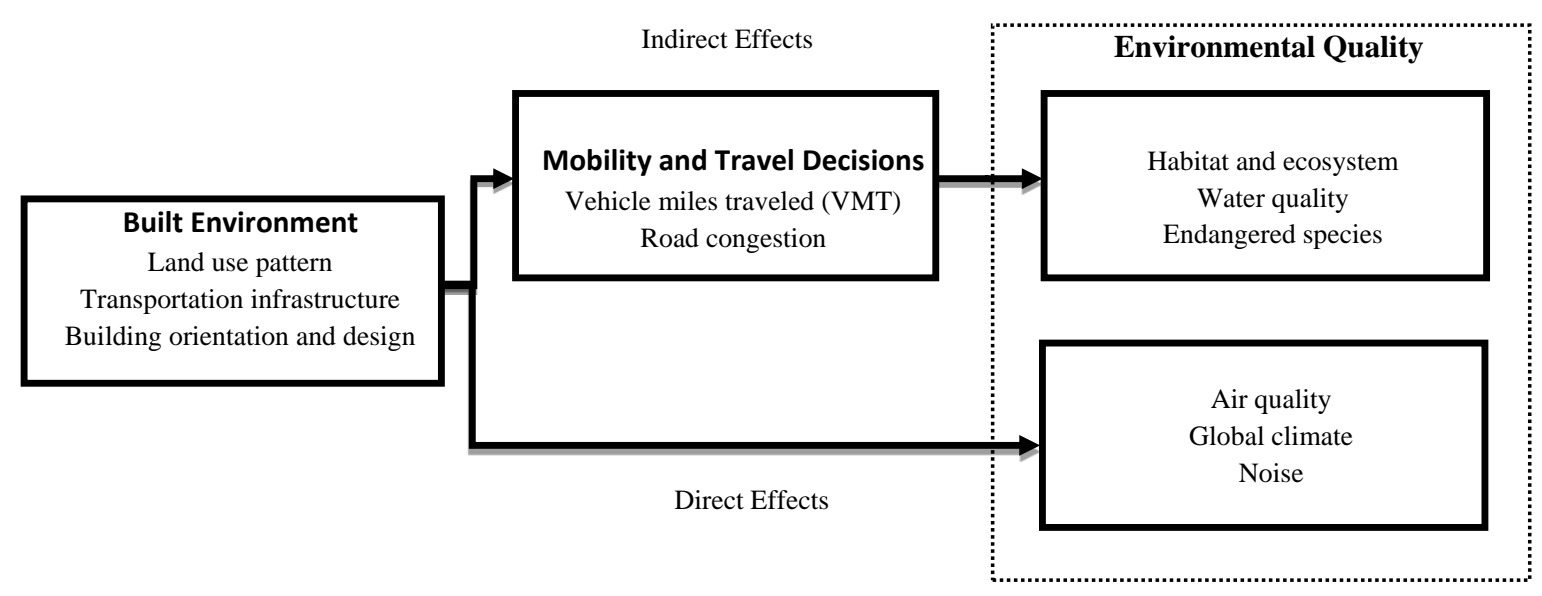

Figure 1.1 Direct and indirect effects of built environment

Source: Reproduced from (U.S. EPA, 2001, p. 2)

There is a general consensus that the design of the urban built environment could dramatically alter natural assets including habitat, ecosystems, species and water quality. Consequently, it has the potential to improve or degrade the human quality of life which heavily depends on factors such as air quality, global climate condition and noise pollution. The main idea of this dissertation relies on the above general consensus. This research develops a framework for simulating the effect of city's spatial structure on the sustainability of urban areas. The proposed integrated framework links design pattern of urban built environments with their economic and environmental sustainability. 


\section{I.2 Background}

The urban areas affect a geographic area vastly greater than their own surface area and their sustainability has significant regional and national implications. From a global perspective, urban areas cover only about 1.5 percent of the earth's surface (UN-HABITAT, 1996) or about 3 percent of the Earth's land surface (Center for International Earth Science Information Network, 2005), but more than half of the world's population live in urban areas and the urbanization rate is likely to increase up to 60 percent within the next two decades (UN-HABITAT, 2008).

Figure 1.2 shows upward urbanization rate during the past decades in various regions and the projected trend for coming decades. In fact, the most significant increase belongs to the developing countries with regions and countries such as India, China and South-East Asia, experiencing the highest growth rate. Figure 1.2 shows that urbanization rates of South-East Asia were below 20 percent until 1960s and increased to more than 40 percent by the year 2013. Among the South-East Asian countries, China's urbanization rate showed a sharp rise from 1995 to 2012, while India has experienced slower growth during this period. On the other hand, urbanization rate of the US and Western Europe was above 60 percent at 1950 and this rate has kept its upward trend during the past decades with only small fluctuations. The forecast indicates this rate will remain almost steady until 2045 (The Economist Online, 2012). 


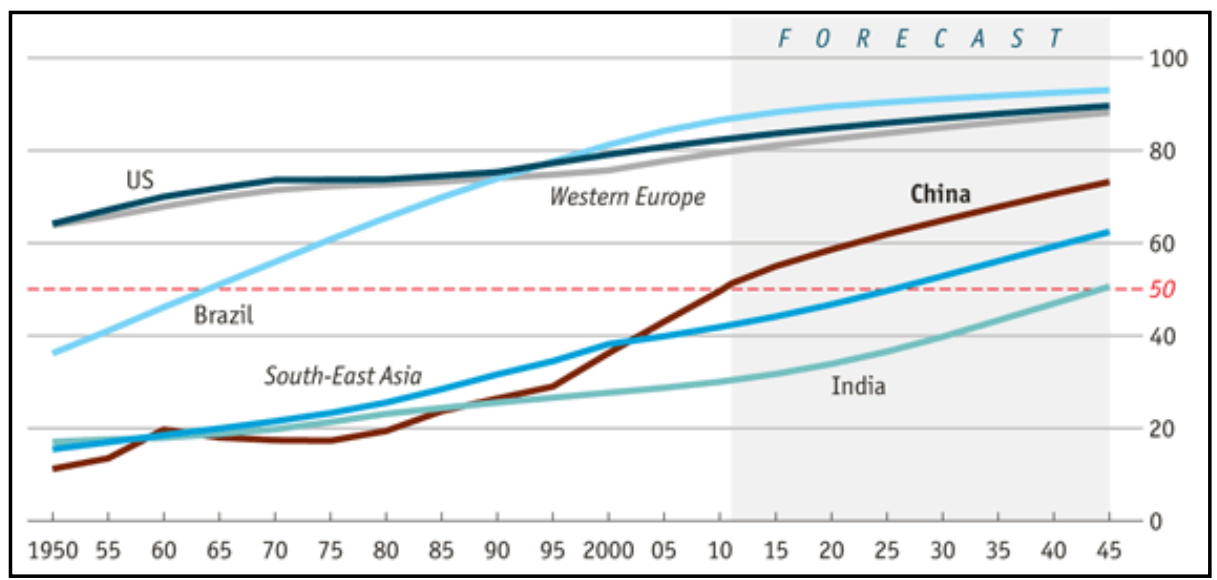

Figure 1.2 Population living in urban areas

Source: (The Economist Online, 2012)

Other research showed that developing countries are experiencing about 90 percent of global urban growth and the entire built-up urban area will triple between 2000 and 2030 from 200,000 square kilometers to 600,000 square kilometers (Suzuki, Dastur, Moffatt, Yabuki, \& Maruyama, 2010). The major reason for this rapid growth is the attraction of cities because of the benefits they create through economies of scale, social interactions, and better access to facilities such as educational centers, health care and recreation. Currently cities are the true engine of economic development, since urban areas are responsible for about 75 percent of global economic production and this share is rapidly increasing in developing countries (Suzuki et al., 2010).

With these important benefits of urban areas also comes many negative environmental, social and economic consequences, especially for future generations. This rapid growth raises some important questions. Newman (2006, p. 275) asks this key question: “Are they becoming so big that their negative impacts outweigh the opportunities that they provide?'. According to the United Nations Environment Program (UNEP)(2011), urban areas are responsible for about 
80 percent of global carbon dioxide emissions, which accounts for 60-80 percent of global greenhouse gases. The major part of this emission, in most urbanized countries, comes from the energy burned to heat the buildings and run the vehicles, which together constitute more than three quarters of global energy usage.

As one of the most important urban issues, urban transportation has dramatically increased in the past decades both in developed and developing countries. The general increase of road congestion and transportation demand has caused significant problems such as traffic accidents, environmental issues and waste of people's time. These problems and issues will not disappear in the near future since they have been created over a long period of time and the solution would require appropriate plans and policies as well as heavy investment. The environmental impacts of urban traffic, including air, noise and water pollutions and their relevant damages are completely visible in most urban areas and these damages have significant negative impacts not only on natural capital but also on human capital and physical capital.

Air pollution is one of the major environmental health risks causing diseases such as depression, stress and respiratory diseases. According to World Health Organization (2011) urban outdoor air pollution is estimated to be responsible for 1.3 million annual deaths or 2.5 deaths per minute. Particles of metal contaminants such as cadmium, nickel, arsenic, sulfate and nitrate ions and hydrocarbons released into the air are responsible for numerous adverse effects, including reduced IQ, stupor, liver damage, asthma and emphysema. The study conducted by the World Resource Institute shows that children under 5 years old are at highest risk in megacities of Mexico, India, China, Brazil and Iran (Davis \& Saldiva, 1999). 
Loss of visibility is probably the most tangible negative effect of air pollution in urban areas. Figure 1.3 shows the extent of visibility loss in Hong Kong's skyline which is caused by air pollution. As a result the visibility distance is less than 8 kilometers for 30 percent of the year (Akouayri, 2012).

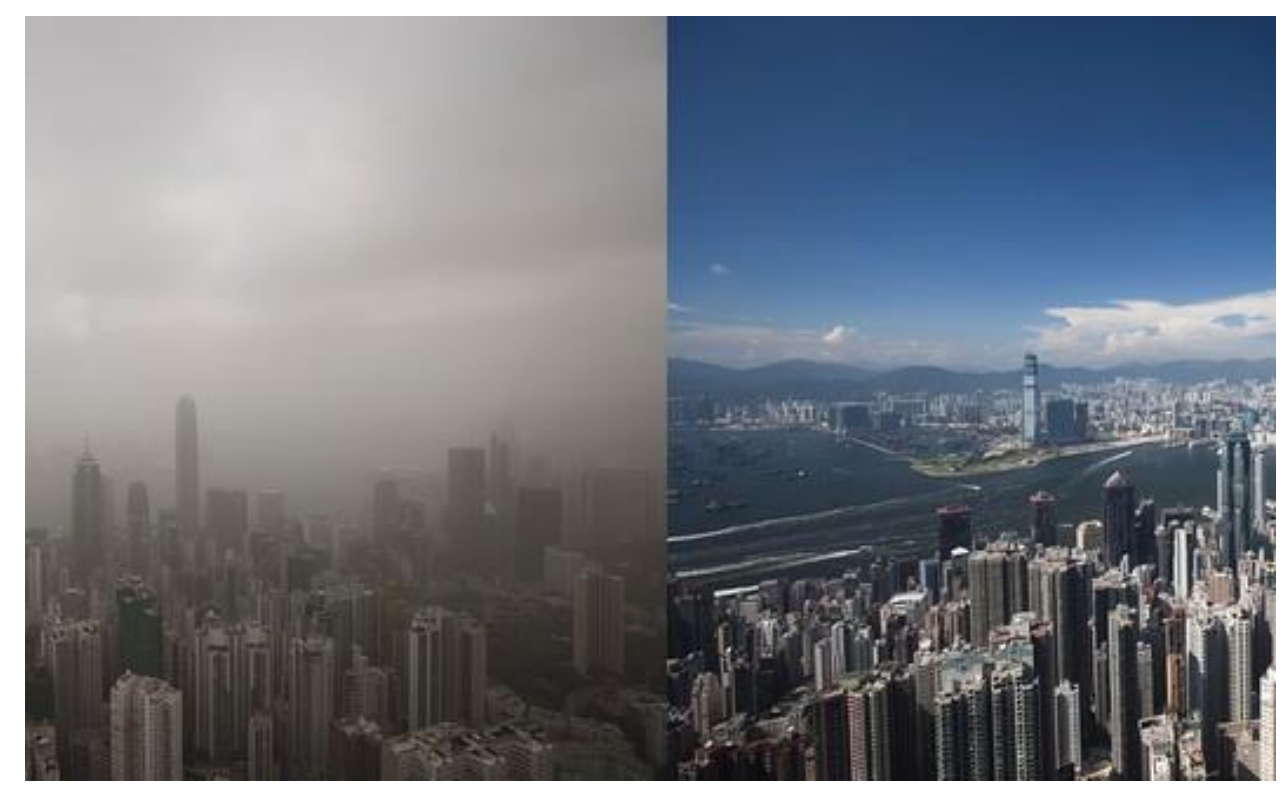

Figure 1.3 Visibility of Hong Kong's skyline in March and June

Source: (Mavin, 2010)

Another considerable impact of air pollution is formation of acid rain which directly causes serious damages to earth's natural assets such as plants and animals. It also can affect plant communities indirectly by changing soil and water chemical and biological characteristics. It is important to say that urban traffic not only has a negative impact on natural and human assets, but also physical assets such as buildings are vulnerable to traffic air pollution. Damage to buildings consists of structural depreciation, loss of property values, corrosion of metal structures, and destruction of historical and cultural monuments (Rodrigue, Comtois, \& Slack, 2009). One study indicates that total Gross External Damages (GEDs) of six important air 
pollutants (sulfur dioxide, nitrogen oxides, volatile organic compounds, ammonia, fine particulate matter, and coarse particulate) was more than 180 billion dollars in 2002 in the United States (Muller, Mendelsohn, \& Nordhaus, 2011).

The externalities of urban traffic congestion are not limited to air pollution. Everyday millions of citizen's hours are wasted in traffic, which imposes notable economic and social costs. A study by Schrank, Eisele, \& Lomax (2012) shows that an average American driver has spent an extra 38 hours in traffic jams in 2011, up from 16 hours in 1982, which costs $\$ 818$ per year for an average commuter.

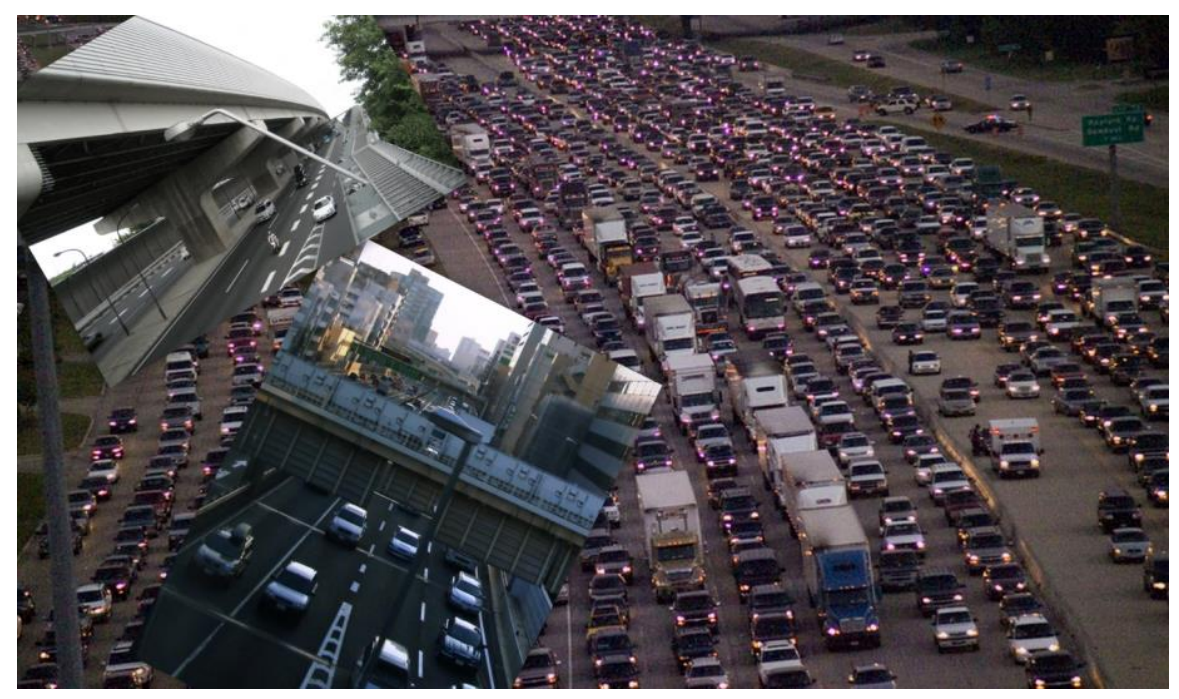

Figure 1.4 Consumption and replacement of natural land cover with man-made surface Source: (Colemanm, 2011)

The high incident rate of injuries and mortalities caused by vehicle accidents is another unfortunate consequence of urbanization for society. Statistics of vehicle accident reveal that the number of traffic accidents is very high, especially in less developed countries. According to world report on road traffic injury prevention (Peden et al., 2004) the global fatal accident rate is 
more than 3000 people per day, most of it (about 85 percent) belongs to low-income and middleincome countries which have limited sources of human capitals. Figure 1.5 shows trends in fatalities due to road traffic for different regions of the world.

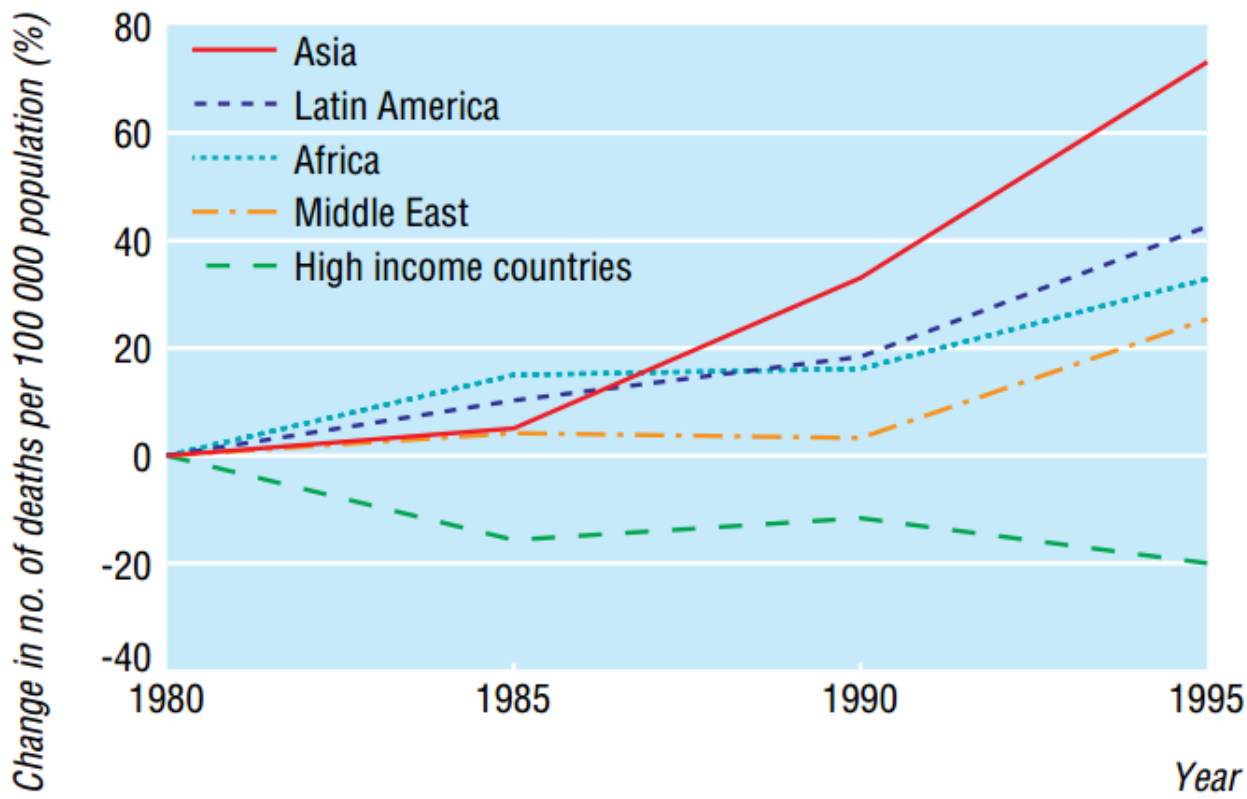

Figure 1.5 Trends in fatalities due to road traffic injuries

Source: (Nantulya \& Reich, 2002)

As can be seen, overall, the number of fatalities tends to increase during past decades from 1980 to 1995 in all regions except the high-income countries. The most significant increases are in the developing countries in Asia, Africa, Latin America and Middle-East. Among these regions Asia's accident fatality rate shows a particularly sharp rise from 1985 to 1995 . On the other hand, accident fatality rates in high-income countries such as the USA and Western Europe have trended downward between 1980 and 1995.

Another important negative environmental effect of urbanization is the consumption and replacement of natural land cover with man-made surfaces such as roads, parking, buildings and 
communication infrastructures. This replacement can cause reduction in precipitation rate and growth of urban heat islands. As can be seen in Table 1.1 the share of urban land devoted to road networks in Tokyo, London and Japan are between 15 to 25 percent. In contrast, only 5 to 7 percent of China's megacities area has been devoted to road networks, which is more environmentally sustainable. In terms of per capita road area, the amount of land assigned to each person in Chinese megacities is about 6 square meters, while it is more than 26 square meters in New York.

Table 1.1

International road space comparison

\begin{tabular}{cccc}
\hline City & $\begin{array}{c}\text { Road Density } \\
(\mathrm{km} / \mathrm{km} 2)\end{array}$ & $\begin{array}{c}\text { Road Share of Urban Area } \\
(\%)\end{array}$ & $\begin{array}{c}\text { Per Capita Road Area } \\
(\mathrm{m} 2)\end{array}$ \\
\hline $\begin{array}{c}\text { Chinese } \\
\text { megacities }\end{array}$ & About 4 to 6 & About 5 to 7 & About 6 \\
Tokyo & 18.9 & 14.9 & 10.9 \\
London & 18.1 & 24.1 & 28.3 \\
New York & 8 & 16.6 & 26.3 \\
\hline
\end{tabular}

Note. From (Petersen, 2002)

This difference is more meaningful when we compare the ecological footprint of highly developed countries like the U.S and developing countries such as China. According to Salat (2007) the limited carrying capacity of earth, which is almost equal to 4.2 hectares per person, for the most part is used by people living in urban areas of highly developed regions such as the USA (12 ha per person) and Europe (6 ha per person), while the rate is less than 0.8 hectares per person for people living in rural areas of developing countries.

In addition to the large variation of ecological footprint of cities in America, Europe and Asia, these cities have also very different energy consumption rates. Figure 1.6 depicts the per capita energy consumption by selected cities in the USA, Canada, Australia, Europe and Asia. 
By decreasing the population density the energy consumption per capita shows a sharp rise. American style cities like Houston, Phoenix, Los Angeles and Melbourne are located at one extreme of this curve, while Asian style cities like Hong Kong and Singapore are located at another extreme. European style cities, fall somewhere between these two extremes.

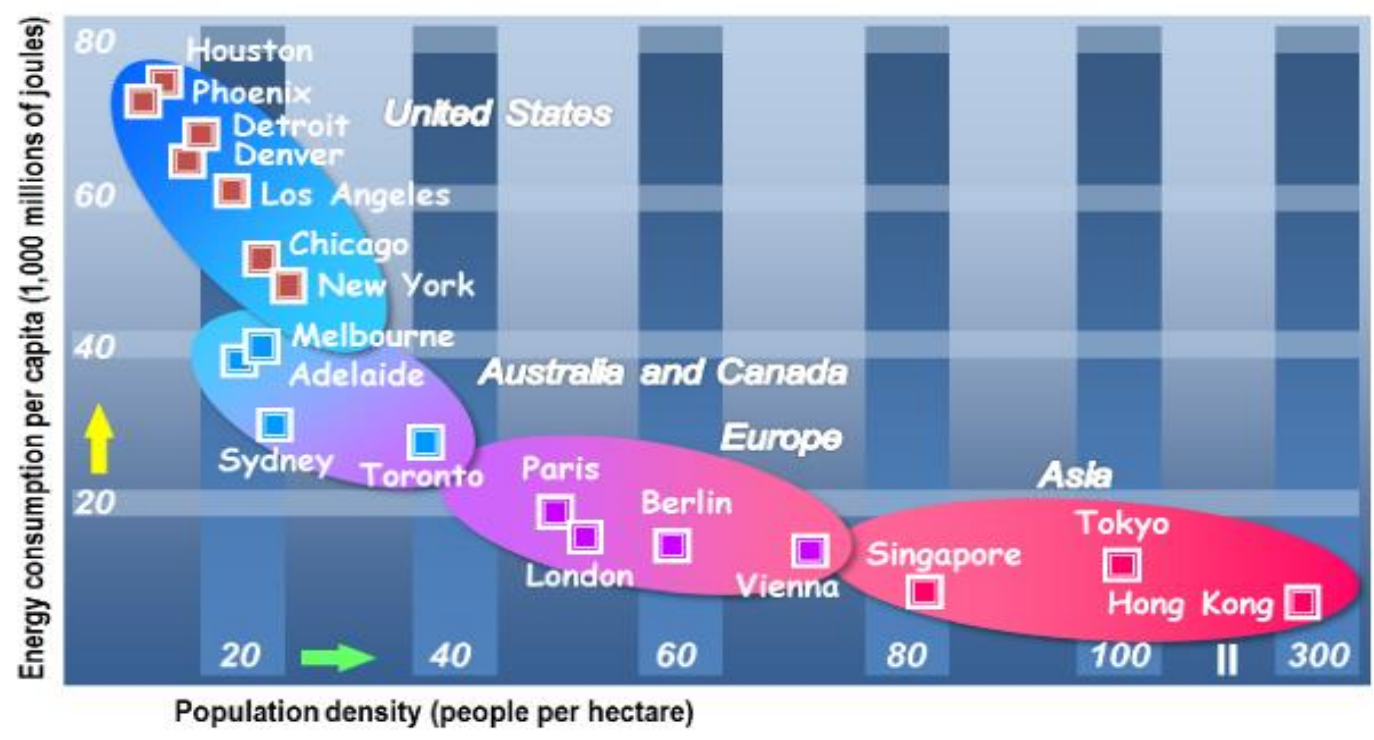

Figure 1.6 Energy consumption versus population density in selected countries

Source: (Newman \& Kenworthy, 1989)

The relationship between population density and energy consumption has been studied by Newman and Kenworthy (1989). According to their model, annual gasoline use per capita is a logarithmic function of population density (person per ha). In other word a strong inverse relationship exists between energy consumption and population density.

Population density could also be a function of urban morphology and urban spatial structure. For a given population, the city area will increase by decreasing the population density. Two cities of Atlanta and Barcelona are a good typical example of this phenomenon. Both have almost the same population but the built-up area of these cities are significantly different. Figure 
1.7 shows the built-up area of these cities at the same scale, this wide area variation indicates how urban morphology could affect the earth's ecosystem through increasing the urban trip length and replacement of natural cover with mane-made surface.
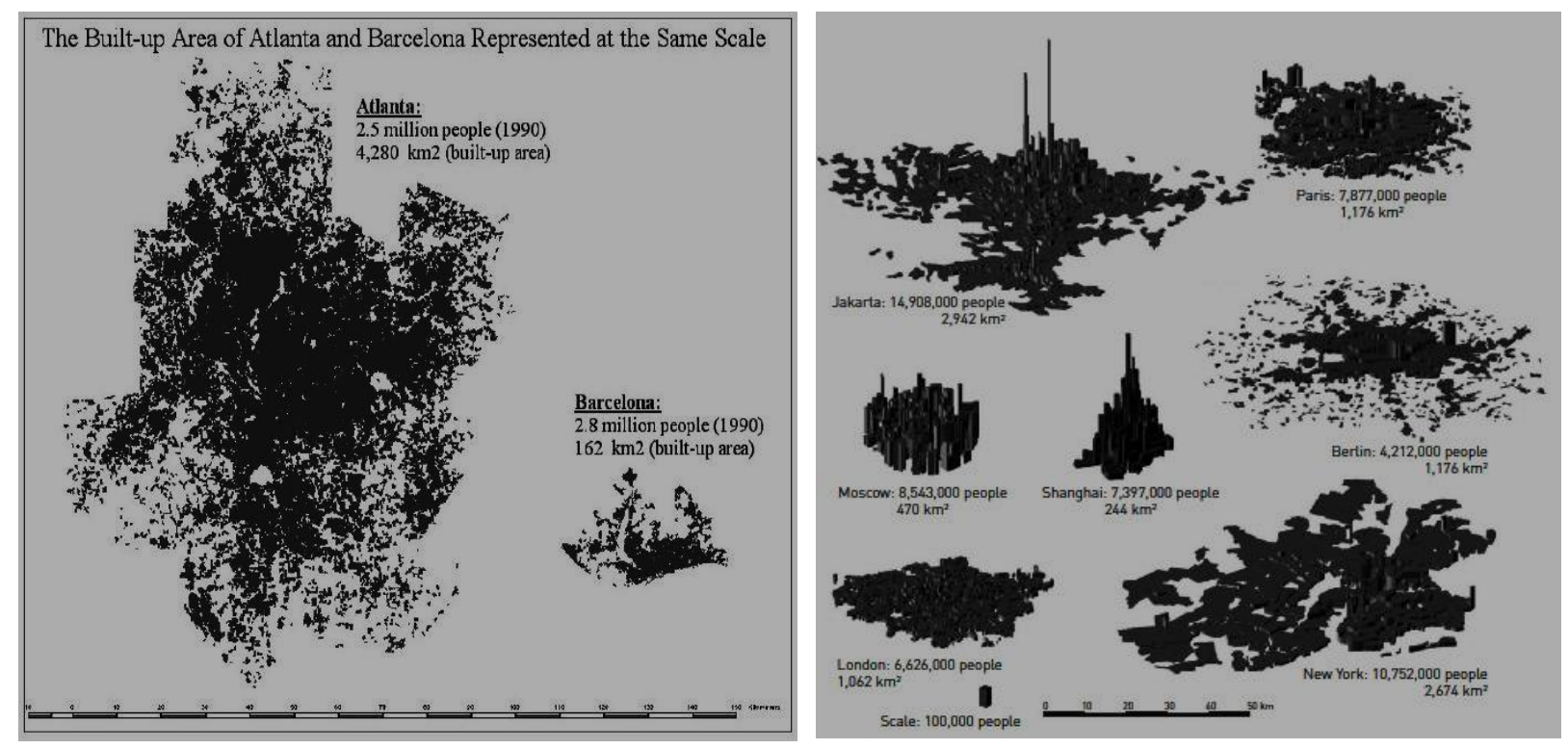

Figure 1.7 Urban built up area in selected cities

Source: (Bertaud, 2001, 2004; Bertaud \& Poole, 2007)

While some researchers argue that "density is a critical typology in determining sustainable urban form" (Jabareen, 2006, p. 41), others reject these hypotheses. Newman (2006) claims that there is no obvious relationship between population density in cities and the solution of urban or global problems. Also Hardoy, Mitlin, \& Satterthwaite (2001) found no evidence that high population density in less developed countries necessarily has impacted the global environment. It is important to note that population density is just one of the several attributes of urban spatial structure and other factors such as urban overall size, overall shape (linear, radial,..), centrality (decentralized vs. mono-centric and polycentric), compactness (compact vs. 
sprawl), equity of spatial distribution, clustering (clustered vs. dispersed), land use diversity (homogenous vs. heterogeneous), neighborhood layout, building density (floor area ratio), walkability, accessibility, and connectivity also represent other morphological attributes of urban areas which could intensify or detract urban problems.

\section{I.3 Main goals and objectives of the research}

Considering the interrelationship between spatial structure of cities and urban sustainability, the main goal of this study is to provide an integrated modeling framework for simulating the effects of urban morphology on sustainable development. In particular, making a model to bridge between "design of urban built environment" and "sustainable development" at the city-region level through simulation and measuring the effect of urban spatial structure on the portfolio of various asset forms including environmental, human and physical. This modeling framework helps us to determine the sustainability of urban spatial pattern using the definition of sustainable development by the World Bank $(1997,2006)$ which defines it as "a process of managing a portfolio of assets to preserve and enhance the opportunities people face" (World Bank, 1997, p. V).

The effect of urban spatial structure on natural resource depletion and its impact on social, economic and environmental dimensions of sustainability has been a subject of numerous studies (Burton, 1996; Jabareen, 2006). For example, the relation between urban density as an important element of urban spatial structure and energy usage has been studied by Newman (2006) and Kenworthy \& Lube (2001; J. R. Kenworthy et al., 2000), while other studies show positive and negative impacts of urban density from different perspectives (Bertaud, 2004; Freedman, 1975; Hardoy et al., 2001; Jabareen, 2006; Sassen, 1994). There are several studies with a focus on analyzing the contribution of other elements of urban form such as compactness, land use mix, 
diversity, complexity, design pattern of residential buildings and spatial attributes of the transportation network; to urban sustainability. From a methodological stand point, several modeling tools and techniques have been developed to simulate the behavior of the three main components of urban spatial structure: land use patterns, transportation infrastructure and building orientation. These models and techniques have been reviewed in detail in Chapter III.

In spite of a vast literature in this area, some authors believe that there still is a lack of proper theories and methods to analyze the cities as spatial artifacts, especially at micro scale (Fallström, Marcus, \& Ström, 2009). Salat (2007) contends that various elements of urban morphology have not been adequately analyzed yet and the city is generally seen as an "homogenous entity". He argues that more studies are needed on the relationship between transportation, urban density and energy consumption. Also Jabareen (2006, p. 39) states that "... there is a lack of theory that helps us to evaluate whether a given urban form contributes to sustainability or to compare different forms according to their contribution to the sustainable development objectives and agenda".

There are only few studies that simultaneously take into account all significant environmental, economic and social impacts of urban spatial structure on sustainable development by using aggregate sustainability metrics. As an example, Yevdokimov (2002) proposed to measure the sustainability of the transportation system using the Genuine Progress Indicator (GPI) (see Section II.1.1 for definition of GPI) as a variant of the Index of Sustainable Economic Welfare (ISEW). He used this metric to capture changes in social well-being due to changes in characteristics of transportation network. The study of Genuine Progress Index for Atlantic Canada (GPIAtlantic) is another example in which the sustainability of Halifax Regional Municipality and 
Nova Scotia's transportation system was assessed using GPI (Savelson, Colman, Litman, Walker, \& Parmenter, 2006; Savelson, Colman, \& Martin, 2008).

The specific objectives and general layout of this study are:

- Identification of key quantitative variables and metrics that enable us to measure urban sustainability. Chapter II provides a background to the sustainable development concept, reviewing its history and definitions, overviewing various dimensions of sustainability and outlining some of the relevant literature on measuring urban sustainability. This background helps to find a more appropriate sustainability indicator to evaluate the model's output and understand the role of the urban built environment on sustainability of natural, physical and human capital assets.

- Determining important elements of the urban built environment and identifying key variables that describe characteristics of spatial structure of a city/town. Second part of Chapter II makes an overview of the urban morphology concept and its definition, highlighting the main elements of urban built environment and attributes of urban spatial structure. Among these morphological attributes, some important ones have been selected and a brief explanation was prepared for each of them based on academic researches reviewed. Then, using the relevant literature such as sustainable society, sustainable community, sustainable city, ecopolis, ecocity, ecotown and ecovillage, the concept of "good" urban form and "sustainable" built environment was explained. 
- Evaluating existing models and tools which help us to make a bridge between characteristics of urban spatial structure and level of urban sustainability. The various types of spatial models, techniques and analytical tools; especially those relevant to land use and transportation, have been reviewed in the first part of Chapter III. These models could address the relationship between different aspects of urban form and sustainability indicators.

- Developing an integrated modeling framework for simulating the effects of urban morphology on sustainable development. The results of the reviews in previous chapters were fed into the spatial modeling methodology in Chapter III. The proposed methodology consists of a spatial modeling framework through which the various spatial configurations of the urban built environment were simulated and a sustainability assessment module through which the simulation results were evaluated and the most sustainable spatial configuration was selected. This method has been discussed in detail in Chapter III.

- Applying the developed modeling framework for Morgantown, WV as selected study area. After developing the spatial modeling framework, it was applied to the study area of Morgantown, WV in Chapter IV. The result of this step could help policy makers/decision makers to predict the environmental, economic and social impacts of changes in location and spatial configuration of urban facilities (i.e. shopping centers, schools, health care centers, etc.) and choose the most sustainable scenario. 


\section{I.4 Research question}

This research aims to answer the following main question: to what extent the urban spatial structure can affect the pattern of urban sustainable development? In order to find the answer of the main research question, the dissertation consists of some steps. Each step aims to answer the following relevant sub-questions:

- What is sustainable development? What are the main dimensions of sustainability?

- How we can effectively measure the level of urban sustainability?

- What are the most comprehensive sustainability indicators that take into account all types of assets (natural, human and physical capitals) and doesn't ignore nonmonetized costs/benefits of environmental and social factors?

- What are the key components of urban spatial structure affecting the sustainability of urban ecosystem?

- What is the role of built environment in patterns of urban sustainability?

- $\quad$ To what extent the urban spatial structure affects people behavior (i.e. travel behavior, shopping behavior), and whether land use and transport interaction influences people behavior?

- How we can measure the direction and magnitude of these influences?

- Which models, tools and techniques are useful for simulating these effects?

- How to build up an integrated modeling framework to simulate these effects?

- How to gather the required information and data for the model?

- How to apply the model to the real world?

- How to interpret the model's output in terms of sustainability? 
To answer these research sub-questions, we will look at various literatures, including the literature about definition of sustainable development, urban morphology; ecocity, ecotown and ecovillage and then we will review papers and articles containing literature about the relationship between urban morphology/spatial structure and sustainable development of cities. Then the analytical techniques and models will be explored and appropriate model will be developed based on these reviews. 


\section{CHAPTER II}

\section{Literature Review}

\section{II.1 Definition of terms}

\section{II.1.1 Sustainable development}

\section{Background}

Sustainable development has a multidimensional nature, simultaneously takes into consideration the environmental, economic and equity (social) aspects of development- so called 3 E's of sustainability (P. Newman, 2006). Therefore, sustainability assessment needs a multidisciplinary approach by contribution of different experts such as urban planners and designers, transportation planners, and economist. Especially when we deal with sustainable cities, this concept becomes more sophisticated due to the fact that cities are simultaneously a complex amalgamation of dynamic human and physical systems (S Salat, 2007).

The most widely cited definition of sustainable development comes from Our Common Future report; where it's been defined as "development that meets the needs of the present without compromising the needs of future generations to meet their own needs" (Brundtland \& World Commission on Environment and Development, 1987, p. 41). This definition is relatively comprehensive, but the word "need" is highly disputable and is subject to various interpretations among researcher in different fields.

For environmental scientists, the word "need " is correlated with environmental aspects of our planet such as rates of renewable resource harvest, non-renewable resource depletion, pollution creation and ecological footprint (Carley \& Christie, 2000). For social scientist the 
quality of life (QOL) is a more meaningful interpretation of human needs. According to Hart (2010, para. 1), sustainability "is related to the quality of life in a community -- whether the economic, social and environmental systems that make up the community are providing a healthy, productive, meaningful life for all community residents, present and future”. Sustainability is about the quality of life, but it is more than just quality of life (Hart, 2010). In the economic literature, economic sustainability is often seen as the ability to sustain a defined level of production over the long-term, mostly presented in economic growth terms such as Gross Domestic Product (GDP), employment, income level or economic welfare. Economic growth can lead to sustainable development, but sustainable development is more than just economic growth. It also depends on social and ecological factors which play important role in human well-being (UNU-IHDP \& UNEP, 2012).

Some researchers have emphasized the need to combine these definitions and making up a more comprehensive one. Newman (2006, p. 286) states that sustainability is "an integrative tool that brings together environmental and human issues". Newman \& Kenworthy (as cited in Newman, 2006, p.286) define it as "reducing Ecological Footprint (energy, water, and land materials waste) while simultaneously improving quality of life (health, housing, employment, community...) within the capacity constraints of the city“. These comprehensive definitions reemphasize that understanding the linkage between social, economic and environmental components of a community is the key to understanding its sustainability.

More recent studies of United Nations agencies define sustainable development as "a pattern of societal development along which (inter-generational) well-being does not decline" (UNU-IHDP \& UNEP, 2012, p. 15). Human well-being is a key element of sustainable development and is determined by consumption of goods and services. Capital assets produce 
goods and services. These capital assets are embodied in the three forms of physical capital $\left(\mathrm{K}_{\mathrm{M}}\right)$, natural capital $\left(\mathrm{K}_{\mathrm{N}}\right)$, and human capital $\left(\mathrm{K}_{\mathrm{H}}\right)$. Wealth is the social worth of these capital forms (UNU-IHDP \& UNEP, 2012) and offers a more comprehensive measure of sustainable development. The definition of sustainability as a non-declining total capital stock - capital approach to sustainability - provides a broad framework for assessment of sustainable development. This framework is more accordant with the definition of "weak sustainability", which allows natural or human capital to be replaced by equal value of manufactured capital. In "strong sustainability", unlike weak sustainability, capital forms are irreplaceable and cannot be substituted by other forms of capital.

The strength of using the wealth as a measure of sustainable development lies behind its ability to translate the different sustainability indicators to monetary terms and values, which allow us to consolidate them as an integrated sustainability indicator. This integrated indicator, which represents the total capital stock, at least, should be non-decreasing over time in order to achieve weak sustainability. Equations in Table 2.1 represent the weak and strong sustainability rules. Under the weak sustainability rule the overall stock of manufactured capital $\left(\mathrm{K}_{\mathrm{M}}\right)$, natural capital $\left(\mathrm{K}_{\mathrm{N}}\right)$, and human capital $\left(\mathrm{K}_{\mathrm{H}}\right)$ should grow or at least not decrease over time. These capital forms are substitutable for each other under this rule but not interchangeable under the strong sustainability rule where it requires every capital stock be non-decreasing over time in order to achieve sustainability (D. Pearce \& Atkinson, 1998). 
Table 2.1

Strong and Weak sustainability

\begin{tabular}{cc}
\hline Form of sustainability & Requirement \\
\hline Weak & $\frac{\Delta \mathrm{K}}{\Delta \mathrm{t}} \geq 0$ where $\mathrm{K}=\mathrm{K}_{\mathrm{M}}+\mathrm{K}_{\mathrm{N}}+\mathrm{K}_{\mathrm{H}}$ \\
Strong & $\frac{\Delta \mathrm{K}_{\mathrm{N}}}{\Delta \mathrm{t}} \geq 0$ and $\frac{\Delta \mathrm{K}_{\mathrm{M}}}{\Delta \mathrm{t}} \geq 0$ and $\frac{\Delta \mathrm{K}_{\mathrm{H}}}{\Delta \mathrm{t}} \geq 0$
\end{tabular}

Note. Reproduced from (D. Pearce \& Atkinson, 1998)

\section{Sustainability measurement and indicators}

The importance of the role that indicators can play in measuring progress toward sustainable development was emphasized in chapter 40 of the United Nations action plan on sustainable development (known as UN Agenda 21). Despite the several efforts by academic centers and international institutions in developing sustainability indicators during past decades, still there is no common consensus on definition and application of these metrics. This issue becomes more complicated when more comprehensive indicators are needed to measure all environmental, social and economic dimensions of sustainability.

According to Hart (2010) a good sustainability indicator should be specific, measurable, achievable, relevant and time-related (S.M.A.R.T) and it should help planners to recognize unsustainable and problematic areas and allow them find ways to fix these problems on timely manner. These characteristics are based on the assumption that a sustainability indicator are quantitative. Quantitative indicators are often precise and applicable but in some instances qualitative indicators are preferable - particularly regarding social and human related aspects of sustainable development. 


\section{Classification of Sustainability indicators}

Several frameworks have been developed for classification of sustainability indicators. One can use the "socio-economic-environmental" framework which classifies single or multiple sustainability indicators into three categories of environmental quality, economic opportunity or social wellbeing according to their dominant dimension. Each category also consists of system of elements and sub-elements and can include single or multiple indicators (Birch \& Lynch, 2012).

Many studies have been done to define single or multiple sustainability indicators using "socio-economic-environmental" framework. The United Nations Commission on Sustainable Development (CSD) (2001) developed a framework consisting of 15 elements, 38 sub-elements and 58 sustainability single indicators. This framework includes equity, health, education, housing, security and population as the main elements of social wellbeing. The environmental dimension includes elements such as land, atmosphere, fresh water, biodiversity and oceans. Also, economic structure and consumption/production pattern have been selected as main elements of economic opportunity. This indicator set has been revised in 2006 and reduced to 50 core indicators.

Another example is the International Institute for Sustainable Development (IISD) which has developed a three-dimensional information system, including economic-socialenvironmental aspects of sustainability, known as Sustainability Indicator System Approach (SISA) (IISD, 2013). European Commission (EC) has also invested in several projects such as EU Sustainable Development Strategy (EU SDS), Planning and Research of Policies for Land Use and Transport for Increasing Urban Sustainability (PROPOLIS) and System for Planning and Research in Towns and Cities for Urban Sustainability (SPARTACUS) in order to identify 
and classify sustainability indicators (EUROSTAT., 2011; Kary Lautso, 2004; K. Lautso et al., 2004; Kari Lautso \& Toivanen, 1999).

Ecological Footprint (EF) and Carbon Footprint are examples of multiple indicators of sustainability which fall under the environmental category. Ecological footprint, introduced by Rees (1992), is a measure of human demand on the Earth's ecosystems. It is defined as the amount of natural resources (land), required to produce the goods (food, water etc.) and services (housing, transportation, etc.) necessary to support a unit (people, city, country etc.) and “... the larger the EF then, by implication, the greater the resources required to sustain the unit's existence" (Bell \& Morse, 2012, p. 14). Merriam-Webster dictionary (2014) defines the Carbon Footprint as "the amount of greenhouse gases and specifically carbon dioxide emitted by something (as a person's activities or a product's manufacture and transport) during a given period”. Other indicators such as the Environmental Sustainability Index (ESI) and Environmental Performance Index (EPI) also fall under environmental category.

Indicators such as the Human Development Index (HDI), Index of Social Progress (ISP), and Physical Quality of Life Index (PQLI) are examples of social sustainability indicators, while Measured Economic Welfare (MEW), Indicator of Sustainable Economic Welfare (ISEW), and Economic Aspects of Welfare index (EAW) are representatives of economic sustainability (Pourasghar, Salehi, \& Masnavi, 2010; Singh, Murty, Gupta, \& Dikshit, 2009).

Other researchers suggest "Pressure-state-response (PSR)" framework which has been introduced by Organization for Economic Co-operation and Development (OECD) for classification of sustainability indicators. This framework is based on the fact that human activities exert pressure (i.e. consumption and air pollution) on the environment which changes 
the state of the environment. Then society responses to these environmental changes with various actions, including "5 R's" of sustainability: reduces, reuse, renew, recycle and rethink. The PSR framework is a useful tool for classification of sustainability indicators into three groups of pressure, state, and response indicators For example indicator of vehicle miles traveled (VMT) is a pressure indicator, while Air Quality Index (AQI) is a state indicator as well as fuel economy (mpg) which is a response indicator (Bell \& Morse, 2012; Hart, 1995). This framework has been used by the statistical office of the EU (Eurostat) in EU's Sustainable Development Strategy project (EUROSTAT., 2011).

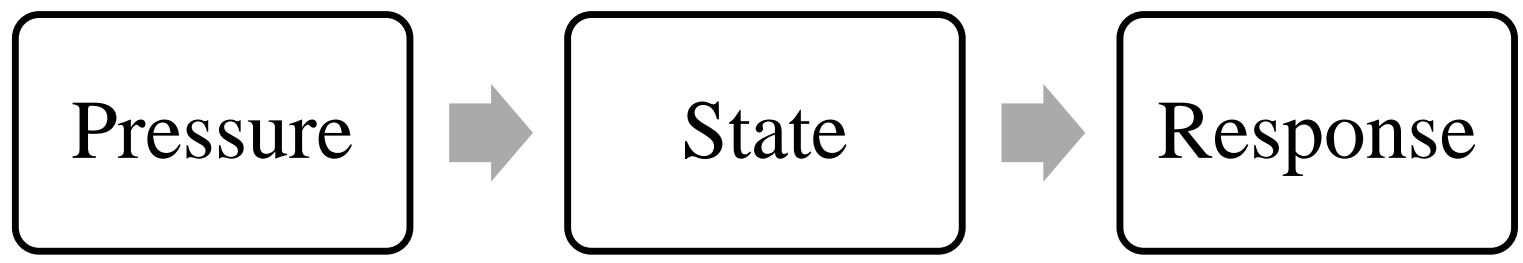

Figure 2.1 Pressure-state-response (PSR) sustainability framework

Another framework for the categorization of sustainability indicator is the "multiple capitals" framework (Bell \& Morse, 2012; Woodhouse, Howlett, \& Rigby, 2000) which classifies indicators of sustainable development into three forms of capital: natural, human and physical. Several studies have used capital as the building block of sustainability, since it allows us to use the assumption of the possibility of substitution between natural capital and Physical (or human) capital, which is the basic assumption of weak sustainability (Atkinson, 2008; Daly, 1990; Hamilton, 2000; D. W. Pearce \& Atkinson, 1993; Solow, 1986; Victor, 1991). 


\section{Integration of Sustainability indicators}

There are several ways to combine these sustainability indicators into one integrated entity. According to Bell and Morse (2012) one can use "visualization" approach by listing or presenting indicators together within a table or a diagram. AMOEBA/RADAR is one example of these diagrams where indicators are arranged as an array of arms with circular or web or polygon presentation.

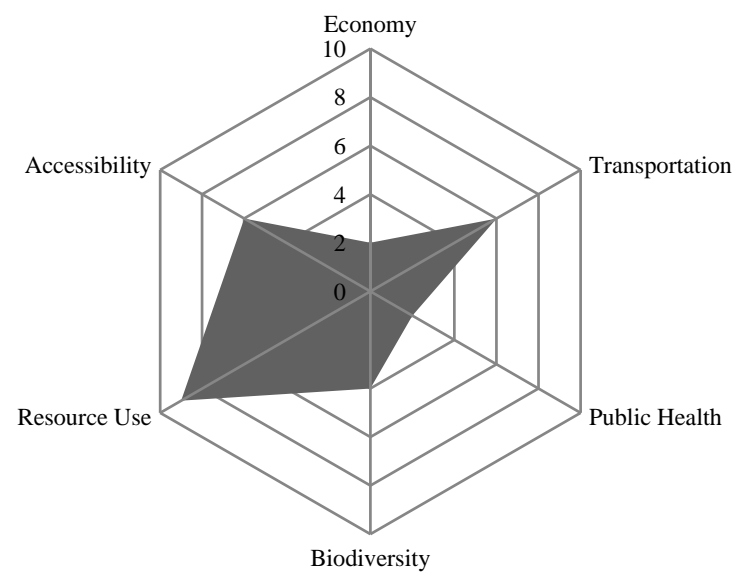

Figure 2.2 AMOEBA diagram

Source: Reproduced from (Bell \& Morse, 2012)

Another popular visualization tool is Sustainability Dashboard. A software developed by the International Institute for Sustainable Development (IISD) (2007) is one of the best applications of Sustainability Dashboard. This software has been developed based on the millennium development goals indicators. Barometers of Sustainability and Sustainability Compass are other visualization techniques for integration of sustainability indicators (Bell \& Morse, 2012). 
The second approach of integration is the numerical integration which combines different indicators into an integrated Index of sustainable development. This integration could be based on monetary or non-monetary valuation of indicators. Weighted Goal Programming (WGP) and Fuzzy set theory are two examples of non-monetary integration techniques (Bell \& Morse, 2012; Cornelissen, Berg, Koops, Grossman, \& Udo, 2000). The use of money as a common unit of integration is a more appropriate approach for the combination of indicators which categorized under 'multiple capitals' framework. Monetization is a very strong tool for integration of different types of indicators, but the process of valuation is a time consuming and expensive task. Also, in some situations it is not possible to valuate assets, especially those relate to environmental or human aspects.

Cost-benefit analysis (CBA) is a popular monetary integration technique which allows us to compare the monetary value of costs and benefits associated with sustainable development. According to Bell and Morse (2012) the strength of CBA lies in the fact that substitution of natural capital with physical capital of equal value is possible.

A more recent example of such monetary integrated indicators is Genuine Saving Rate (GSR), initially introduced by Pearce and Atkinson (1993) and developed by Hamilton (1994) as an indicator of weak sustainability (Figure 2.3). According to Pearce and Atkinson (1998, p. 16) “... genuine savings is simply gross savings less depreciation on assets (here, man-made capital, natural resources and environmental assets)", where negative amount of this indicator implies non-sustainability. GSR also has been defined by the World Bank as gross saving plus investments in human capital (measured by education expenditures) minus the depreciation of produced capital as well as changes in certain natural capitals including depletion of minerals, energy, and forests; and damages from local and global air pollutants (World Bank, 2006). Some 
researchers argue that genuine saving can provide a holistic view of sustainability by integrating the value of natural, human and manufactured assets (Hamilton \& Clemens, 1999; World Bank, 1997).

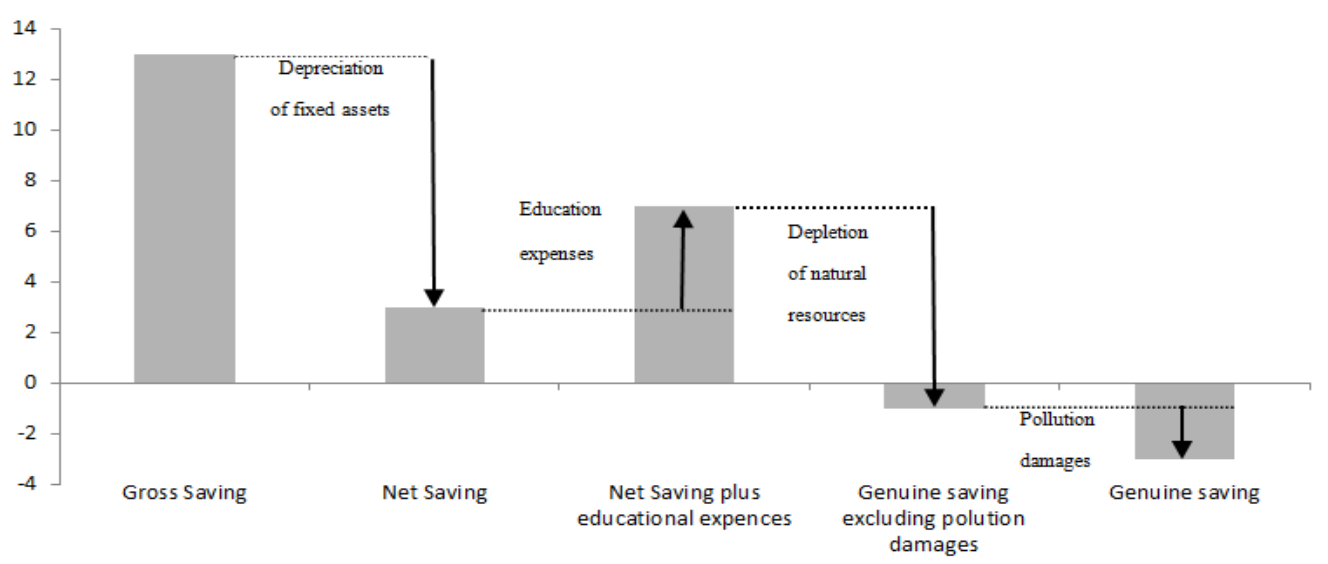

Figure 2.3 Genuine Saving Rate (GSR)

Source: Reproduced from (World Bank, 2006, p. 40)

The Genuine Progress Indicator (GPI) is similar to the GSR and was first proposed by Cobb et al. (1995) based on the concept of sustainable income introduced by Hicks (1946). It has been suggested to replace Gross Domestic Product (GDP), since GDP doesn't take into account non-monetized costs and benefits of environmental and social factors which are important components of well-being (Talberth, Cobb, \& Slattery, 2007). From a national perspective, GPI is the GDP minus the environmental costs (i.e. cost of resource depletion, ozone depletion, air pollution, water pollution, noise pollution, loss of farmland and loss of wetlands) and the social costs (i.e. cost of crime, family breakdown, commuting, automobile accident, loss leisure time) . (Stiglitz, Sen, \& Fitoussi, 2009; Talberth et al., 2007). 
The strength of GPI as a measure of sustainable development lies behind its ability to value natural and human capital flow in addition to physical capital flow. According to Talberth et al. (2007) an increasing or constant GPI over time implies that stocks of natural and social capital will be at least as great for the next generation while decreasing GPI implies unsustainable development. In the urban and regional context, the spatial structure of a city/region could greatly contribute to the increase or decrease in GPI level. For example, urban sprawl can significantly increase the costs associated with resource depletion (fuel consumption), land consumption, automobile accident, air pollution, noise pollution and commuting time.

The standard form of GPI contains more than twenty components (see Table 3.1) which can be classified into three main categories of environmental, social and economic. Also among these components, some are a direct or indirect function of travel distance (transport related indicators). Accordingly one can link the changes in value of GPI components to the changes in pattern of urban spatial structure through spatial modeling process. For example the social GPI components of costs of commuting, automobile accident, and loss of leisure time can be expressed as a function of variables such as vehicle miles traveled (VMT), Passenger Miles Traveled (PMT) or Average Travel Distance (ATD) which depend on the spatial characteristics of urban areas (size, shape, density, layout, etc.). Also the environmental GPI components could be a derivatives of urban spatial pattern. GPI components such as depletion of non-renewable energy resources, cost of air pollution, carbon dioxide emissions damage and ozone depletion are correlated with automobile fuel consumption. Loss of wetland, farmland, and primary forest area are also direct results of replacement of natural land cover with man-made transportation infrastructure (such as highways, streets and parking). Finally, noise and water pollutions can be considered as consequences of traffic congestion. In this research, considering the strength of 
GPI as a comprehensive sustainability indicators which can link urban spatial structure and total capital stock, it was chosen to assess the sustainability of simulation results (see Section III.2.4 for detail).

\section{II.1.2 Urban form}

\section{Background}

Anderson, Kanaroglou, \& Miller (1996, p. 9) define urban form as "the spatial configuration of fixed elements within a metropolitan region”. Khisty and Lall (1990, p. 62) define it as "the spatial pattern or arrangement of individual elements such as buildings, streets, parks, and other land uses (collectively called the built environment), as well as the social groups, economic activities, and public institutions, within an urban area". The urban form represents the spatial organization of communities' social activities over a long period of time. In other word, urban form is the result of interaction between human, natural and man-made forces. The human forces mostly include historical, social, cultural, religious, economic, political, mental and aesthetic aspects of a community. The natural forces consist of a wide variety of factors such as climate conditions, type of soil or materials, topography, vegetable land coverage, water supply, etc. And finally the artificial man-made forces include construction, material and structural technologies and their combination with each other as well as their combination with a surrounding environment. Buildings, urban open spaces, road network, roundabouts and other infrastructures in combination with earth topography, water streams and vegetable land cover shape the urban form and cities' spatial structure as an integrated system which has a systematic and dynamic interaction with the outside environment. 
Williams, Jenks, \& Burton (2000, p. 4) define urban form as "morphological attributes of an urban area at all scales". These attributes range from the micro scale to the macro scale at which urban form can be considered as individual building, local street, urban block, neighborhood, road network, city and even region. Morphological attributes such as overall size, overall shape (linear, radial,..), and overall density are more meaningful in the macro scale, while characteristics like centrality (decentralized vs. mono-centric and polycentric), clustering (clustered vs. dispersed), equity of spatial distribution, and land use diversity (homogenous vs. heterogeneous) are more appropriate for meso scale, as well as neighborhood layout, building density (floor area ratio) and walkability for micro scale. Also, some characteristics such as accessibility and connectivity are applicable for all scales.

Among the above morphological attributes, some important ones have been selected and a brief explanation was prepared for each of them based on the academic literature reviewed. But before doing this step, it could be helpful to review the main elements of urban form.

\section{Elements of urban form}

The spatial structure of urban areas is a function of human, natural and man-made forces. The interaction between these forces and their effect on urban spatial structure is subject of several studies. The many factors that make up the city form could be categorized in three broad elements of transportation infrastructure, land use and building. According to Dempsey et al. (2010) these elements of urban form also play primary role in urban sustainability and human behavior. The dynamic interaction between these elements is the main subject of many urban planning models. 
Rodrigue et al. (2009) contend that transportation has significant impact on the spatial organization of city-regions. They also state that “... space shapes transport as much as transport shapes space" (Rodrigue et al., 2009, p. 81). Anas, Arnott, \& Small (1998) argue that spatial structure of modern cities is mainly influenced by advances in transportation and communication technologies in recent centuries. They argue that before the railroad era cities were located close to waterways in order to gain the benefits of water transportation, but after development of rail transportation at the latter part of the $19^{\text {th }}$ century the growth pattern of major cities such as Oklahoma City, Denver, and Salt Lake City were influenced by railroad network. Especially their central business districts (CBD) developed and reshaped around rail stations. The same story repeated later for cities like Dallas, Houston and Phoenix after the automobile era. This time the highway network was the key building block to the construction of these cities.

The role of transportation system in shaping spatial structure of cities was considered by many well-known architectural and planning pioneers in their urban plans. For example in "Linear City" plan, developed by Arthur Soria, the linear form of the city follows its function as a settlement along a linear public mass-transit system (Lynch, 1981). Transportation infrastructure was also viewed as a main element of city structure by Le Corbusier (1987) in his famous plan "City of Tomorrow". Depending on the characteristics of traffic, he proposed three different types of road including: 1) below ground system of streets for heavier traffic, 2) at the ground network of ordinary streets for lighter traffic and 3) two axes of elevated reinforced concrete bridges for fast traffic. He also suggested a network of rail transport lines connected to the main station in the center of the city. In "Broadacre City" model of Frank Lloyd Wright (1935), the transportation infrastructure received special attention. He proposed a multi-lane highway without any grade crossing or left turn as well as a road system without any signal or 
lamp-posts. In addition to these road networks, he also suggested a long distance monorail for passenger transportation. The role of transportation is even more transparent in the city of Radburn; a city designed by Clarence Stein and Henry Wright and founded in 1928 in response to the necessities of the automobile era. In this city an innovative system of superblocks surrounded by main roads was used instead of traditional gridiron pattern. This new system separates pedestrian and automobile traffic and also makes a hierarchical road network ranging from the smallest scale (cul-de-sac) to the largest scale (major arterial road) (Birch, 1980; Gatti). "Industrial City" plan of Tony Garnier, "Garden City" plan of Ebenezer Howard, and "Neighborhood Unit" plan of Clarence Perry are other clear examples showing the importance of transportation infrastructure in the plan and design of city form (Garnier \& Mariani, 1990; Howard \& Osborn, 1965; Perry, 1929).Land use as the second major determinant of urban form has also been investigated in several urban studies. According to Dempsey et al. (2010) the efficiency of a city and sustainability of urban form critically depend on the spatial pattern of land use. City plans prepared by famous architects and urban designers such as Ebenezer Howard, Tony Garnier, Frank Lloyd Wright, Le Corbusier, Clarence Perry, Arthur Soria contain detailed land use plans.

Burgess's "Concentric Zone Model”, one of the earliest theoretical models, describes spatial structure of city based on pattern of land use. Burgess in his book depicts a schematic model of a city which includes some concentric rings around the center of the city, each ring representing a unique pattern of land use. In his model the most interior ring is the central business district (CBD) which hosts the business and trade activities. Next rings are transitional zones of mixed industrial and residential (deteriorating housing) land uses. Other rings are working-class residential, residential and commuter/suburban zones (Park \& Burgess, 1984). 
This model is also based on the bid-rent theory developed by Von Thünen a century earlier (Rodrigue et al., 2009). This theory is based on the competition of land users to occupy the most accessible land within the central business district of the city in order to maximize their profit. This theory is based on the assumption that the land price increases as the distance from CBD decreases and consequently the highest bidders such as retailers will occupy these profitable lands of CBD; they have more willingness to pay for lands close to the center of the city. The second group of land users are factory owners that occupy lands located in outer ring around the CBD and finally the third ring will be occupied by residents for residential land use, since they have lowest willingness to pay for expensive lands close to the center of the city. This competition between various land users will shape the spatial structure of the city based on concentric rings. This theory was further developed by William Alonso (Alonso, 1960, 1964).

In contrast with concentric zone model, Homer Hoyt argued that cities can't always maintain their concentric structure of land use pattern and the wedge-shaped pattern is more appropriate for city growth. According to Hoyt's "Sector Model", the commercial land users such as retailers tend to remain in the $\mathrm{CBD}$, while manufacturing land users prefer to locate in wedges bordering major transportation corridors. The lower-class residents also tend to occupy the lands close to these corridors along the railroad line and in adjacency of manufacturing and industrial zones. Finally the middle-class and higher-class residents will choose the land wedges far away from mentioned land use zones as they want to avoid the exposure to traffic, air pollution and noise. Hoyt plan might be one of the earliest models in which interaction of land use and transportation was clearly identified.

Harris and Ullman improved these models by adding new assumptions. They argue that the spatial structure of land use in most large cities has a polycentric pattern rather than 
monocentric pattern. According to their "Multi Nuclei" model different land use activities tend to group around separate centers based on the three major factors of differential accessibility, land use compatibility/incompatibility and location suitability. This model is more realistic compared to previously discussed models, since the effect of travel distance, land price, economy of scale and environmental compatibility are simultaneously considered in the model. This model is also very interesting as it uses concepts such as accessibility, compatibility and suitability which are subject of recent urban and regional science studies focusing on morphological attributes of urban areas. Other land use models such as the hybrid model developed by Walter Isard are also based on these early models (Rodrigue et al., 2009).

Urban spatial structure is a resultant of interrelation between land use and transportation. As can be seen in above simple models, this fact has also been considered by planners, revealing that this relationship has been understood for centuries. But the theoretical basis of this interdependency was explained by Lowry's Model of Metropolis in 1964 (Wegener, 2004).

According to this model, land use is one of the initial determinant factors for level of urban activities. In other word each piece of land with certain types of land usage generates certain numbers of urban trip. By increasing the level of activity, the demand for urban mobility will rise. As a consequence of increasing demand for better mobility services, need for additional supply of transportation infrastructure, such as new highways and new public transit facilities, will rise in the medium and long term. In turn, by supplying these new transportation infrastructure the level of system's accessibility will naturally increase, which will probably change the land value. Again, increasing the land value will affect the land use, since different land users have a different willingness to pay - for example changing residential land use to commercial. Finally, this land use change will raise again the level of activity and mobility and a 
complete cycle of changes occurs. Obviously, the spatial structures of the city will slowly change by gradual changes in land use type and gradual supply of new transportation infrastructure.

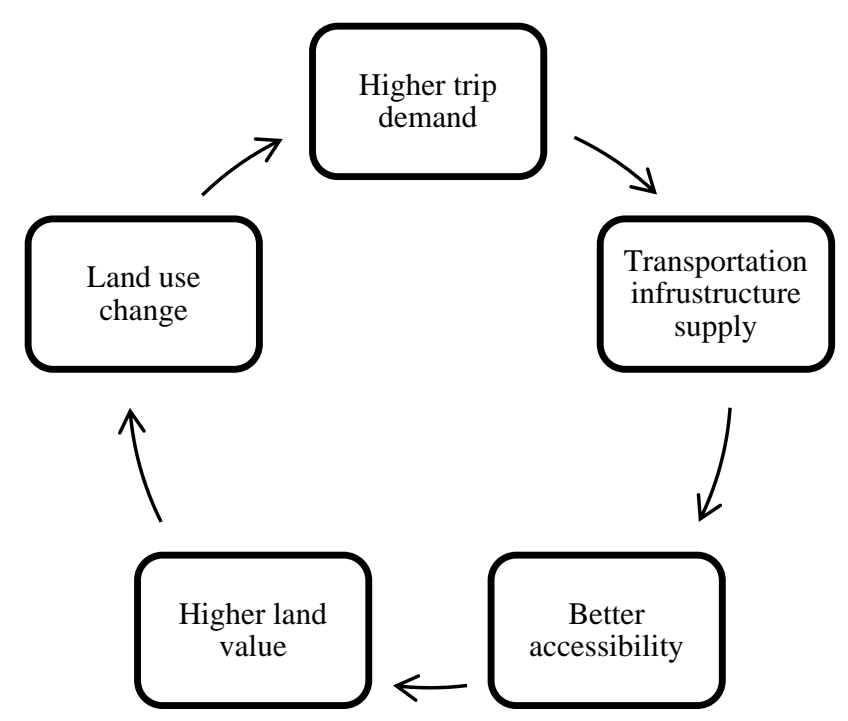

Figure 2.4 Land use-transportation cycle

As represented in Figure 2.4 transportation is closely associated with land use through accessibility. Accessibility refers to the ability to reach desired goods, services, activities and destinations together called opportunities (Victoria Transport Policy Institute, 2011). The higher the level of accessibility, the more attractive land for development.

\section{Morphological attributes and indicators of urban areas}

Before investigating the role of urban spatial structure in sustainable development, it is necessary to define some indicators for measuring the attributes of urban spatial structure. Fallström, Marcus, \& Ström (2009, p. 2) state that "development of indices of the spatial 
constitution [structure] of urban regions on both the macro and micro level can inform urban designers, planners and policy makers in their work towards successful development”.

There are several indicators each describing some aspects of urban spatial structure, but there is little consensus on most of them. Some indicators are very illusive since there is a lack of universal agreement on definition of concepts like sprawl, centrality, clustering etc. Another reason for this ambiguity is because different indicators can be viewed from different geographical scale. Additionally, the interpretation of these metrics is also challenging. For example the interpretation of density and high density area seems to be different in Asian cities and American cities, as they have different living standards. The following sections review the literature and provide transparent and succinct definition of selected indicators. These definitions will help a better understanding of ways to measure and quantify the morphological attributes of the city and examine the effect of these metrics on urban sustainability in order to recognize more sustainable urban forms.

\section{Overall shape}

In order to better understand morphological attributes of urban spatial structure we should first start from the macro scale attributes such as urban "overall shape" which is more visually understandable. The overall shape of cities can be divided into organic/irregular, radial star/asterisk, grid and linear categories. In the organic cities, the spatial structure of the city is not based on any planning or well-designed map and it doesn't follow any predetermined regular geometry. It usually consists of curvy streets and alleys which are connected together without any clear hierarchy. Most of European medieval cities follow this pattern as well as ancient Asian cities. Hillier (2009) argues that organic cities seems to contribute to all 3 E's of 
sustainability. Mumford (1961) was also an advocate of the organic city model. Figure 2.5 represents an example of an organic city pattern.

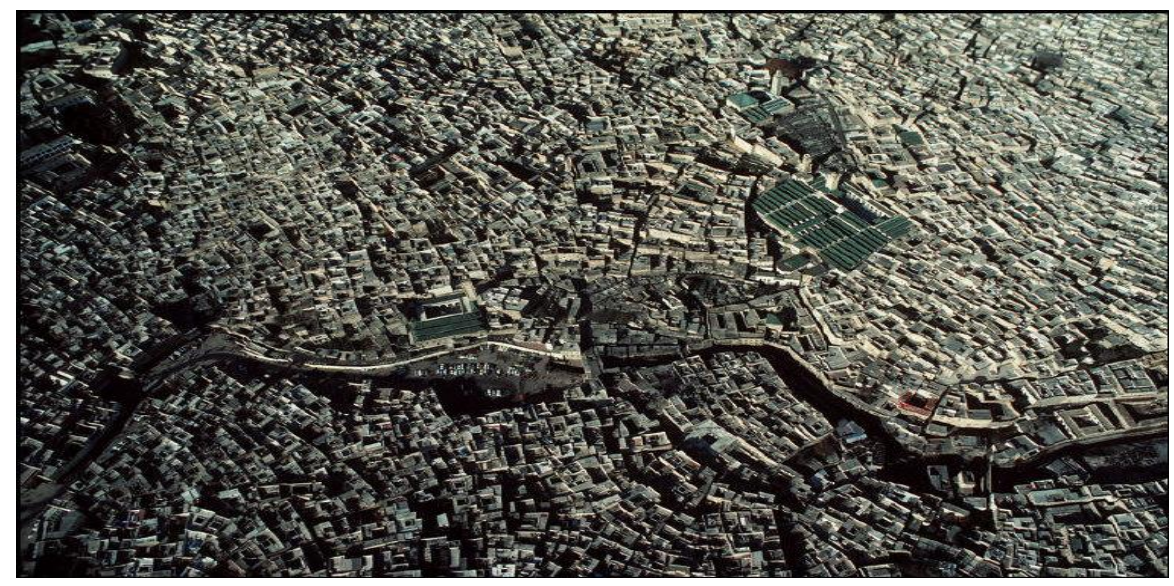

Figure 2.5 Aerial view of Fez, Morocco

Source: (Barbey, 1985)

The radial star or asterisk city has defined by Lynch (1981, p. 373) as a city with "a single dominant center, of high density and mixed land use, from which four to eight transportation lines radiate outward”. This dominant center plays a primary role in urban activities and other sub-centers along the transportation lines could play a secondary role. The basic plan of Washington and Copenhagen, respectively, as well as the general plan of Moscow are mainly based on this pattern (Lynch, 1981). The radial star form was also very common in ancient cities in which the center of the city contained a governmental palace and the residential areas were located around this center. However the defensive issues were the main reason for choosing this pattern for ancient cities, other motivations such as aesthetic and artistic aspects might be important in this design especially in Renaissance era. Palmanova in Italy is a classic example of Renaissance star cities, was designed by Vincenzo Scamozzi in 1593 mainly as an 
army garrison (Morris \& Morris, 1994). Firozabad in Iran is another example of an ancient radial city. The aerial view of these cities are shown in the next figures:

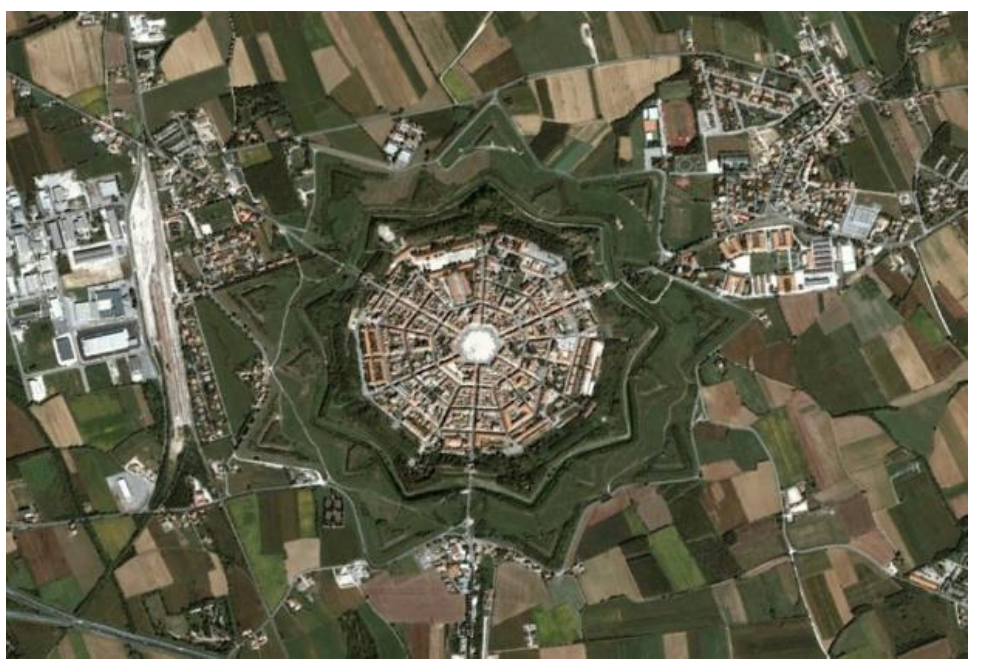

Figure 2.6 (a) Aerial view of Palmanova, Italy

Source: (Urban Times, 2012)

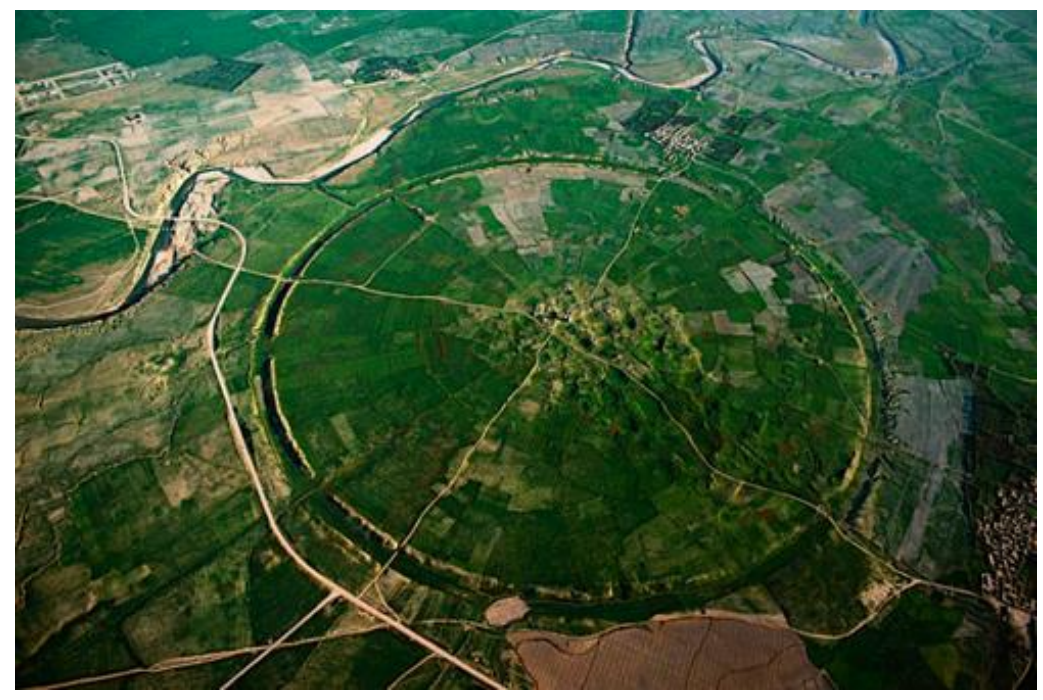

Figure 2.6 (b) Aerial view of Firuzabad, Iran

Source: (Gerster, 2013) 
In special cases where a city is located adjacent to natural features such as river, forest, mountain the city form tends to semi-radial pattern because of growth limitations on one side. Amsterdam in the Netherlands is one of the best examples of semi-radial city form. Another special case of radial star pattern is multi-central radial city that has more than one center instead of one central point. This pattern usually occurs in cities which their main center has reached its ultimate density. Cities like Canberra in Australia are good examples for this type of urban form.

However the linear settlements existed along roadside, riverside or seaside since long times ago, this concept was proposed by Arthur Soria in 1882 in Madrid and then followed by designers such as Le Corbusier in France, Frank Lloyd Wright in the United States (Lynch, 1981). This type of city form is not very common, since the distances between origins and destinations are very large compared to other urban spatial patterns. Some communities along the Saint Lawrence River in Quebec, Canada, as well as Volgograd in Russia are examples of linear settlements. 


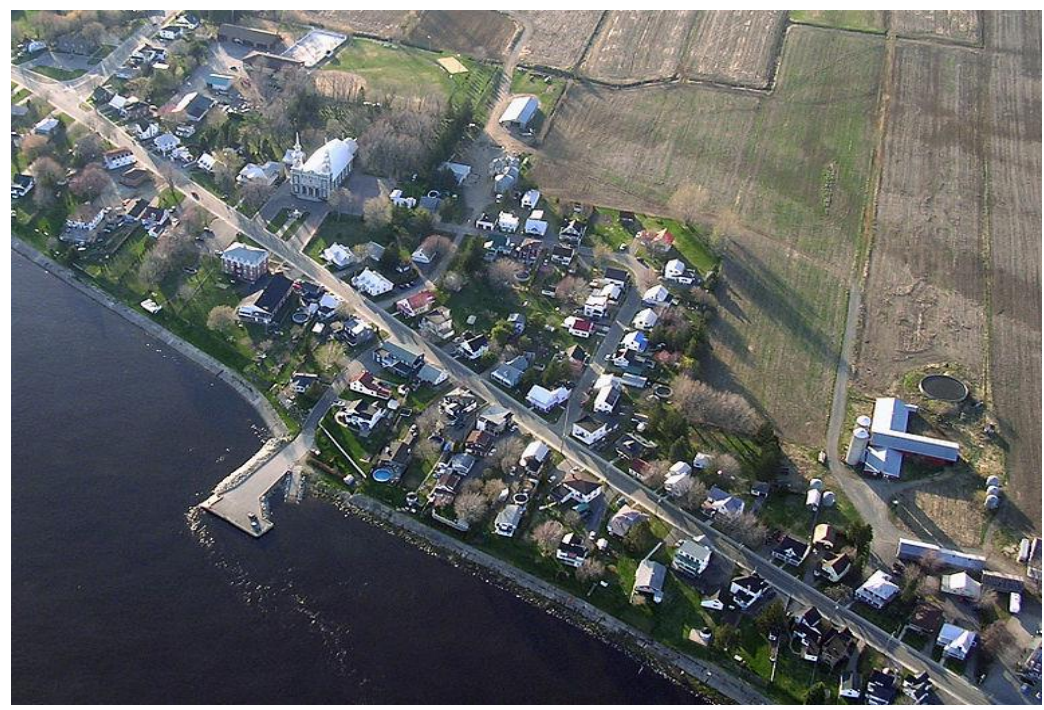

Figure 2.7 (a) Aerial view of Champlain, Quebec

Source: (Wikipedia, 2013a)

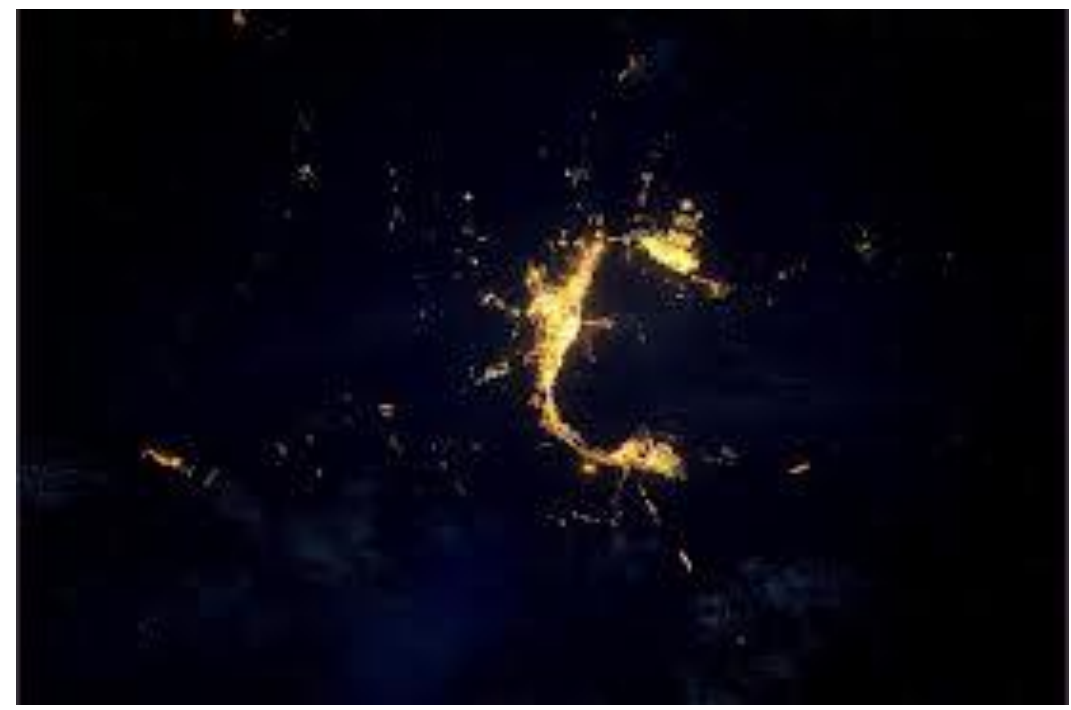

Figure 2.7 (b) Aerial view of Volgograd, Russia

Source: (European Space Agency, 2012)

There are several examples of cities with grid pattern both in ancient and current times. In this type of cities, as its name implies, streets form a rectangular grid and the city doesn't have a 
clear center. Thus, all origins and destinations, except those are located in city edges, have equal access to each other (Lynch, 1981). This pattern has high flexibility and efficiency for development. One of the best examples of modern cities with grid pattern is New York.

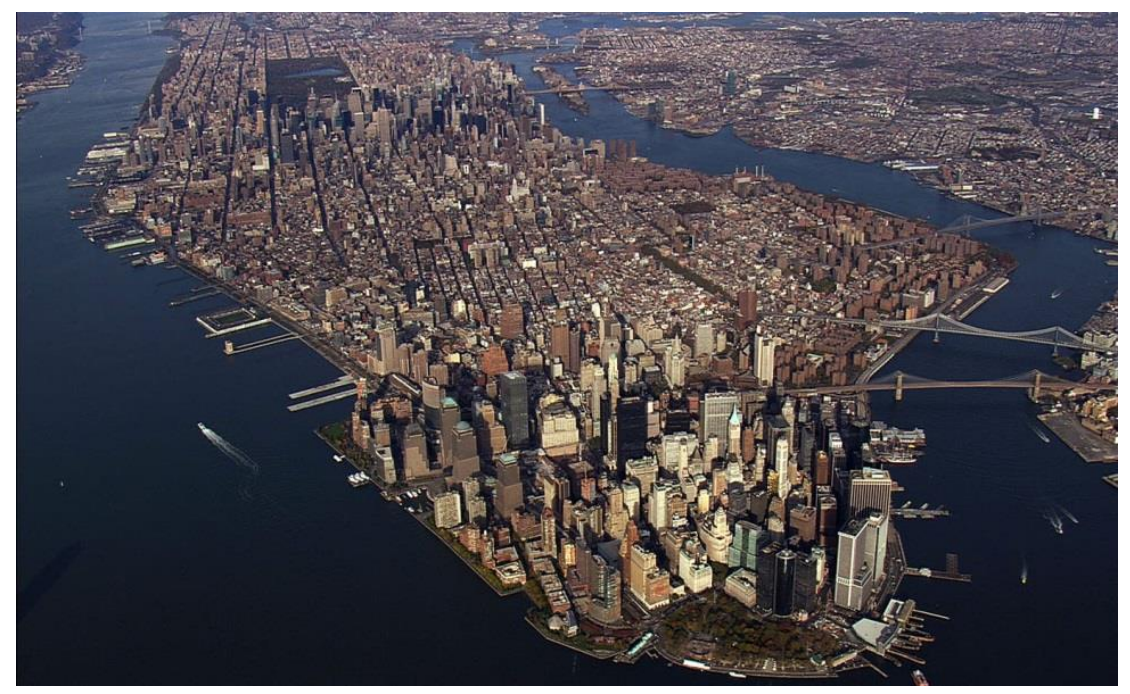

Figure 2.8 Aerial view of New York, USA

Source: (Smithsonian Channel's Aerial America, 2010-2012)

The overall shape of a city is a mixture of these simple pure forms. In particular the modern cities have a more complicated spatial pattern because of various human, natural and man-made forces they are experiencing every day. However Planners and designers have limited chance to control all these forces, but at least they can use some tools such as land use regulations, infrastructure investments and taxation policies in order to influence the spatial pattern of cities (Bertaud, 2004)

\section{Overall size}

Overall size is a metric to measure the total amount of land covered by the city which is an important parameter in defining an urban structure (Bertaud, 2004). It also could be 
considered as the simplest index of urban sprawl. The large size of an urban area does not necessarily imply that urban sprawl exists but it usually happens in the real world.

\section{Density}

Density is another dimension of urban form and many studies suggest that urban density and urban sustainability are highly correlated. Galster et al. (2001, p. 687) define density as "the average number of residential units per square mile of developable land in a UA [urban area]". They also determined density as one of the eight important indicators of urban sprawl. There are also a variety of other ways of measuring the density, such as floor area ratio (FAR), population density, and employment density, each indicator is more appropriate for a certain urban scale.

Overall size

Density

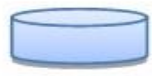

Low Density

Equity of spatial distribution

Centrality and clustering

Widely Spread

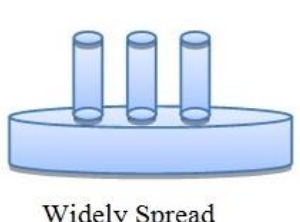

Equally Distributed

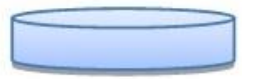

Large

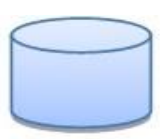

High Density
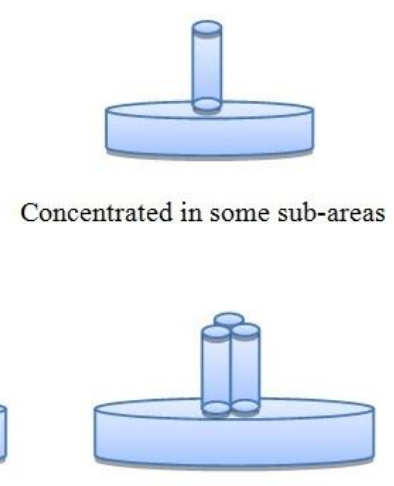

Highly Clustered

Figure 2.9 Schematic model of urban form

Source: Reproduced from (Tsai, 2005) 
A convenient way to visualize the spatial structure of a city is through density profile. Density profile depicts the distribution of densities by distance from city center (Figure 2.10).
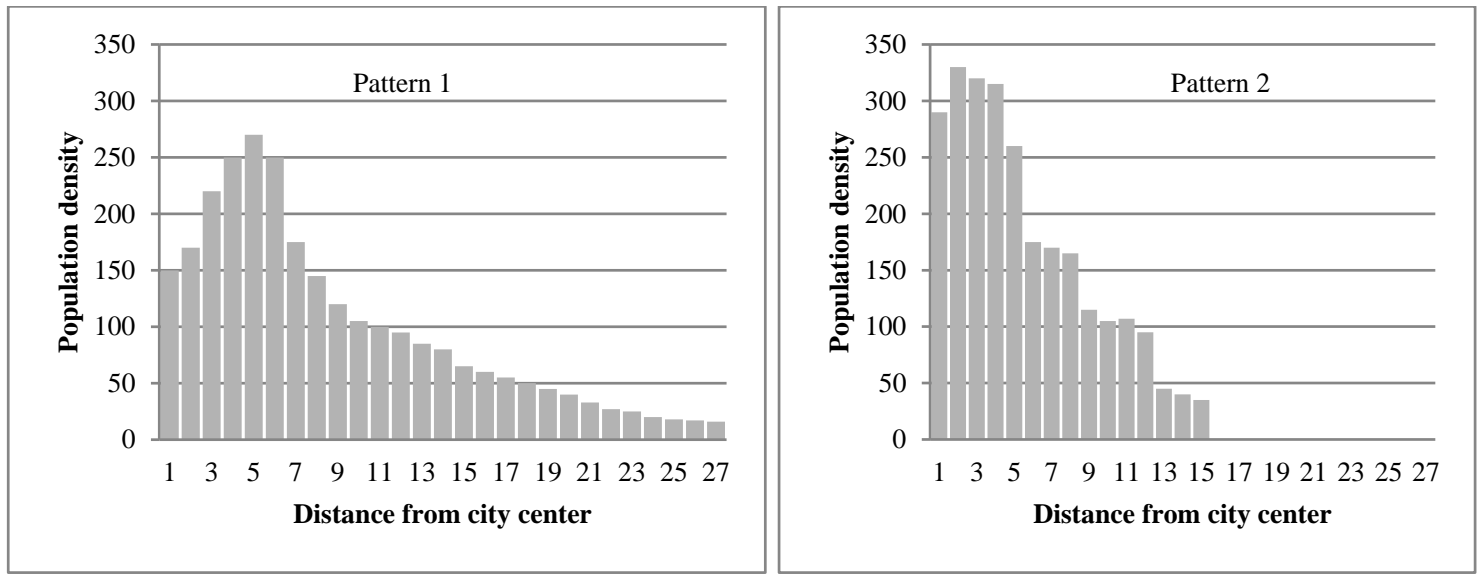

Figure 2.10 Example of urban visualization using density profile

Source: Reproduced from (Bertaud, 2004, p. 11)

\section{Equity of spatial distribution (entropy)}

Equity of spatial distribution is another useful spatial structure indicator which displays how much urban system components; such as population, buildings or activities; are uniformly distributed within a city. Tsai $(2005$, p. 143) defines this indicator as “... the degree to which development is concentrated in a few parts of a metropolitan area..". Shannon's entropy is one of the most useful indexes for degree of equal distribution among several others, since it ranges from 0 to 1 . The lower amount of Shannon's entropy indicates the lower degree of equal distribution. In other word, if the entropy index tends to zero, it means that the spatial distribution is not uniform within the city area and some parts of the city have higher density than other parts. The Shannon's entropy formula is as follows: 


$$
\begin{aligned}
& H=\sum_{i=1}^{n} p_{i} \cdot \ln \left(p_{i}\right) / \ln (n) \\
& p_{i}=\frac{D E N i}{\sum_{i=1}^{n} D E N i}
\end{aligned}
$$

Where, $H$ is the relative Shannon's entropy, DEN $i$ the density of subarea $i$ and $n$ number of subareas. This index only shows the extent urban components are concentrated in a number of sub-areas and it doesn't give any information about clustering of these of high-density sub-areas.

\section{Centrality and clustering}

The next important dimension of urban spatial structure is centrality. Given an urban area with unevenly distributed population, buildings, or employment, centrality refers to the situation that high-density sub-areas are clustered together around one or a small number of centers such as a central business district (CBD) or public transit terminals. If this clustering happens just around one focal point (high clustering) it is called mono-centric development and if happens around more than one center (medium clustering) it is called poly-centric development. Finally, if high-density sub-areas were dispersed, it is called scattered or decentralized development.

According to the definition of Galster et al. (2001, p. 691) clustering is "the degree to which development has been tightly bunched to minimize the amount of land". "Global Moran" index is one of the best indexes could measure the level of clustering/dispersion.

$$
\text { Moran }=\frac{N \sum_{i=1}^{N} \sum_{j=1}^{N} W_{i j}\left(X_{i}-X\right)\left(X_{j}-X\right)}{\left(\sum_{i=1}^{N} \sum_{j=1}^{N} W_{i j}\right)\left(X_{i}-X\right)^{2}}
$$


Where, $X_{i}$ and $X_{j}$ are population or employment in sub-area $i$ and $j$ respectively, $X$ is the mean of population or employment, $W_{i j}$ is the weighting between subareas $i$ and $j$, and $N$ is the number of sub-areas. The absolute value of the global Moran index ranges from 0 to 1 . A higher value indicates a higher clustering pattern and a lower value indicates dispersion.

\section{Compactness and sprawl}

The two antonym metrics of compactness and sprawl are probably the most frequently cited dimensions of urban spatial structure, although there is no consensus regarding their definition. According to Tsai (2005) despite general disagreement about the definition of compactness, concentration of development is a common idea of all these various definitions. Sprawl is often described as a low density development. In fact the relation between compactness/sprawl and density is not always constant and depends on the geographic scale of the area over which density is measured. Fulton, Pendall, Nguyen, \& Harrison (2001) argue that overall city area is usually used as a unit for density measurement, but individual persons generally feel sprawl and compactness in smaller scales such as neighborhood. As a consequence, overall density of urban area is not applicable to these smaller geographical scales and results are illusive. For example "scattered development" and "leapfrog development" were considered as "decentralized sprawl” by some scholars such as Ewing (1997), Fulton (1995) and Ottensmann (1977), while these development patterns consist of dense subareas within a larger low density area. Other researchers have defined compactness/sprawl based on dimensions such as clustering and centrality (Anderson et al., 1996; Galster et al., 2001; Gordon \& Richardson, 1997; Tsai, 2005). Nelson and Duncan (1995, p. 1) have summed up different definitions and defined sprawl as: “...unplanned, uncontrolled, and uncoordinated single use development that does not provide for a functional mix of uses and/or is not functionally related to surrounding 
land uses and which variously appears as low-density, ribbon or strip, scattered, leapfrog, or isolated development."

Tsai (2005) summarizes various definitions and proposes a new quantitative approach to redefine these terms. His comprehensive approach is based on different metrics such as density, degree of equal distribution (Shannon's entropy or Gini coefficient), centrality (Moran clustering index) and continuity. Figure 2.11 depicts a summary of his approach.

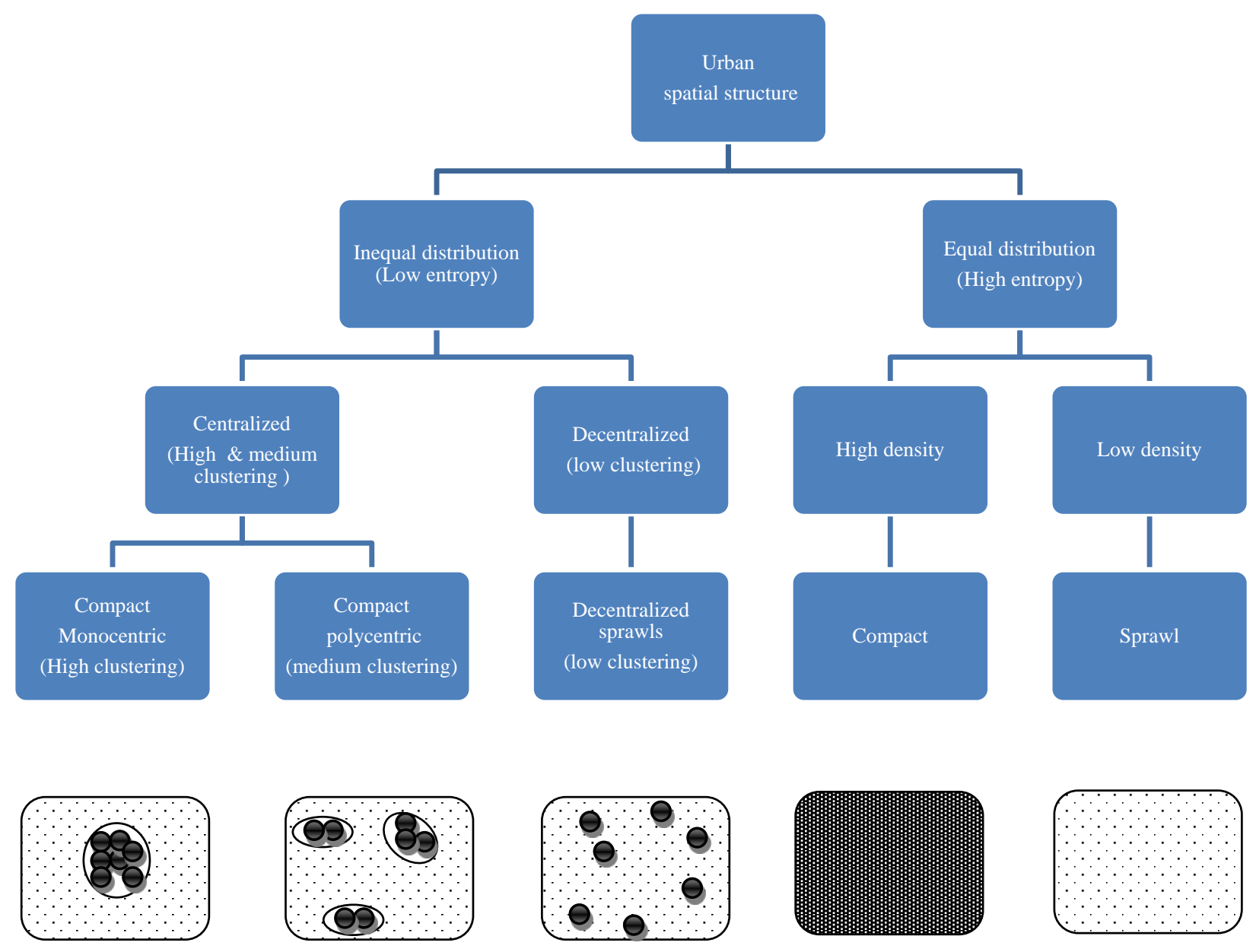

Figure 2.11 Tsai's approach for quantifying urban form

Source: Adapted from (Tsai, 2005) 


\section{Diversity}

Diversity of land use, amenities and building types is another useful indicator of urban form. The concept of urban diversity was used for the first time by Jacobs (1961). She argues that land use mix and diversity could increase social interactions as well as social security. She also claims that, however diversity seems to be a kind of chaos or disorder, but in fact it is essential to sustainable life of the city. Land use diversity measures the degree to which different land use types are mixed. In contrast, Homogeneity measures the degree of segregation of uses, building and activities (Khisty \& Lall, 1990). Salat, Bourdic, \& Nowacki (2010) used Simpson's formula to quantify level of diversity. Shanon's entropy coefficient is another popular index of diversity (Aurand, 2007).

\section{Accessibility, walkability and connectivity}

Accessibility is a key indicator underlying the interrelation between land use and transportation. Accessibility refers to the ability to reach desired goods, services, activities and destinations together called opportunities (Victoria Transport Policy Institute, 2011). Accessibility represents not only the morphological attributes of urban spatial structure such as land use location relative to road network, but also reflects other attributes of transport system such as travel time and travel cost between origin and destination pairs. According to Apparicio, Abdelmajid, Riva, \& Shearmur (2008) there are three general approaches for measuring accessibility: 1) the number of facilities within a certain distance/time threshold;2) the distance to closest /n closest /all facilities; and, 3) the gravity model. It should be noted that Euclidian distance (straight-line), Manhattan distance (distance along two sides of a right-angled triangle 
opposed to the hypotenuse) or shortest network distance are generally used for accessibility calculation (Equation 4).

$$
A_{i}=\sum_{j} T_{i j} \cdot F_{j} \quad \forall T_{i j}<t
$$

Where, $A_{i}$ is accessibility of point $i, F_{j}$ is number of facilities/activities in area $j, T_{i j}$ is distance/time between $i$ and $j$, and $t$ is threshold.

Walkability is a measure of how friendly an area is for walking. Similar to accessibility index, walkability index is also calculated based on the distance to the closest amenity or the number of facilities within certain walkable distance or time. The reasonable walking threshold is $1 / 4$ to $1 / 2$ mile or 5-15 minutes (NJ Transit, 1994).

Finally, Connectivity refers to the number of intersections along a path or road network. A connected street network has several shortcuts and intersections as well as minimal cul-desacs. A connected form of network can provide better condition for walking and biking as it provides more shortcut links and route options, allowing more direct trips between origin and destinations and reducing travel distance. Also, it better supports public transport. Degree of connectivity is measured by dividing the number of links (road segments) by the number of nodes (intersections or cul-de-sacs). The connectivity index is applicable for walking, biking and motor vehicle networks. 


\section{II.2 Related literature}

\section{II.2.1 Sustainable built environment}

Sustainable development as a new concept has been introduced since the last decades of the 20th century, attempts to define and design environmentally, socially and economically sustainable built environments in which people live in harmony with nature. The Garden City is one of the first examples of these practical efforts illustrated by Ebenezer Howard in the late 19th century in reaction to poor environmental conditions of the industrial era. The Broadacre city is another example of an ecological utopia. This so called Ecotopia was designed by American architect and urban planner Frank Lloyd Wright in order to create a better place to live and work. More recent manifestations of these ideal communities set forth by contemporary visionaries have appeared under titles such as sustainable community, sustainable city, ecopolis, ecocity, ecotown, ecovillage, smart city, compact city, green city, low carbon city etc. Despite the multiplicity of terms related to concept of sustainable built environment, they all attempt to address the challenges of unsustainable development in various geographical scales of a region, a metropolitan area, or in smaller scales such as a village or an urban neighborhood. These challenges (of unsustainable development) have been illustrated in programs such as UN agenda 21 and UN Earth Summit. A brief review of these definitions provides a useful context for understanding of the concept of sustainable built environment.

\section{Sustainable society, sustainable community and sustainable city}

According to Dresner (2008) an early use of the term "sustainable society" goes back to the conference on Science and Technology for Human Development organized by the World Council of Churches in 1974: 
First, social stability cannot be obtained without an equitable distribution of what is in scarce supply or without common opportunity to participate in social decisions. Second, a robust global society will not be sustainable unless the need for food is at any time well below the global capacity to supply it and unless the emission of pollutants are well below the capacity of the ecosystems to absorb them. Third, the new social organization will be sustainable only as long as the use of non-renewable resources does not out-run the increase in resources made available through technological innovation. Finally, a sustainable society requires a level of human activities which is not adversely influenced by the never-ending large and frequent natural variations in global climate. (Dresner, 2008, p. 32)

This definition is very similar to more recent definition of sustainability, since it simultaneously considers social and environmental aspects of sustainability. With respect to physical aspects, terms such as sustainable community and sustainable city are commonly used in urban and regional field, offering new solutions for urban and regional problems. "Sustainable Community" refers to a community designed with consideration of maintaining and improving the quality of life in order to provide healthy, productive and enjoyable life for its present and future members (Hart, 1995). "Sustainable City" is a city designed to enable citizens to meet their needs, while consuming minimum inputs of assets (energy, land, water etc.) and causing minimum waste output of air, water or noise pollution. Girardet's definition of sustainable city illustrates this concept: " a sustainable city, Ecopolis, enables all its citizens to meet their own needs and to enhance their well-being, without degrading the natural world or the lives of other people, now or in the future" (Girardet, 2004, p. 6). 
Several sustainable cities exist or are planned across the world. Freiburg in Germany is regarded as a successful case of sustainable cities (Holtgard, 2009). The key features of sustainable city design in Freiburg include using solar energy source, radiant cooling and heating system, walking and cycling as an alternative transportation system, waste recycling system, green roofs and dense urban fabric. Freiburg's master planning started in 1970's and has resulted in more than 10 percent per capita reduction in $\mathrm{CO}_{2}$ emission and 100 percent increase in public transport use (Holtgard, 2009; Joss, Tomozeiu, \& Cowley, 2011; Suzuki et al., 2010). Mesa del Sol, New Mexico is an example of large ecocity project in the United States. It was designed by Peter Calthorpe, one of major proponents of new urbanism. This ecocity is being developed in a 12900-acre land and will be a home for a population of 100,000 and provide several facilities such as industrial parks and town centers (Metcalf, 2008).

\section{Ecopolis, ecocity, ecotown and ecovillage}

The term "Ecopolis", used in Girardet's definition of sustainable city, was firstly adopted by Downton in 1989. According to Downton (2008) this term consists of the "eco" prefix originated from Greek word "oiklos" and "polis" suffix also originated from Greek word "polis". He states that “...'eco' refers to ecological purpose and 'polis' to the ideas and ideals of governance that encompass community and self-determination" (Downton, 2008, p. 22). Ecopolis is a settlement which provides healthy life and ecological stable environment. It should be noted that "eco" has also been used as prefix of other terms such as ecocity, ecotown and ecovillage.

The term "Ecocity" was in use since early 1970s but it was first defined by Register (1987) as "an ecologically healthy city" in his book (Downton, 2008; Suzuki et al., 2010). There 
are various aspects of in building Ecocities including renewable energy usage (solar, wind, geothermal, etc.), improved public transport (transit-oriented development, intelligent transportation systems, etc.), reduced urban sprawl (urban compactness, mixed land use, smart growth, etc.), innovative agriculture systems (urban agriculture), and integrated waste management systems (cyclic urban metabolisms) and so on.

According to a global survey conducted by Joss et al. (2011) the number of ecocities has rapidly increased from 79 in 2009 to 174 in 2011 and currently a huge amount of money is being invested in different countries across the world. Curitiba in South America is one of the best examples of ecocities, as it has implemented a set of sustainable and innovative solutions for transportation, resource recycling and education.

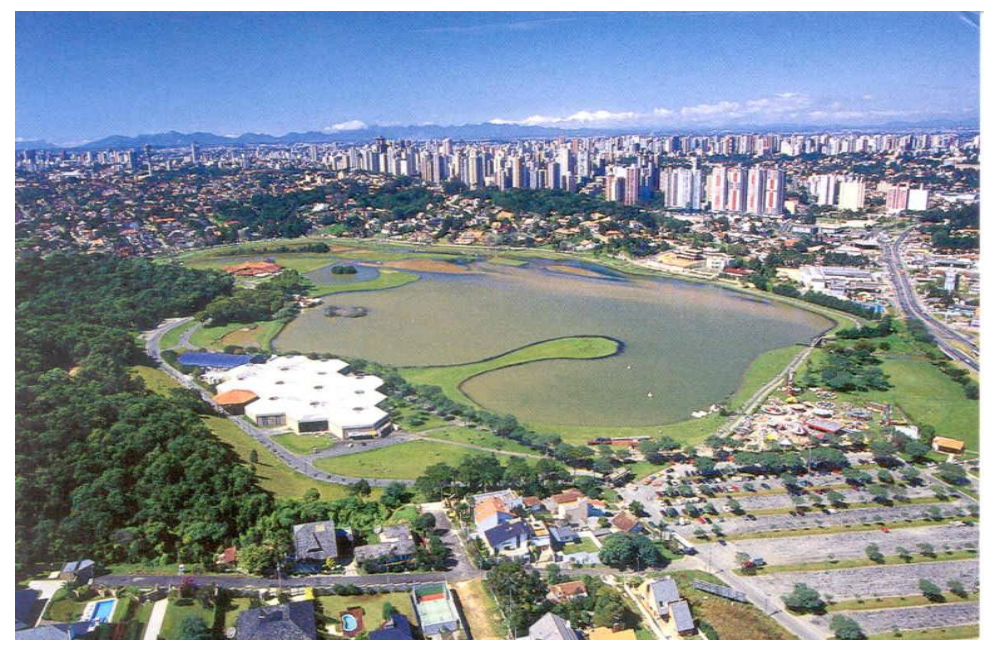

Figure 2.12 (a) Aerial view of Curitiba, Brazil

Source: (DS World's Lands, 2013) 


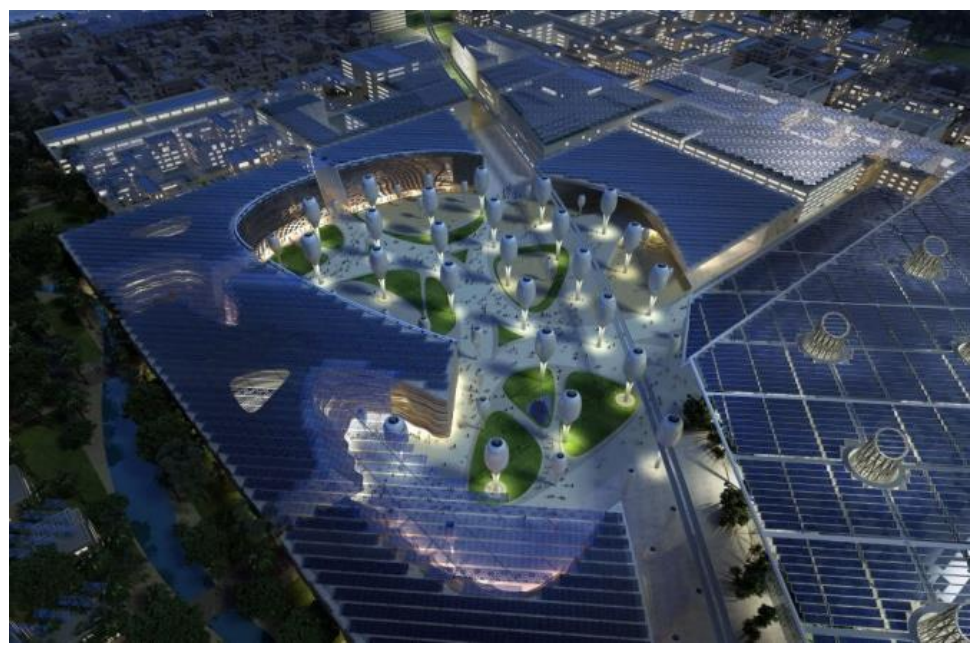

Figure 2.12 (b) Aerial view model of Masdar, UAE

Source:(Kannfinch, 2011)

There are also several new ecocity developments in Asian countries, particularly in China and India. Dongtan in China is one of the world's first ecocities planned to be ecologically friendly with close to zero carbon emission, as well as being socially and economically sustainable. This ecocity, designed to be home of 500000 by 2040 , will generate its own energy from renewable sources such as solar, wind, bio-fuel and recycled city waste and its transportation system consists of electric or hydrogen-powered vehicles (Qiang, 2009). SinoSingapore Tianjin is another Asian ecocity designed for population of 350000 by 2020 in order to be a socially harmonious, environmentally friendly and resource-conserving city (Government of Singapore, 2013). Masdar city in United Arab Emirates (U.A.E) is also being developed as first ecocity in Middle East located close to Persian Gulf beaches. This ecocity aims to become the world's first Zero Carbon City and a potential "silicon valley" for renewable energy through using solar energy, energy usage monitoring sensors, driverless electric vehicles and other innovative technologies (Maxwell, 2009). 
Beside the efforts to develop new ecocities, the concept of $\mathrm{Eco}^{2}$-Cities has been introduced by World Bank since 2009. The definition of $\mathrm{Eco}^{2}-$ City is based on the integration and interdependency of ecological sustainability and economic sustainability and their potential for synergy. The $\mathrm{Eco}^{2}-\mathrm{City}$ is used to represent a new generation of ecocities that not only considers ecological indicators of sustainability, but also tries to address a city as an integrated ecological and economic complex system. Singapore, Stockholm in Sweden, Brisbane in Australia and Yokohama in Japan are examples of $\mathrm{Eco}^{2}-$ City cases (Moffatt, Suzuki, \& Iizuka; Suzuki et al., 2010).

"Ecotown" is another relevant term; first introduced in Japan in 1997 as a town where ecology, economy and environment are integrates together, seeking to achieve zero-emission community and recycle-oriented region. First ecotown projects were initiated in Kitakyushu and Kawasaki and then the government of Japan approved 26 ecotown plans (Norton, 2007). This term also was used as a broader concept by UK government in order to launch development of ten sustainable towns of 5000 to 20000 new homes in reaction to the issues of climate change, poor living conditions and lack of affordable housing (Shaw, 2007).

The followings are key requirements of an ecotown: 1) providing good internal and external connectivity with surrounding areas in terms of job, transport and services; 2) being in harmony with natural world by increasing energy efficiency, using renewable energies, providing sustainable mobility options, reducing land and water consumption and recycling waste; 3) supporting land use, buildings and people diversity; 4) increasing social justice by providing convenient access to job, shopping, education, and affordable housing by all members of community; 5) designing the landscape to conserve and enhance valuable natural features; 
and, 6) having a strong identity in order to offer a choice of attractive places to live and economic activities.

Whitehill-Bordon (UK), Northstowe (UK), Rackheath, St. Austell (UK), Kronsberg (Germany), Vauban (Germany), HafenCity (Germany), Adamstown (Ireland) and Hammarby Sjöstad (Sweden) are examples of ecotowns in the Europe (Joss et al., 2011). According to the literature reviewed, Front Range ecotown in Boulder, Colorado and Greensburg ecotown in Kansas are the only two ecotown plans in the USA, none of them are developed yet (Clough, Sears, \& Sears, 2005).

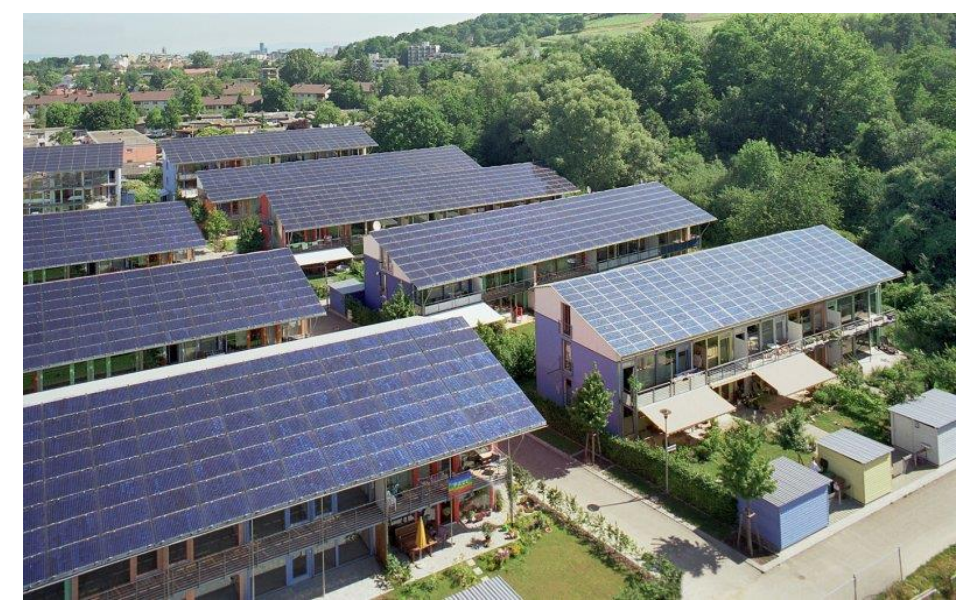

Figure 2.13 (a) Aerial view of Vauban, Germany

Source:(Blériot, 2010) 


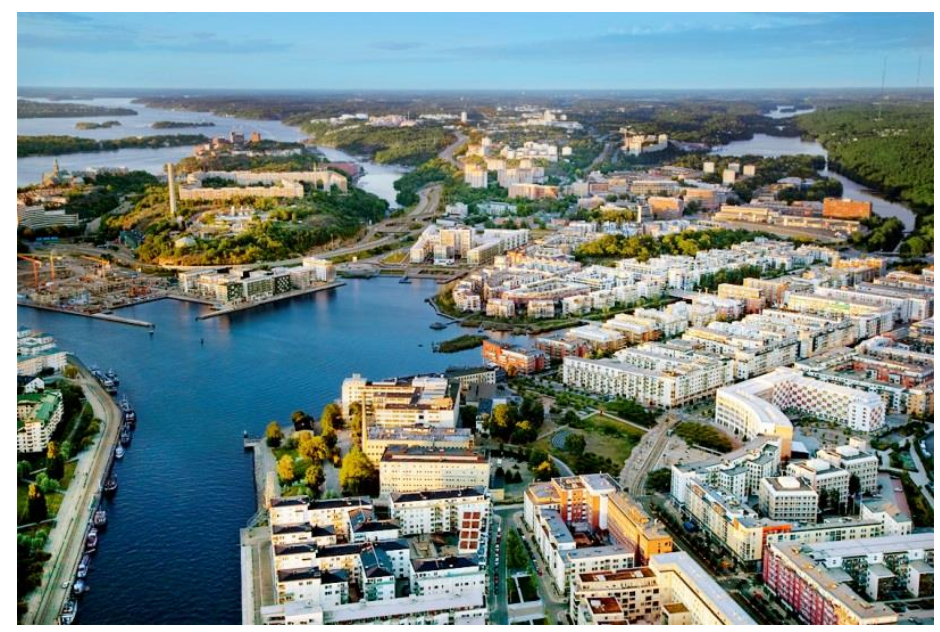

Figure 2.13 (b) Aerial view of Hammarby Sjöstad, Sweden

Source:(Olsén, 2014)

"Ecovillage" is another relevant term which is used for small sustainable communities. According to Kasper (2008) ecovillage is a specific form of intentional community. The most common definition of ecovillage describes it as a human-scale full-featured settlement (Bang, 2005). Global Ecovillage Network (GEN) defines the ecovillage as “.... an intentional or traditional community using local participatory processes to holistically integrate ecological, economic, social, and cultural dimensions of sustainability in order to regenerate social and natural environments" (Global Ecovillage Network, para. 1). Based on these definitions the goal of ecovillage is to be a place where people live and work while becoming more economically, environmentally and socially sustainable through the integration of human activities and the environment in a way that supports healthy human and community development.

The ecological goals consist of preserving quality, biodiversity and abundance of natural resources through reducing ecological footprint of ecovillage in order to maintain sustainability of natural capitals such as wildlife habitats, land, soil and subsoil resources, water and air (Jonna, Neff, Livingston, Giles, \& Stutzman, 2005; Sycamore Springs EcoVillage, 2013).The social goals 
include maintaining quality of life through organizing community around the activities that benefit individuals and support positive social interactions within community as well as promoting sustainable relations with outside communities (Irrgang, 2005; Sycamore Springs EcoVillage, 2013). The economic goal is to grow sustainable local economy through promoting different alternative economies such as co-operative economy (producer co-ops, consumer co-ops, credit co-ops, and co-ops for marketing, health, insurance etc.) in which the decisions are not just based on maximizing short-term profits (Gerster, 1977). Another way is to promote creative economy which is more sustainable, since it is based on the potential of creative capitals more than traditional production factors (Burger, 2012; UNCTAD, 2008).

These goals and objectives are achievable by integrating the "5 R's" of sustainability reduce, reuse, renew, recycle and rethink - in the lifestyle of a ecovillage community (Abdala \& MOCELLIN, 2010). An ecovillage usually incorporates components of "green infrastructure", "smart building", "affordable and energy efficient housing" and "renewable energy to minimize ecological footprint and maximize economic efficiency. For example, a study conducted in 2007 by the Global Ecovillage Network (GEN-Europe) in collaboration with the Sustainable Development Research Centre (SDRC) has found that the Findhorn ecovillage in Moray, Scotland has recorded the lowest-ever ecological footprint for any community in the industrialized world (Tinsley \& George, 2006).

According to Gilman (1991) and Abdala and Mocellin (2010) an ecovillage should have human scale. However most of ecovillages are aimed for a population of up to 2000 but they usually have 50-500 residents (Jackson, 2004). Another key feature of an ecovillage is selfsufficiency. One of the first self-sufficient settlements in North America was self-sufficient Harmony Society community in Pennsylvania which was founded by the Johann Georg 
Rapp and his Harmony Society in early nineteen century (Streissguth, 1999). Following this tradition, residents of today's ecovillages also try to be self-sufficient by reducing fossil energy use and relying on renewable energy, creating local creative businesses, and local farming. It's important to realize that while energy and resource independency is desirable, it is not possible for an ecovillage to be completely self-sufficient (Kasper, 2008). A well planned ecovillage is integrated into the natural world, supports healthy human development, and is a place that can successfully continue on the same path into the indefinite future. Some useful ecovillage design principles are listed by Holmgren (2007) as: (1) observe and interact; (2) catch and store energy; (3) obtain a yield; (4) apply self-regulation and accept feedback; (5) use and value renewable resources and services; (6) produce no waste; (7) design from patterns to details; (8) integrate rather than segregate; (9) use small and slow solutions; (10) use and value diversity; (11) use edges and value the marginal; and (12) creatively use and respond to change.

Depending on the definition of ecovillage there are four to five thousand ecovillages around the world. Arcosanti is one of the earliest well-known ecovillages in the USA, designed by the Italian-American architect, Paolo Soleri. Arcosanti is an experimental ecovillage of 5,000 people that began construction in 1970 in central Arizona based on Soleri's concept of Arcology. Arcology is a term used for architecture combined with ecology. It supports the sustainable design of built environment through minimizing the use of natural resources and environmental pollution and maximizing the interaction with natural environment as well as access to urban environment (Wikipedia, 2013b). Ecovillage in Ithaca, NY is another well-known ecovillage in the USA. 


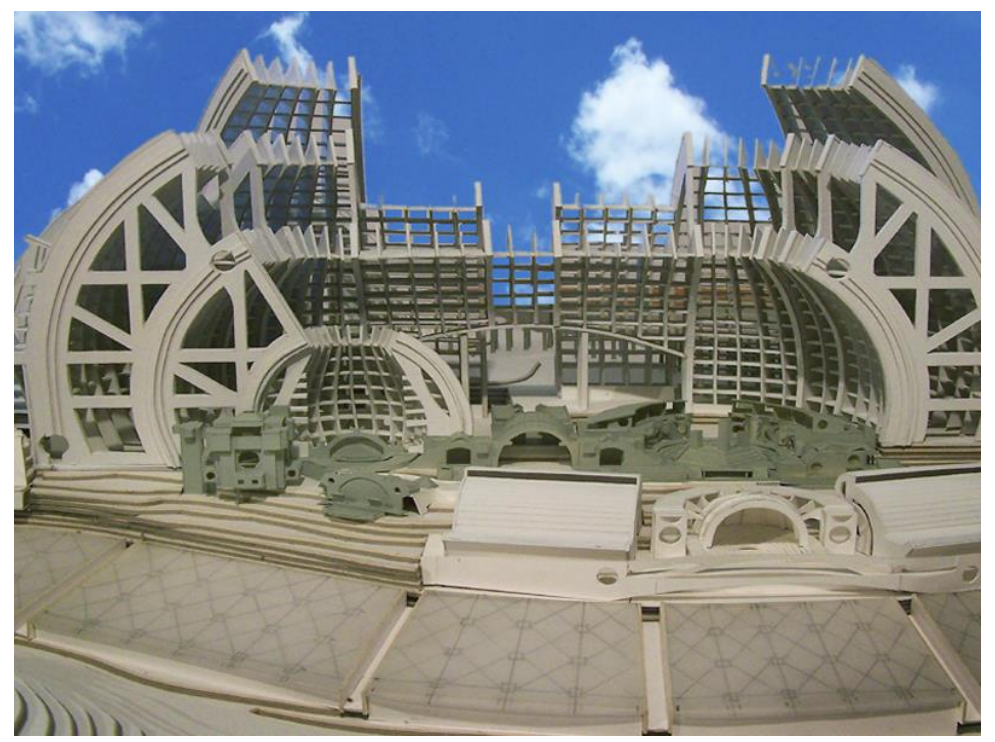

Figure 2.14 (a) Architectural model of Arcosanti. Arizona

Source:(Arcosanti, 2014)

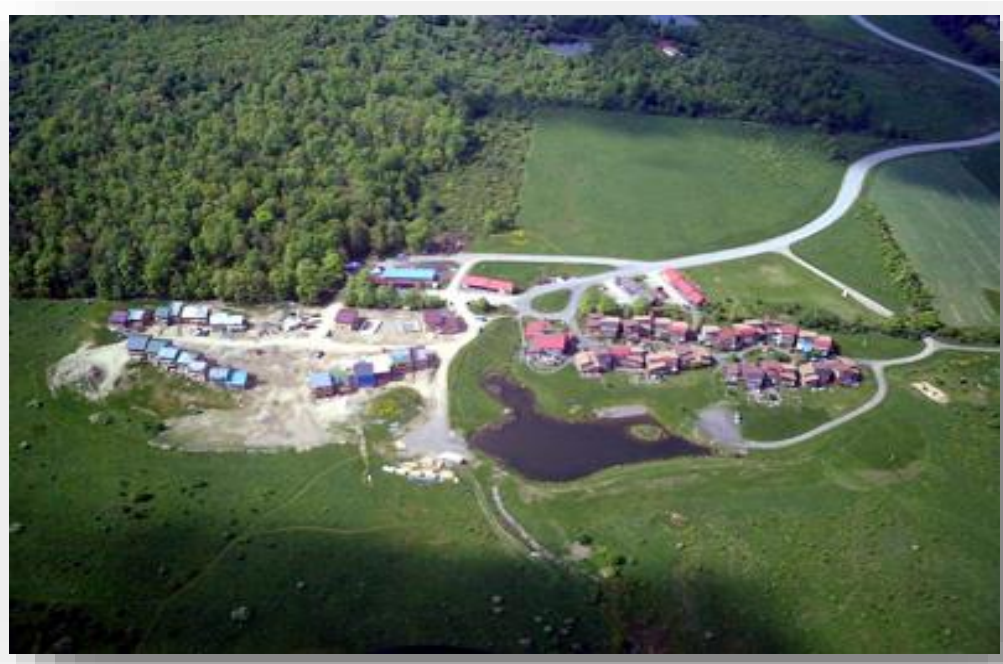

Figure 2.14 (b) Aerial view of Ecovillage in Ithaca, NY

Source:(Kirby, 2004) 


\section{II.2.2 Urban morphology and sustainability}

The urban form is an important element of sustainability. The effect of urban form on resource depletion and its role on social, economic and environmental dimensions of sustainability has been discussed by many scholars (Burton, 1996; Jabareen, 2006). But there is still lack of theories and methods to analyze the cities as spatial artifact, especially on micro scale (Fallström et al., 2009). Jabareen (2006, p. 39) states that "there is a lack of theory that helps us to evaluate whether a given urban form contributes to sustainability or to compare different forms according to their contribution to the sustainable development objectives and agenda".

Also Salat (2007) argues that the city generally is often seen as a "homogenous entity" and that various elements of urban morphology, such as size, hierarchy, accessibility, connectivity of transportation network as well as overall texture of city such as grain size, porosity, grid density, connections between empty spaces, major and minor breaks have not been thoroughly analyzed yet. He argues that more studies are needed on relationship between transportation, urban density and energy consumption. Anderson, Kanaroglou, \& Miller (1996) emphasize the role of urban form as an important element of any municipal planning process, especially the relationship between urban morphology, energy consumption and environment.

An urban area consists of residential and non-residential buildings, transportation and communication and other utility networks, and green spaces. The interaction between these physical structures, people, and institutions shapes a complex system that determines the spatial characteristics of an urban area. In turn these spatial characteristics, also called urban spatial 
structure, directly and indirectly determine/characterize/shape/are linked with the sustainability of development

A large body of literature focuses on the relationship between different urban forms characteristics and different aspects of sustainability. For example, studies by Newman (2006) and Kenworthy et al. $(2001 ; 1999)$ reveal a significant correlation between urban density, activity intensity, and private passenger transport energy usage. Also A worldwide study by International Association of Public Transport (UITP) shows that cities with high density have high share of walking, biking and public transport, while they have lower annual trip rate. For example, Hong Kong's annual trip rates are almost five times lower than Houston while its aggregated share of walking, biking and public transport is sixteen times higher (Table 2.2). There is an abundant evidence that cities with higher density level tend to be more transitoriented which is more sustainable (Petersen, 2002).

Table 2.2

Correlation between urban density, activity intensity, private transport, and energy usage

\begin{tabular}{ccccc}
\hline City & $\begin{array}{c}\text { Population } \\
\text { Density } \\
\text { (Person per ha) }\end{array}$ & $\begin{array}{c}\text { Annual travel } \\
\text { (KM per capita) }\end{array}$ & $\begin{array}{c}\text { Trips on Walking, } \\
\text { Biking and public } \\
\text { transport (\%) }\end{array}$ & $\begin{array}{c}\text { Energy Usage } \\
\text { (MJ per capita) }\end{array}$ \\
\hline Houston & 5 & 25600 & 9 & 86000 \\
Melbourne & 26 & 13100 & 14 & - \\
Sidney & 25 & - & 19 & 30000 \\
Paris & 56 & 7250 & 48 & 15500 \\
Munich & 60 & 8850 & 56 & 17500 \\
London & 51 & - & 59 & 14500 \\
Tokyo & 68 & 9900 & 88 & 11500 \\
Singapore & 48 & 7850 & 94 & - \\
Hong Kong & 82 & 5000 & 320 & 6500 \\
\hline
\end{tabular}

Note: From (Petersen, 2002, p. 8) 
Bertaud (2004) claims that dense continuously urbanized area; especially the monocentric cities; are more transit friendly and they cause less air pollution since they could significantly reduce trip length over the city. High density may reduce total amount of air pollution, but the exposure to pollution could be higher in center of city because of concentration of pollution in the area. Bertaud used an imaginary city of 1 million people, with an average density of 100 people per hectare, to test his hypothesis. He defined 20 typical spatial structure scenarios for his imaginary city by changing the spatial distribution of density within the city area while keeping the average density, total population and built-up area constant. Then he analyzed the variation of "average distance per person between random points" and "distance per person to the CBD" for all defined spatial scenarios. The analysis results confirm his hypothesis which states that "the type of spatial structure, i.e. the degree of monocentricity and the density have a direct impact on trip length" (Bertaud, 2004, p. 13).

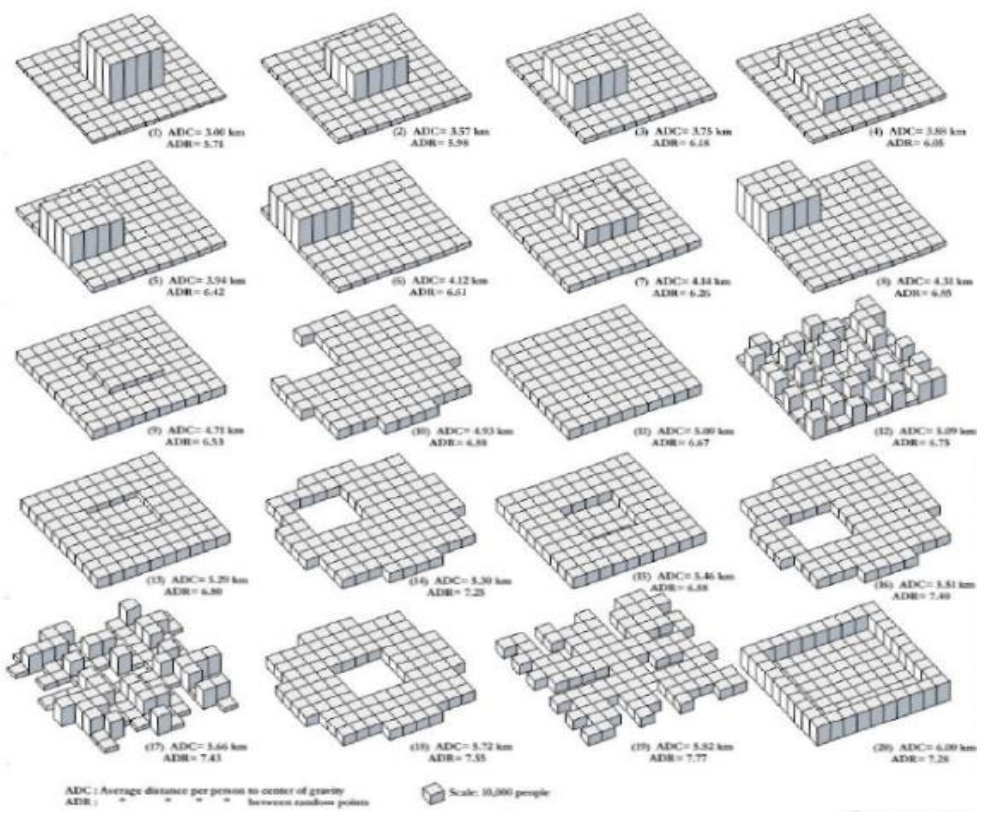

Figure 2.15 Bertaud's imaginary city and various scenarios of urban spatial structure

Source: (Bertaud, 2004, p. 15) 
Given the result of this study, one can conclude that total amount of air pollution, travel accidents, energy usage and land consumption are closely correlated with spatial structure of urban area. The effect of density is not limited to transportation issues. According to the study of Sassan (1994) density and economies of scale are crucial elements of making cities more attractive places for absorbing knowledge economy jobs and services. The denser the city, the more opportunities are created through people network.

While most scholars agree that "density is a critical typology in determining sustainable urban form" (Jabareen, 2006, p. 41), some others reject this hypothesis. Newman (2006) claims that there is no obvious relationship between population density in cities and the solution to urban or global challenges. Also Hardoy, Mitlin, \& Satterthwaite (2001) show that there is no evidence that high population density in less developed countries has necessarily impacted the global environment. Also, some researchers mostly focused on the negative impacts of density. Freedman (1975) argues that there is no causal relationship between density and social problems, only suggests that it acts as catalyst which could intensify them.

Compactness as a more comprehensive attribute of urban form (compared to density) is also a high contention area in the literature. Jabareen (2006) has summarized the benefits of compactness in four main categories: 1) rural protection; 2) promotion of quality of life including social interaction and ready access to amenities; 3) reduction of energy consumption by providing building densities capable of supporting district heating or combined heat and power system; and, 4) reduction of greenhouse gases by minimizing the number and length of trips. Similarly, Neuman (2005) argues that compact city is beneficial for sustainable development as it reduces land consumption, energy and resource waste, air pollution and social segregation and increases accessibility. 
In recent decades, researchers have embarked on a new line of research focusing on the effect of compactness on social issues. These studies mostly focus on social benefits of compactness such as social interaction and social justice through higher level of accessibility in compact cities. According to these studies accessibility is one of the most important aspects of social justice. Better accessibility can ease equal access to opportunities and facilities such as job, markets, green space, education and healthcare services; it can also increase exposure to urban negative effects such as noise and air pollution (Burton, 2000; Maoh \& Kanaroglou, 2009; Mobaraki, Mohammadi, \& Zarabi, 2012). Studies about the connection between compactness and personal health are also on the rise. Research results reveal that compact form of cities increases the walkability index and make walking or biking easier and consequently increases people's physical activity, hence, directly increasing the level of personal health (Neuman, 2005). The negative aspects of compactness including bad neighbor, social conflict, decrease in housing inner space and quality of living environment, lack of acceptable housing and higher death rate because of respiratory deceases have also been explored in some papers and books (Burton, 2000; Katie Williams et al., 2000).

Other urban form characteristics such as mixed land use, clustering, diversity and complexity have also been considered by other researchers. According to a paper published by Salat et al. (2010) complexity (diversity), one of morphological characteristics of any city, is very vital for the sustainable metropolis. Complexity enriches urban fabric through maximizing the points of contact, exchange and interface as well as increasing energy efficiency of cities, minimizing energy consumption and decreasing the structural needs in energy. The importance of diversification in cities' resilience, competitiveness and dynamism has also emphasized by other researchers (Jacobs, 1961, 1992; Suzuki et al., 2010). 
Some researchers emphasize the central role of mixed land use in achieving sustainable urban form due to decreasing the number of trips as well as travel distance between the activities, encouraging cycling and walking, and enhancing security in public space (Alberti, 2000).

Cervero et al. (2003) claims that land use diversity is strongest urban design factor determining passenger's decision to walk. The study argues that desirable visual characteristics along walking path as well as existence of business services such as retail stores and restaurants nearby job place could significantly reduce number of trips and encourage public transport, since without these facilities employees tend to use their automobiles for lunch or other activities during break hours. A similar study reveals that existence of service facilities such as banks, ATMs, cafes, onsite childcare, postal service and restaurants nearby job-place can reduce average weekly private car travel by 14 percent as a result of lower trip rate and higher public transport usage (Davidson, 1994). Table 2.3 shows the result of a study on effect of various land use features on drive-alone commuting rate.

Table 2.3

Drive alone share at worksites based on land use

\begin{tabular}{cccc}
\hline Land Use Characteristics & Without & With & Difference \\
\hline Mix of Land Uses & 71.7 & 70.8 & -0.9 \\
Accessibility to Services & 72.1 & 70.5 & -1.6 \\
Preponderance of Convenient Services & 72.4 & 69.6 & -2.8 \\
Perception of Safety & 73.2 & 70.6 & -2.6 \\
Aesthetic Urban Setting & 72.3 & 66.6 & -5.7 \\
\hline
\end{tabular}

Note: From (Systematics \& Deakin, 1994)

Some researchers believe that mixed land use neighborhoods with balanced housing and job can help to reduce commute distance by 7 to almost 30 percent (Kuzmyak, Pratt, Douglas, \& 
Spielberg, 2003). Of course, one may argue that effect of housing-job balance is negligible as limited number of households tend to choose their residence location based on minimizing their daily commuting trip. According to this view, housing-job balance doesn't necessarily mean that workers will reside nearby their work place. Most studies, however, indicate that there is a correlation between mixed land use with balanced housing-job and number and length of trips.

In addition to change in travel pattern, land use diversity has several other benefits. According to Jane Jacobs (1992) diversity is one of the most crucial factors of urban sustainability. She argues that we should study the land use diversity and functional complexity of a city in order to better understand its characteristics. This functional mixture and diversity can help increase the social interaction as well as security and safety which are essential for city life. She proposes three design patterns in order to increase diversity within neighborhoods:

First, the inner part of the neighborhood should contain more than one land use. This mixed land use pattern will diversify resident's daily trip purpose and consequently will increase the number of interactions during different hours of a day. In turn, it can improve the economic activities within the neighborhoods. Jacobs chose Manhattan, NY as an interesting case study for investigating the economic impact of land use diversity. This area was a good example of single functional land usage. In 1961, around 40,000 workers were working in various business activities within this area. Although these activities were complicated enough but this area only contained commercial land use type. This land use pattern causes the neighborhood to look like a dead city during non-business hours, resulting in high crime rate and safety issues. This poor safety condition may force retail stores, cafe and restaurants to work only during daylight hours which in turn can decline level of economic activities. 
Second, building blocks should be small enough to increase diversity and circulation of streets within a neighborhood. The role of small blocks in the diversity of a city or neighborhood can be seen in Figure 2.16.
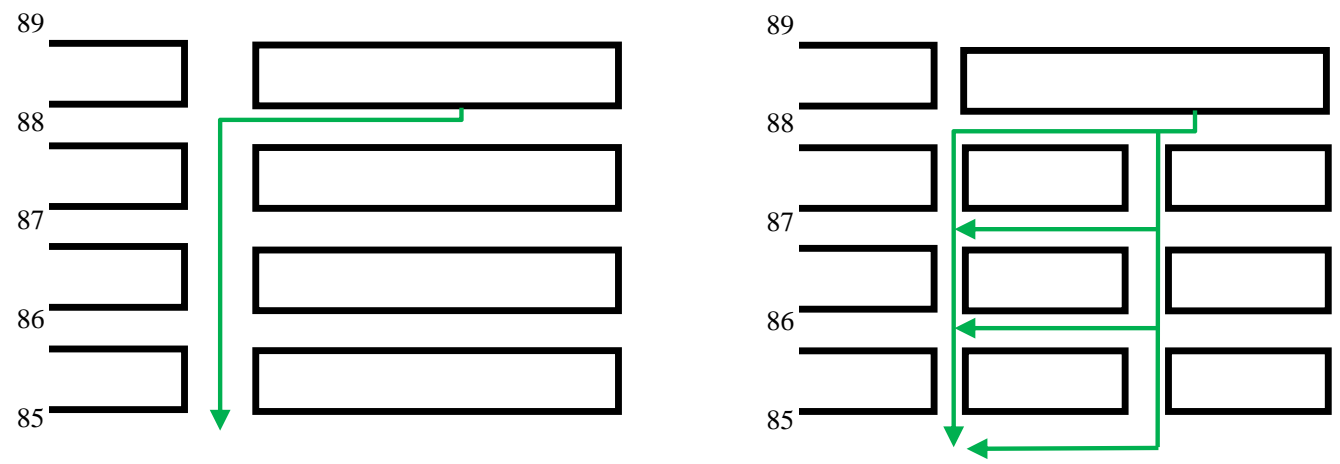

Figure 2.16 Role of small blocks in diversity of a city or neighborhood Source: From (Jacobs, 1961, 1992)

This figure shows that if one lives on Street 88 (for example) and wants to travel to the southern part of the neighborhood has two logical options. She/he could move toward the west or east and then enter and pass the main street. In both cases she/he doesn't use streets 87,89 or other secondary streets and perhaps never sees other neighbors over the years. It's clear that in this case the level of social interaction significantly declines. Also in this situation, local businesses such as retail stores and restaurants tend to locate on main streets instead of secondary streets, since the high volume of people pass through these streets. As a consequence, the neighborhood shifts toward single functionality and land use. As an alternative by using small building blocks, people have more options to reach their final destination and this can lead to more diversity in the neighborhood. Third, the neighborhood should contain enough density of peoples who reside or work within the neighborhood area. It should also contain a mixture of building with different characteristics and age in order to absorb people with different income level and different social class. 
Buildings are one of the three main elements that make up a city form. Several studies indicate that people tend to walk or use bicycle within traditional business districts, since buildings design in these areas are more attractive. Most modern car-oriented business districts contain a large parking area in front of stores while buildings located in traditional business districts generally consist of stores and restaurants directly facing the streets. This building type provides better instant access and more attractive urban space for pedestrians.

Spatial configuration of residential buildings is also significantly influence people's travel behavior. According to Meurs et al. (2001) spatial structures of residential environment such as density, characteristics of houses, existence of facilities in the neighborhoods and characteristics of the street patterns affect people's travel behavior and modal choice. They argue that the traditional urban housing of "block wing edge" form have some benefits such as immediate access from home entrance to the pedestrian walkway. This building form is a combination of shop at the ground and residential unit on upper floors providing better access to stores, restaurants, bus stops and other facilities within short walking distances.

Another important element of urban form is transportation network layout and this is "arguably the single biggest issue for environmental debates relating to the urban form" (As cited in Jabareen, 2006, P. 40). Walking, cycling and effective public transport are usually considered the three main sustainable transportation mode. Sustainability could be achieved through well designed transportation network and more effective urban form that facilitates the access to urban amenities and services as well as encouraging social interactions. Design of street layout can affect travel pattern through several ways. A connected network of streets can provide better accessibility compared to a hierarchical ordinary network which has more dead-end streets (Handy, Paterson, \& Butler, 2003). In other word, a connected form of network can provide 
better condition for walking and biking as it provides more shortcut links and route options, allowing more direct trips between origin and destinations and reducing travel distance. Also it better supports public transport. Results of a traffic modeling study conducted by Kulash et al. (1990) indicates that a connected road network could reduce more than 50 percent of vehicle miles traveled (VMT) within a neighborhood and 3 to 5 percent of total VMT within a city compare to traditional street network layout.

By recent advances in GIS technology as well as traffic modeling software; such as Cube Dynasim, Synchro and Aimsun; the effect of network connectivity on travel pattern is predictable with a high degree of precision. Figure 2.17 represents how a system of connected streets could reduce trip length. The picture on the left shows a traditional hierarchical street network, which has more dead-end streets. This type of street layout doesn't allow direct travel between different points and all travels must be done through the main street. As a result, in traditional hierarchical network the shortest path between a selected origin and destination pair is longer than the shortest path between the same origin and destination pair in a connected network (right picture). This example, simply reveals the important role of micro scale urban form in sustainable development. 

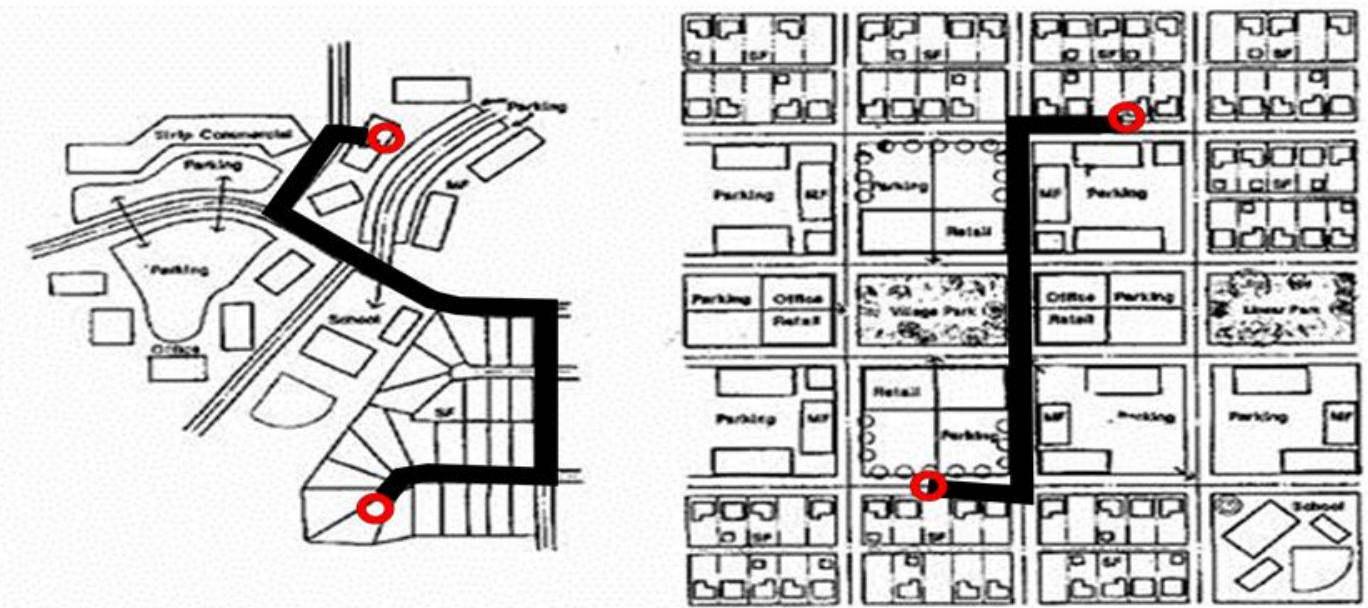

Figure 2.17 Effect of street layout design on travel pattern

Source: Base map from (Victoria Transport Policy Institute, 2014)

Other spatial attributes of transportation network such as the amount of land devoted to road network are also important in urban sustainability. Counter to common perception, increasing the road land coverage area increases the total number of trips in the long term with none or minimal overall improvement. This fact is represented in Table 2.4. As can be seen, by increasing the specific road length in American cities not only the passenger car usage will not decline, but also role of none motorized transportation and public transportation will decrease (J. Kenworthy et al., 2000). 
Table 2.4

Travel pattern in Asian, European and American cities

\begin{tabular}{cccc}
\hline Travel Pattern & Asian Cities & $\begin{array}{c}\text { European } \\
\text { Cities }\end{array}$ & $\begin{array}{c}\text { American } \\
\text { Cities }\end{array}$ \\
\hline $\begin{array}{c}\text { Specific road length (meters per capita) } \\
\text { Non-motorized transportation (walking, } \\
\text { biking and Pedi-cab, \% of work trips) } \\
\text { Role of public transport (\% of all } \\
\begin{array}{c}\text { passenger-km) } \\
\text { Car use per person (KM per capita per } \\
\text { year) }\end{array}\end{array}$ & 1.1 & 2.4 & 6.7 \\
$\begin{array}{c}\text { Car ownership (passenger car per 1000 } \\
\text { persons) }\end{array}$ & 1397 & 23 & 3 \\
\hline
\end{tabular}

Note: From (Petersen, 2002, p. 5)

On the other hand, devoting more land to transportation infrastructure has negative effects on the quality of the urban environment. It will increase noise and air pollution, hence, the high-income households tend to relocate to cleaner suburban lands which results in urban sprawl and social segregation which many consider as important aspects of unsustainable development. Also by increasing the amount of land covered by roads, we will lose green space which is an important component of natural capital. American development pattern reflects a very high land consumption while the Asian development pattern represents higher density and more land use diversity. 


\section{CHAPTER III}

\section{Methods}

\section{III.1 Background}

Transportation infrastructure and land use patterns are two main spatial component of the built environment which could have a direct and indirect effect on the sustainability of the built environment. The design of these elements could dramatically alter the environmental quality, availability of economic opportunities, and social wellbeing in general. This chapter first provides a review of various types of spatial models, techniques and analytical tools; especially those relevant to land use and transportation. This brief review will help to gain a better understanding of spatial models and their application for simulation of urban spatial structure. In the second part of this chapter, the proposed modeling framework is explained. This framework links design pattern of urban built environments with their economic and environmental sustainability and provides a mechanism for simulating the effect of city's spatial structure on the sustainability of urban areas.

\section{III.1.1 Transportation models}

Transportation models are used to estimate and forecast the travel demand and commonly are presented in a general structure known as four step model. First introduced in 1960's, the overall structure of the four step model has remained unchanged despite several technical advances in subsequent decades. Figure 3.1 shows this overall structure. 


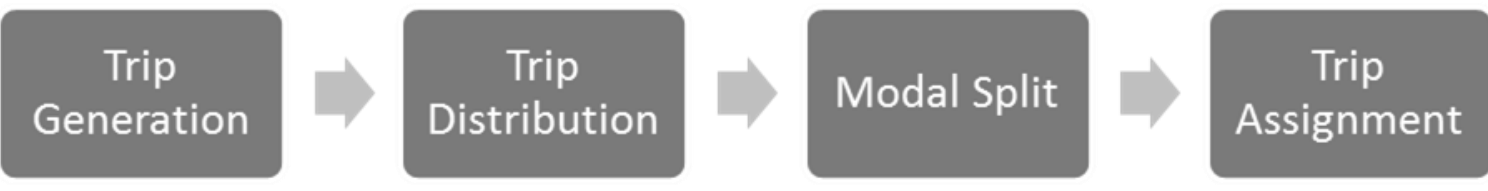

Figure 3.1 Classic four steps transportation model

Generally, the classic transportation models are classified into four steps including trip generation, trip distribution, model split and trip assignment (Khisty \& Lall, 1990; Papacostas \& Prevedouros, 1993). Based on the spatial distribution of population and employment in the study area, trips could be generated, then distributed, and assigned to transportation modes and networks. The model assumes land use to be fixed and static during long term period. This unrealistic assumption was modified or relaxed in integrated land-use and transportation models that were developed later. Given the importance of these models to this study, we introduce the components of four step models in more detail.

Trip generation is a process in which magnitude of urban and regional activities are converted to the number of trips that will begin from or end in each Travel Analysis Zone (TAZ) within the region for a typical day of the target year. Before constructing the model, some useful information such as the current travel situation in the study area, the number and types of trips are collected. Basically three main techniques exist for analyzing the generated trips, including linear regression, trip rate analysis, and cross classification.

The next formula represents the general equation of multiple linear regression method:

$$
\mathrm{Y}=\mathrm{A}+\mathrm{B} 1 . \mathrm{X} 1+\mathrm{B} 2 . \mathrm{X} 2+\mathrm{B} 3 . \mathrm{X} 3+\ldots
$$


Where, $\mathrm{Y}$ is number of generated trips in each $\mathrm{TAZ}, \mathrm{X} 1, \mathrm{X} 2$ and $\mathrm{X} 3$ are socioeconomic variables such as population, employment and car ownership in each TAZ, A, B1, B2, B3 are model parameters. The socioeconomic variables are forecasted based on data collected in the base year for each TAZ. In trip rate analysis technique, the number of generated trips is simply determined by the average trip-production or trip-attraction rates associated with the different land-use categories within the region. These average trip-production and trip-attraction rates are usually expressed in terms of the "number of trips per thousand square feet" for each land use category based on observed data in a reference region. The cross classification technique is originally similar to simple trip rate. But in this technique, the number of generated trips is determined by the average trip-production and average trip-attraction rates associated with each type of household. Additionally, various household types are cross tabulated against levels of household size, level of car ownership, residential density and trip purpose.

Trip distribution model determines the number of trips from each origin to each destination and the final product of this model is a matrix of flows between each pair of zones. Several techniques exist for analysis of trip distribution, including: Fratar, Gravity and Detroit. Due to frequent usage of Fratar and Gravity techniques, they are briefly described here.

Gravity model is based on the adaptation of Newton's law of gravitation to the urban and regional transportation case. According to this law, the gravitational attraction between two masses is directly proportional to the product of their masses and inversely proportional to the square of the distance between them. Similarly, the number of trip between two regions is directly proportional to activities in the two zones, and inversely proportional to geographical distance (or travel time) between these regions (Equation 2). 


$$
T_{i j}=\frac{p_{i} A_{j} F(t)_{i j} K_{i j}}{\sum_{j=1}^{n} A_{j} F(t)_{i j}}
$$

Where, $T_{i j}$ is number of trips produced in zone $i$ and attracted to zone $j, P_{i}$ is trips produced from zone $i, A_{j}$ is trips attracted to zone $j, F(t)_{i j}$ is friction factor (distance or time) for interchange $i j$ and $K_{i j}$ is socio-economic characteristics of zones. Fratar technique is based on the study of Cleveland, Ohio Metropolitan Region by T. J. Fratar in order to analyze the distribution of trips within this region (Papacostas \& Prevedouros, 1993). This technique has been used in several transportation studies. Frater's formula is as follows:

$$
t_{i j}^{f}=t_{i j}^{o} \frac{O_{i}^{f}}{O_{i}^{o}} \frac{D_{j}^{f}}{D_{j}^{o}} \frac{\sum_{k=1}^{n} t_{i k}^{o}}{\left(D_{k}^{f} / D_{k}^{o}\right)\left(t_{i k}^{o}\right)}
$$

Where, $O_{i}^{f}$ and $O_{i}{ }^{0}$ are future and base year origin trips from zone $i, D_{j}^{f}$ and $D_{j}{ }^{0}$ are future and base year destination trips to zone $j$ and $t_{i j}{ }^{f}$ and $t_{i j}{ }^{0}$ are future and base-year trips from $i$ to $j$.

The modal split model analyzes people's travel choice among various transportation options (i.e. bus, private car and train) based on factors such as passenger characteristics (i.e. income level and household size), trip characteristics (i.e. distance and time) and modal characteristics (i.e. access and waiting time). The Logit technique is the most important modal split technique in which the probability of choice of each mode is proportional to mode's relative desirability for any given trip (Khisty \& Lall, 1990; Papacostas \& Prevedouros, 1993). The general form for Logit model is as follows: 


$$
P i=\frac{e^{v(i)}}{\sum_{r=1}^{n} e^{v(r)}}
$$

Where, $P(i)$ is the probability of using mode $i, V(i)$ is the utility of mode, $V(r)$ is the utility of mode $r$ and $n$ is the number of transportation modes. The utility of each mode is a function of its characteristics such as travel time, travel cost and trip convenience. In case of modal split between public transport and private transport, the Logit model will have a S-shaped form:

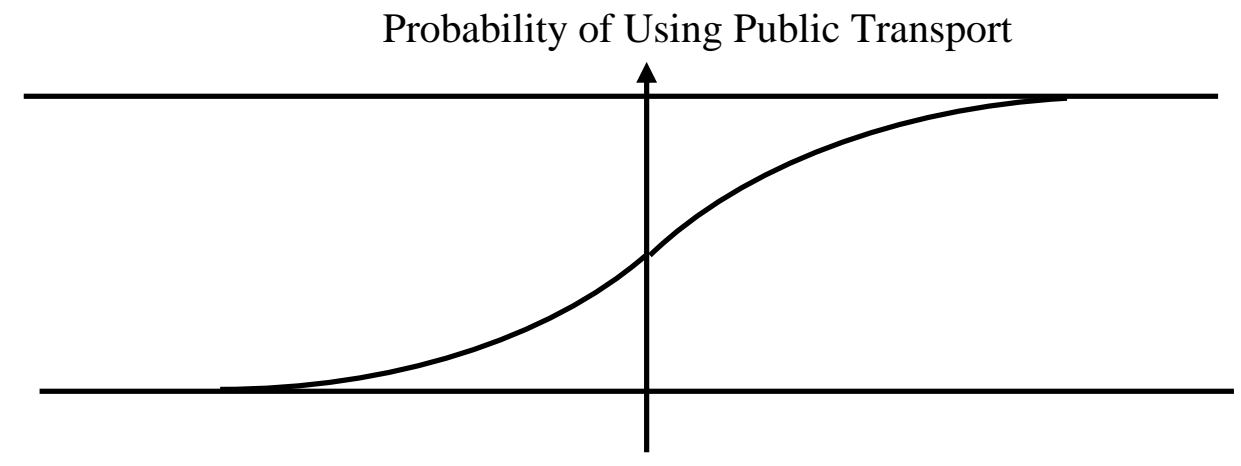

Better Private

Better Public

Figure 3.2 Utility function curves for transportation modal split

The trip assignment model predicts the number of trips on each route of the network. The trip assignment procedure results in a map of road network that contains information of traffic volume on each link. The amount of traffic volume on each link depends on length, number of lanes, travel speed, and travel time on network's links. This information allows us to simulate the passenger's behavior for choosing the most desirable path between two points on road network. 
Minimum path (all or nothing), capacity-restricted traffic assignment and Incremental assignment are three assignment techniques among several (Khisty \& Lall, 1990; Papacostas \& Prevedouros, 1993).

All these techniques are based on the assumption that passengers tend to use the routes with minimum resistance. The most common method for finding this shortest route is Moore's algorithm which is based on "operation research" algorithms. In this method, which is also known as all-or-nothing, all trips are loaded on links with minimum impedance. As a result, some links may be loaded more traffic volume than its capacity. This problem has been solved by using the capacity-restricted assignment technique.

The main assumption of capacity-restricted technique is that travel speed is inversely proportional to the growth of traffic volume and this relationship is unique for each type of road (Equation 5).

$$
T_{Q}=T_{0}\left[1+a\left(\frac{Q}{Q_{\max }}\right)^{B}\right]
$$

Where, $T_{Q}$ is travel time at traffic flow, $T_{0}$ is zero-flow travel time, $Q$ is traffic flow and $Q_{\max }$ is practical capacity of the link. Using this formula one can incrementally loads the traffic on the road network, which results in more realistic trip assignment. 


\section{III.1.2 Land use models}

Land use models are analytical techniques that explain, forecast or optimize layout of urban areas. As mentioned in Chapter II, Burgess's "Concentric Zone Model”, Hoyt's "Sector Model" and Harris and Ulman's "Multi Nuclei" model are earliest analytical land use models introduced in the first half of the twentieth century. Advances in computer sciences in the second half of the twentieth century, made it much easier to develop advanced and complex land use models. The theoretical basis and mathematical tools of these models are very diverse and difficult to fit in simple classification schemes.

Berechman and Small (1988) divided land use models into four classes: gravity (GarinLowry model), deterministic (Herbert-Stevens and Mills-Kim models), economic equilibrium (Anas and CALTAS models), and agglomeration economies (Caruthers, Wilson, Allen-Sanglier and Fujita-Ogawa models). Southworth (1995) classified the land use models into five main groups of Lowry models, normative planning models, multi-sectoral spatial models, urban economics models and micro-analytic simulation. More recent classification proposed by Briassoulis (2000) includes four categories of models: statistical and econometric models, spatial interaction models, spatial optimization models and integrated models. The following subsections provide a review of statistical and econometric, spatial interaction, urban economic, multi-sectoral spatial (input-output) and spatial optimization models. Land suitability analysis is also reviewed because of its importance for this research.

\section{Statistical and econometric models}

Statistical analysis techniques have been widely used in most of land use models. The most common formulation of statistical model is linear regression which is an approach for 
modeling the relationship between a dependent variable such as land use change and some predictable explanatory variables such as population and employment within a study area. This relationship is constructed using data set of observed past land use changes and then the model is applied to simulate future land use changes. The earliest application of statistical techniques in land use change modeling traces back to models constructed by Chapin and Weiss in 1970's, also known as North Carolina model (Briassoulis, 2000). The general form of this model is as follows:

$$
L U T_{i}=a+\sum_{j=1}^{n} B_{i} X_{j}+\varepsilon
$$

Where, $L U T_{i}$ is the area of land occupied by land use type $i$ in each zone, $X_{j}$ is explanatory variable, $B_{i}$ is regression parameter and $\varepsilon$ is error term. These models are relatively easy to construct but they have weak theoretical foundation as they don't explain the causality relationship between land use changes and deriving forces such as population and employment (Koomen \& Stillwell, 2007).

\section{Spatial interaction models}

The origin of spatial interaction models dates back to late 19th century and early 20th century when regional researchers such as H. C. Carey (1859), Ravenstein (1885), Reilly (1931), Stewart (1947) and Zipf (1949) started to use Newton's gravity law to study spatial interaction between two cities (Briassoulis, 2000; Koomen \& Stillwell, 2007). These models are based on the assumption of gravity law which states that the magnitude of interactions (i.e. trade, immigration, and commodity transaction and passenger travel) between two geographical regions depends on their mass (size, population, etc.) and the distance between them. The larger 
the region's mass (or the shorter the distance between them), the more interaction they would have. Figure 3.3 shows a conceptual representation of Reilly's Law of Retail Gravitation:

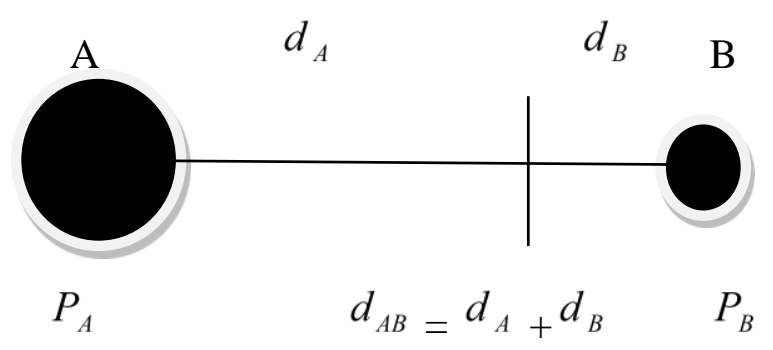

Figure 3.3 Schematic model of Reilly's Law of Retail Gravitation

Source: Reproduced from (Rodrigue, 2014)

The general form of his equation is as follows:

$$
d_{B}=\frac{d_{A B}}{1+\sqrt{\frac{p_{A}}{p_{B}}}}
$$

Where, $d_{A B}$ is distance between regions $\mathrm{A}$ and $\mathrm{B}, p_{A}$ and $p_{B}$ are respective population of regions $\mathrm{A}$ and $\mathrm{B}$, and $d_{B}$ is sphere of influence for region $\mathrm{B}$.

The earliest application of gravity law in urban areas can be traced back to the accessibility model of Hansen (1959). He used this concept to predict the distribution of population centers in urban residential zones based on their accessibility to employment centers. 
His work was expanded by Stouffer (1960) and Schneider (1959) by introducing the intervening opportunities model (Briassoulis, 2000).

In 1964, Lowry (1964) introduced his model of metropolis, which is the most operational gravity-based land use model today. Lowry's model is based on the assumption that the location of employment sectors (whether basic or non-basic sectors) governs the location of residents. Using this assumption, his model links two dependent gravity sub-models. The first sub-model relates the spatial distribution of population (as labor force supply) to spatial distribution of basic employment sector (as labor force demand) and the second one computes the spatial distribution of non-basic sectors such as retail, shopping etc. (as derived demand of the population) based on the distribution of population which was calculated in the first sub-model. In turn, the changed distribution of non-basic sectors creates new demand for the labor force which could change again the population distribution. This iterative cycle will continue until equilibrium is reached. Figure 3.4 shows this process:

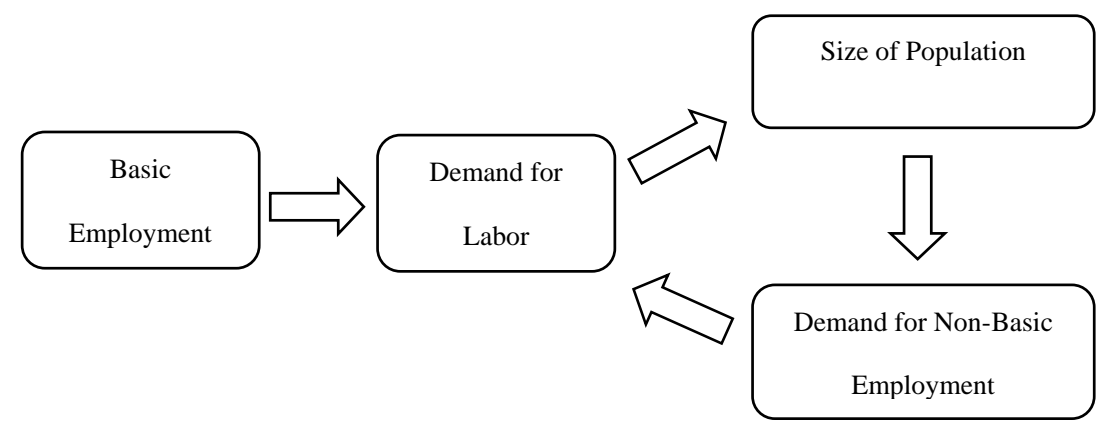

Figure 3.4 Lowry's land use model 
In the original Lowry model, the amount of population allocated to each zone is determined as:

$$
\begin{aligned}
& P_{j}=S C \sum_{j=1}^{n} \frac{B_{i}}{D_{i j}} \\
& B_{i}=E_{i}-S_{i}
\end{aligned}
$$

Where

$P_{j}$ is the amount of population allocated to zone $j$

$B_{i}$ is the basic employment in zone $i$

$S_{i}$ is the non-basic employment in zone $i$

$E_{i}$ is total employment in zone $i$

$D_{i j}$ is the impedance factor (travel cost) between zone $i$ and zone $j$

$S C$ is scaling factor

According to Timmermans (2003) the first application of Lowry's model was the Time Oriented Metropolitan Model (TOMM) which was developed as a part of the Pittsburgh Community Renewal Program. Also Projective Land Use Model (PLUM) was another early application of Lowry's model, implemented in Bay Area.

Lowry's model of metropolis also provided a mathematical basis for land-use transportation modeling approach. As mentioned in Chapter II, the main assumption of this approach is that urban spatial structure is a resultant of interrelation between land use and transportation. Putman (1983) used land use-transportation modeling approach in the Disaggregate Residential Allocation Model (DRAM) and the Employment Allocation Model 
(EMPAL). Later, he also improved his model by integrating DRAM and EMPAL together and developed the integrated transportation land-use package (ITLUP) which is composed of a residential allocation model, an employment allocation model, and a travel demand model. This model has been widely used in the USA (Alberti, 2008). The Leeds Integrated Land-Use model (LILT) and IRPUD are other applications of integrated land use-transportation modeling approach (Timmermans, 2003).

According to Alberti (2008), Koomen and Stillwell (2007), other researchers such as Wilson (1967) and McFadden (1974) have combined gravity models with two powerful statistical theories of entropy-maximization and discrete choice in reaction to limitations of gravity model. For example the entropy maximization model, which draw from the Second Law of Thermodynamics, includes balancing features that help to match observed and predicted flows in constrained gravity model (Koomen \& Stillwell, 2007; Torrens, 2000). This improved Lowrytype model has been widely used in Britain and other countries (Anas, 1987).

\section{Urban economic (market-based) models}

The third most commonly used modeling approach is economic market-based modeling technique which is based on bid-rent theory. The bid-rent theory, developed by von Thünen in the 19th century, describes the spatial distribution of urban activities on the basis of a trade-off between land price and transportation cost. Alonso (1964) used this theory to construct land-rent and land-market models. The main assumption of these models is that land users and land owners are assumed to select optimum location for their activities by maximizing their utility which includes land price and transportation cost (Equation 10). 


$$
\text { p.x }+r \cdot h=y+w \cdot(1-t-T)
$$

Where, $\mathrm{h}$ is the amount of housing space used, $\mathrm{r}$ is price per unit of housing space (rent), $\mathrm{x}$ is the consumption of other goods and services, $\mathrm{p}$ is commodity price, $\mathrm{T}$ is the amount of leisure time, $\mathrm{t}$ is the commuting time, $\mathrm{w}$ the wage rate, and $\mathrm{y}$ the nonwage income. Given $\mathrm{t}, \mathrm{r}$ and $\mathrm{p}$ the household maximizes utility: $\mathrm{U}(\mathrm{x}, \mathrm{h}, \mathrm{T})$.

The economic market-based models have also been improved by adding statistical tools such as discrete choice and maximum entropy. As an example, Anas (1983) introduced new generation of market-based models by adding discrete choice behavior to model and developed a highly integrated economic model of transportation and land use called METROSIM (Alberti, 2008; Oryani \& Harris, 1997; Southworth, 1995). Urbansim developed by Waddell (1998) and CUF2 developed by Landis and Zhang (1998) are among other examples of models that use this approach.

\section{Multisectoral spatial (input-output) models}

Another wave of modeling was emerged after introducing the quantitative economic technique of input-output analysis by Leontief. The input-output (IO) approach provides a framework for depicting relationships between various sectors of an economy by representing how the output from one industrial sector may become an input to another industrial sector. Equation 11 shows the matrix notation of Leontief's IO model:

$$
X=(I-A)^{-1} Y
$$


Where, $\mathrm{A}$ is the technical coefficient matrix (total use flows); $\mathrm{X}$ is the total output column vector and $\mathrm{Y}$ is the final use column vector. IO models are generally constructed in national, state or regional scale, since accurate economic data is not available or easily accessible in local scale. Multi-sectoral spatial models are a combination of IO model and spatial interaction (Loweybased) models. Integrated urban models such as MEPLAN (Echenique, Crowther, \& Lindsay, 1969), TRANUS (De La Barra, 1989), and PECAS (John Douglas Hunt, 2003) are examples of multi-sectoral spatial models which convert production and consumption into interregional transportation flows of goods (Alberti, 2008; Johnston \& McCoy, 2006; Timmermans, 2003).

\section{Spatial optimization models}

The optimization theory provides another framework for finding optimal land use configuration. This approach consists of several techniques including Linear Programming (LP), Non-linear Programming, Dynamic Programming, Hierarchical Programming, Maximum Utility, Multi-Objective/Multi-Criteria Decision Making (MADM). By using these techniques, one can minimize or maximize the objective function of a spatial interaction problem. This objective function could have various forms such as minimum household expenditure, maximum household income, minimum environmental impacts, minimum development cost, etc.

The application of optimization theory in urban studies dates back to 1960, when Herbert and Stevens (1960) used linear programming technique for Penn-Jersey transportation study in order to find best land use configuration so that maximizes the household's rent-paying ability. In the Herbert-Stevens model, the household's rent-paying ability was formulated based on Alonso's bid-rent theory (Briassoulis, 2000). According to Alberti (2008) other researchers such as Wheaton (1974) and Boyce and Southworth (1979) have also used other optimization 
techniques such as non-linear programming for land use modeling. Non-linear programming is similar to linear programming with the exception that the relationship between variables of objective function doesn't have linear form. The matrix notation of linear programming formula is as follows:

$$
\begin{aligned}
& \text { Maximize: } C^{T} X \\
& \text { Subject to: } A X \leq b \\
& \text { And } X \geq 0
\end{aligned}
$$

Where, $X$ represents the vector of variables (to be determined); $C$ and $b$ are vectors of coefficients; and $A$ is a matrix of coefficients.

The projective optimization land-use system (POLIS) developed by Prastacos (1986) and the Optimum Placement of Activities in Zones (TOPAZ) developed by Brotchie (1980), are two examples of urban land use models that have used optimization techniques.

Utility maximization is another type of spatial optimization models which differs from other spatial optimization models in that it is better rooted in economic theory. The utility maximization model maximizes producer's profits from selling the goods or services they produce (the supply side of the economy) as well as maximizing consumer's utility derived from consuming various goods and services (the demand side of the economy). The main assumption of this model is that "land" can be considered as a good and landowners and land users tend to maximize their profit and utility from land. Equation 13 shows the general form of the household's utility maximization model. As can be seen the constraint equation is directly derived from Alonso's bid-rent function. 


$$
\text { Max: } \mathrm{U}=\mathrm{U}(\mathrm{x}, \mathrm{h}, \mathrm{T})
$$

Subject to: $Y=p \cdot x+r(k) h+T(k, y)$

Where, $\mathrm{x}$ is the consumption of all commodities except housing and transportation, but including leisure, $\mathrm{p}$ is commodity price, $\mathrm{h}$ is amount of housing space used, $\mathrm{r}(\mathrm{k})$ is price per unit of housing space (a function of distance), $\mathrm{Y}$ is household's total income, $\mathrm{k}$ is distance from city center, and $\mathrm{T}$ is commuting cost (a function of income and distance).

The optimization theory is also used to find the optimum location of urban facilities. This kind of problems are known as optimal facility location problem. The origin of facility location problem dates back to 1909, when Alfred Weber (1909) presented a theory of industrial location. This theory was applied later by Hotelling (1929), Christaller (1933), Lösch (1954), and Krugman (1991). Weber's location theory is an approach that seeks to find the optimum location for industrial firms based on the assumption that firms select a location to maximize their profit or minimize their cost. This optimum location is identified by minimization of production and transportation cost. Weber's theory is applicable for finding the optimum location of other facilities such as warehouses, schools, military houses, waste material dumps, fire engine depots, hospitals, administrative buildings, and department stores based on the minimization of transportation costs (Zhang, 2002). It is important to note that the Weber's theory is commonly used at disaggregated spatial scale (i.e. urban facilities and buildings); it can also be used at more aggregated spatial scales for allocation of land and the structures in land use (Beckmann \& Miksch, 1968).

The Weber problem means finding a point where minimizes a sum of weighted Euclidean distances to $N$ given points. To solve this problem, Weber used a simple location triangle in which an industrial factory is located where the transportation costs of raw materials and final 
product is a minimum. This theory was later improved by Hakimi $(1965 ; 1964)$, who defined two problems of p-center and p-median. The object of p-median problem is to locate $\mathrm{P}$ "facilities" in order to minimize the total weighted distances of "customers" from their nearest facility, while the goal of p-center problem is to locate $\mathrm{P}$ "facilities" in order to minimize the maximum of distance between each costumer and its nearest facility. These facilities (supply points) can include schools, stores, hospitals, parks, fire stations, or other kinds of structures in land use which supply goods or services. Also the population centers are commonly considered as costumers (demand points) which demands goods or services. Equation 14 shows the mathematical form of p-median problem, which has been proposed by ReVelle and Swain (1970) as an integer programming problem. This formula has been used by several other researchers, such as Campbell (1996), Chan (2005) and Neebe (1978).

$$
\text { Minimize: } \sum_{i \in l} \sum_{j \varepsilon l}\left(h_{i} \times d_{i j} \times y_{i j}\right)
$$

Subject to:

$$
\begin{aligned}
& \sum_{j \in J} x_{j}=p \\
& \sum_{j \in J} y_{i j}=1 \quad \forall i \in I \\
& y_{i j}-x_{j} \leq 0 \quad \forall i \in I \quad \forall j \in J \\
& x_{j} \in\{0,1\} \forall j \in J
\end{aligned}
$$

Where, $i$ is the set of demand points, $j$ is the set of candidate supply points, $d_{i j}$ is the distance from point $i$ to point $j, P$ is number of supply points to be chosen from $j$ candidate points, $h_{i}$ is 
demand for goods or services in point $i$ (usually be expressed as number of trips originated from point $i$ ), and

$$
\begin{aligned}
& \mathrm{y}_{\mathrm{ij}}= \begin{cases}1 & \text { if point } \mathrm{i} \text { is assigned to candidate } j \\
0 & \text { otherwise, }\end{cases} \\
& x_{\mathrm{j}}= \begin{cases}1 & \text { if candidate } \mathrm{j} \text { is chosen } \\
0 & \text { otherwise. }\end{cases}
\end{aligned}
$$

\section{Land use suitability Analysis (LSA)}

Land suitability analysis is a tool to answers the question of where the best location is for land use development or land use change. Broadly defined, Land use suitability analysis is a process for defining the appropriateness of a given land for locating future land uses by examining the combined effect of important determinants of land suitability (Collins, Steiner, \& Rushman, 2001; Kaiser, Godschalk, \& Chapin, 1995; Malczewski, 2004). According to Wang and Von Hofe (2007) these determinants of land suitability are classified in three main categories of physical constrains (slope, flood plains, etc.), accessibility (distance to major road, airports, population centers, etc.), and benefit/cost of development (solar exposure, visibility etc).

According to Eastman et al. (1995), the procedures for combination and evaluation of several land suitability criteria are called multicriteria evaluation or multicriteria technique. In this technique all criteria are multiplied by a preference weight and then summed to arrive at a final suitability index. This combined index indicates the overall suitability score of each land. The 
greater the suitability score, the more suitable the land. A common aggregation equation that combines preference weights and criterion scores is as follows:

$$
S_{j}=\frac{\sum_{i=1}^{n} w_{i} * x_{i j}}{\sum_{i=1}^{n} w_{i}}
$$

$$
\begin{aligned}
& S_{j}: \text { Overall suitability score for site } j \\
& x_{i j}: \text { Score of criterion i for site } j \\
& W_{i}: \text { Preference weight of criterion } i \\
& n: \text { Number of criteria }
\end{aligned}
$$

Recent advances in Geographic Information System (GIS) technologies have made it easier to develop GIS-based land use suitability mapping and modeling. In this approach, the results are displayed on a map which highlights areas of high to low suitability. Different integration methods are available in GIS-based land use suitability analysis, including Boolean Overlay, Index Overlay and Fuzzy logic (Joerin, Thériault, \& Musy, 2001; Malczewski, 2004).

\section{III.2. Research methodology}

The main objective of this research is to develop a quantitative modeling framework for simulating the effect of a city's spatial structure on its sustainability. According to Keirstead and Shah (2013, p. 179) "quantitative works on the relationship between urban form and function typically falls under the general title of LUT [land use and transportation] modeling". The LUT models were reviewed in the previous sections. Keirstead and Shah (2013) also state that the 
application of spatial optimization models for finding the optimal layout of a city, comparing the efficiency of urban spatial structures and designing hypothetical optimal configurations of urban facilities like shopping malls is supported by scholars such as Hunt, Kriger, and Miller (2005), Yu, Yang, and Cheng (2007), Jiang-Ping and Qun (2009). The spatial optimization model, as a subcategory of LUT models, were also reviewed in the previous section.

Considering the literature reviewed, we generated a quantitative framework for simulating the relationship between urban spatial structure and urban sustainability. This framework consists of an integrated modeling framework through which various spatial configurations of the selected urban facilities are simulated and simulation outputs are evaluated in terms of sustainability. The main components of the proposed framework consist of:

1. A spatial database which provides necessary input data needed by the model.

2. A land suitability analysis (LSA)

3. A spatial optimization model through which the various spatial configurations of selected urban components are simulated.

4. A sustainability assessment module through which the simulation outputs are evaluated and the most sustainable spatial configuration is determined.

The spatial database (component 1) is constructed in GIS environment. This database consists of various GIS raster and vector data layers needed for LSA (component 2) and spatial optimization model (component 3). The LSA (component 2) provides a set of suitable sites within the city boundary which can be used as potential candidate sites for the spatial optimization model (component 3). The spatial optimization model (component 3) has two subcomponents: i. optimal facility location model, and ii. optimal shopping frequency model. 
The spatial optimization model (component 3) determines optimal spatial configurations of candidate sites that minimize the total travel demand (objective function). Ultimately the various simulation outputs of spatial optimization model (component 3) are checked against the sustainability assessment (component 4) in which non-declining level of capital stocks determines the level of sustainability. In this component; using the concept of Genuine Progress Indicator (GPI); changes in environmental costs such as the cost of energy resource depletion (fuel consumption), air pollution, and loss of land are calculated for each spatial configuration scenario. Changes in economic and social benefits are also determined by measuring the consumer welfare (surplus) for different scenarios. The relationship between these main components is depicted in Figure 3.5.

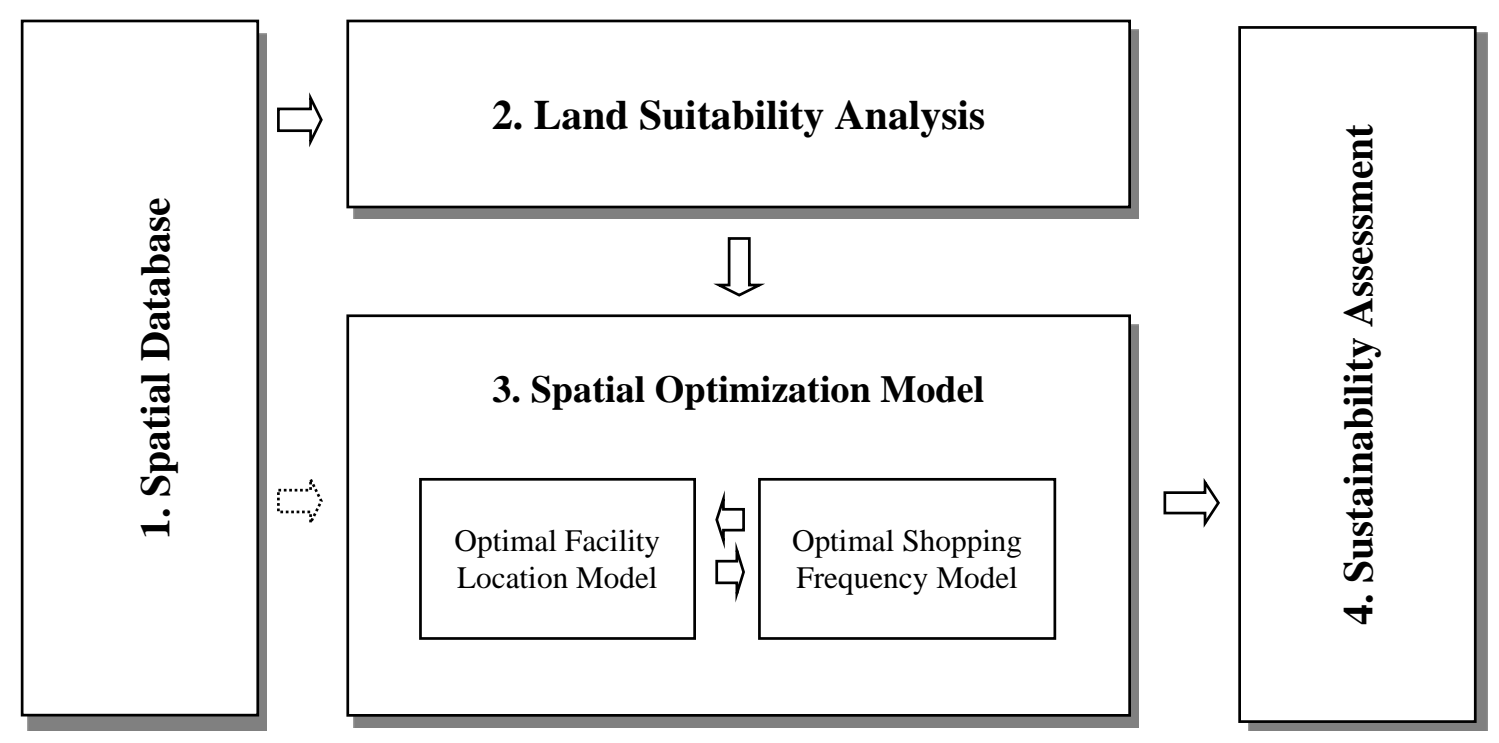

Figure 3.5 Proposed modeling framework 


\section{III.2.1 Spatial database}

The spatial database is constructed in GIS environment and includes various raster and vector data layers needed for LSA and spatial optimization model. The basic GIS layers used for this research included city boundary, land use (in parcel level), road and street network, elevation data, and demographic layers. Other GIS layers (i.e. distance to road and streets, slope and visibility) were constructed and reclassified by using those basic layers (see Chapter IV for details).

\section{III.2.2 Land Suitability Analysis}

LSA was used to determine a set of feasible candidate point within the selected study area and avoid selecting unsuitable lands (such as restricted lands or lands on unsuitable topographic areas). Land suitability identification is generally dependent upon the facility type and its characteristics. The first steps for land suitability analysis is to define evaluation criteria. Selecting the appropriate evaluation criteria depends on the nature of problem and availability of data in study area. Generally speaking, evaluation criteria are classified into three main categories of physical constraints, accessibility, and benefit/cost of development (Wang \& Vom Hofe, 2007). The evaluation criteria considered here are those general criteria that can help us find a set of suitable candidate points for spatial optimization model. The list of applicable general criteria is not limited, but can include the followings (see Chapter IV for details):

- Distance to major road network (accessibility)

- Exposure to noise and highway pollution

- Visibility from highway network

- Proximity to existing urban amenities such as health care, parks, public transport etc. 
- Exposure to renewable energy sources (solar energy, wind...)

- Be on a buildable grade (favorable slope)

- Not on developed or public/semipublic and preserved lands

- Not on floodplains and not on wetlands

At the next step as the measurement scale of each criterion is different than others, it is necessary to rescale (normalize) them before combining them together using equation 15 . Various normalization techniques such as reclassification, normal Z score and fuzzy logic membership are available. In this research the reclassification technique is used for ordinal rescaling of all values into a $0-5$ integer range in which 0 is unsuitable, 1 is least suitable and 5 is most suitable. The reclassifying process is based on the selected evaluation criteria. As an example, for buildable grade criterion the slopes over 25 degrees is rescaled to 0 (unsuitable) and slope range of 0-25 degree equally is divided into five subcategories $(20-25,15-20,10-15,5-10$, $0-5)$ and then these subcategories are rescaled to 1-5.

Third step consists of assigning a preference weight to each criterion in order to express their relative importance. A variety of preference weighting techniques exists among which ranking, rating and pairwise comparison methods are used the most. Each method has its strength and weaknesses. For example ranking and rating methods are easy to use but they don't have strong theoretical foundations and also they become difficult to rank many criteria. Alternatively, the pairwise comparison technique is more accurate but requires a more time consuming computation process. In this study we use pairwise comparison or Analytic Hierarchy Process (AHP) technique developed by Saaty (1977). This technique is based on a simple comparison between each pair of criteria by 1-9 (or 1-7) range of points in order to find a set of criteria's 
weights. The Consistency Index (CI) and Consistency Ratio (CR) are also calculated using equations below in order to avoid bias in weighting process.

$$
\begin{aligned}
& \mathrm{CI}=(\lambda-\mathrm{N}) /(\mathrm{N}-1) \\
& \mathrm{CR}=\mathrm{CI} / \mathrm{RI}
\end{aligned}
$$

Where, RI is the random index, $\lambda$ is the average of the consistency vector, and $\mathrm{N}$ is number of criteria. After assigning criteria scores and weights to each grid cell, we can calculate the composite suitability score by integrating all normalized maps and using the following formula:

$$
S_{j}=\frac{\sum_{i=1}^{n} W_{i} * x_{i j}}{\sum_{i=1}^{n} w_{i}}
$$

Where, $S_{j}$ is a composite suitability score of grid cell $j, x_{i j}$ is the score of the criterion $i$ for grid cell $j, W_{i}$ is preference weight of the criterion $i$, and $n$ is number of criteria. The integration steps can be summarized as following diagram: 


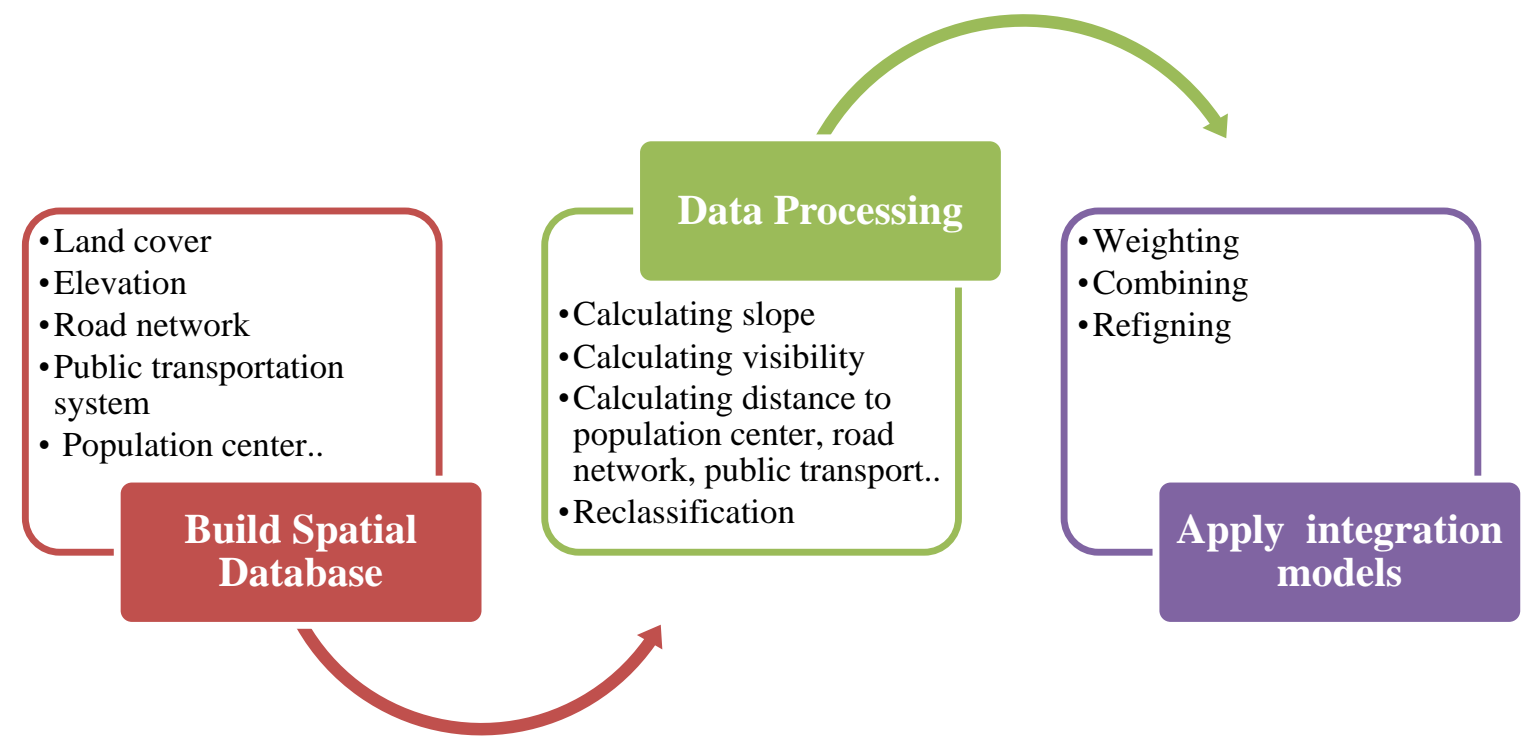

Figure 3.6 Map integration steps

\section{III.2.3 Spatial optimization model}

The spatial optimization model is based on the model proposed by ReVelle and Swain (1970), formulated as a linear programming form of optimal facility location model. The model is shown in equation (19):

Minimize: $\sum_{i \varepsilon l} \sum_{j \varepsilon l}\left(\operatorname{pop}_{i} \times f_{i} \times 2 \times d_{i j} \times y_{i j}\right)$

Subject to:

$$
\sum_{j \varepsilon J} x_{j}=p
$$




$$
\begin{aligned}
& \sum_{j \varepsilon J} y_{i j}=1 \quad \forall i \in I \\
& \sum_{j \varepsilon J}\left(y_{i j} \times \text { pop }_{i}\right)=\sum_{i \varepsilon I} \text { pop }_{i} \forall i \in I \quad \forall j \in J \\
& y_{i j}-x_{j} \leq 0 \forall i \in I \quad \forall j \in J \\
& x_{j} \in\{0,1\} \quad \forall j \in J
\end{aligned}
$$

and

$$
\begin{gathered}
\mathrm{y}_{\mathrm{ij}}= \begin{cases}1 & \begin{array}{l}
\text { if point } i \text { is assigned to candidate } j \\
0
\end{array} \\
\text { otherwise },\end{cases} \\
x_{\mathrm{j}}= \begin{cases}1 & \text { if candidate } j \text { is chosen } \\
0 & \text { otherwise }\end{cases} \\
I=\{0,1, \ldots, N\} \\
\quad J=\{0,1, \ldots, N\}
\end{gathered}
$$

Where, $I$ is set of demand points, $J$ is set of candidate supply points, $d_{i j}$ is the distance from the point $i$ to point $j, P$ is number of supply points to be chosen from $j$ candidate points, pop $i$ is the population of costumers assigned to point $i, f_{i}$ is trip rate (trip frequency) in point $i$, and $N$ is the total number of candidate supply points which is determined using the LSA component (see III.2.2).

The above model allows us to find the optimum spatial configuration of selected subjects (urban facilities) among a set of possible spatial configurations for a given number of $\mathrm{P}$. The optimum spatial configuration is the one that minimizes the value of objetive function of spatial optimization model. The number of possible spatial configuration (combinations), for a given number of $\mathrm{P}$, is equal to $\mathrm{C}(\mathrm{N}, \mathrm{P})=\mathrm{N}$ ! / $\mathrm{P} !(\mathrm{N}-\mathrm{P})$ !. For example, for given value of $\mathrm{P}=2$ and $\mathrm{N}=6$, 
the above model selects the best pair of points among 15 possible combinations that can be drawn from the set of candidate points.

As shown each demand point $i$ has a demand for goods or services that are supplied by supply points $j$. This demand can be expressed as the number of trips generated by each demand point and denoted by рор $_{i} \times f_{i}$. It is essential to note that trip rate $\left(f_{i}\right)$ value may not be fixed and can change depending on the distance between demand and supply points $\left(d_{i j}\right)$, particularly for shopping activities. For example, trip distance between home and store can play an important role in consumer's "shopping behavior" (defined by the average size of the shopping basket and the shopping trip frequency). In other word, by increasing the trip distance between the home and store, households tend to increase the size of shopping basket and decrease the frequency of store visits. This strategy will help them to purchase several items in a single trip, saving the travel time and transportation costs.

The above fact has been pointed out by numerous researchers, see for example Park (1915), Berry (1967), Rushton(1969), Stahl (1987), and Eppli (1996). A model of the frequency of shopping and the optimal shopping frequency was first expressed as an optimization model by Reinhardt (1973) and later was improved by Bacon (1984; 1992), Di Pasquale and Wheaton (1996). The optimal shopping frequency model starts with calculating the combined cost of purchase price, transportation cost and inventory cost to store merchandize at home using the following equation:

$$
P_{i}=P_{j}^{*}+\frac{2 f_{i} \cdot d_{i j} \cdot c_{i j}}{X_{i}}+\frac{1}{2} \cdot \frac{S_{i}}{f_{i}}
$$


Where, $P_{i}$ is final price per unit of good; $P_{j}^{*}$ is sale price per unit of good; $f_{i}$ is purchase frequency; $d_{i j}$ is distance travelled to shop; $c_{i j}$ is transportation costs per unit of distance; $S_{i}$ is storage cost per unit of good ; and $X_{i}$ is total amount purchased by consumer. This equation consists of three components. The first component $\left(P_{j}^{*}\right)$ is purchase price, the second component represents the transportation cost and the third component shows the storage cost. Consumers supposed to optimize their shopping frequency by minimizing the final price of product. So the optimum shopping frequency is calculated by first-order derivative of equation (20) :

$$
f_{i}=1 / 2 \sqrt{\frac{s_{i} \cdot X_{i}}{d_{i j} \cdot c_{i j}}}
$$

Where, $f_{i}$ is optimal shopping frequency, $d_{i j}$ is distance travelled to shop, $c_{i j}$ is transportation costs per unit of distance, $S_{i}$ is storage cost per unit of good, and $X_{i}$ is total amount of goods purchased by consumer. It also should be noted that value of $X_{i}$ can be obtained from good's demand function. Figure 3.7 depicts the relationship between good's price and quantity of good demanded by consumer (Robert W Bacon, 1992). 


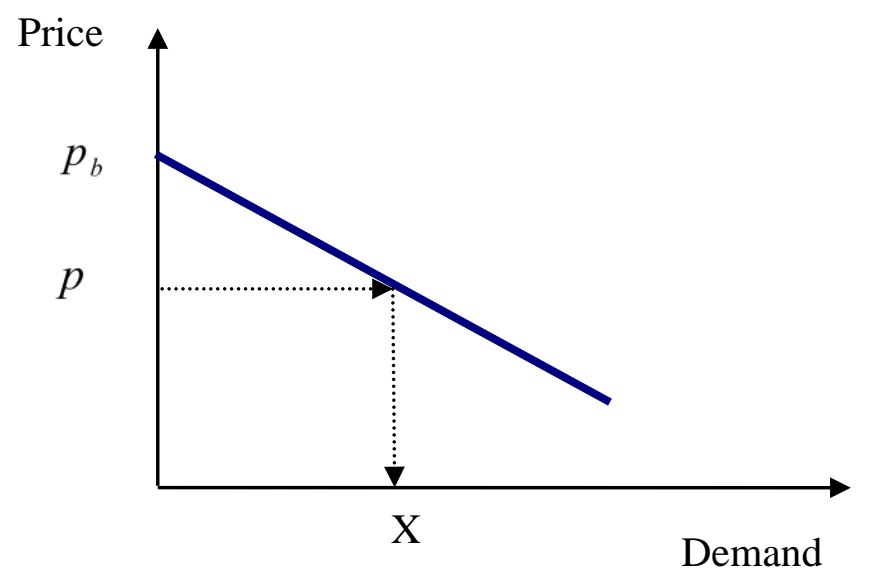

Figure 3.7 Good's demand versus good's price (demand curve)

The next equation shows the mathematical form of households shopping demand, determined based on above curve:

$$
X=\frac{P_{b}-P}{r}
$$

Where, $P_{b}$ is maximum price; $P$ is final price; and $r$ is the slope of the demand curve. By substituting the equation 20 in the above equation, we will have:

$$
P_{b}-r \times X_{i}=P_{j}^{*}+\frac{2 \cdot f_{i} \cdot d_{i j} \cdot c_{i j}}{X_{i}}+\frac{1}{2} \cdot \frac{S_{i}}{f_{i}}
$$

So, the value of two unknown parameters of $f_{i}$ and $X_{i}$ can be determined by solving two simultaneous equations of 21 and 23 and then $f_{i}$ can be used as an endogenious varibale (trip rate) in the objective function of the optimal facility location model (see equation 19). 


\section{III.2.4 Sustainability assessment}

The sustainability assessment component evaluates outcomes of spatial optimization model on the basis of a long-run urban sustainability criteria. We used wealth - embodied in natural, physical and human capital- as the main indicator of sustainability. Within this context, we picked GPI to capture changes in the total capital stock due to the changes in the spatial configuration of selected urban facility within the city area. According to Cookson (2012, p. 246) "the GPI treats the money spent on capital items as a cost, and the value of the service they provide year after year as a benefit"; therefore, change in the GPI reflects net change in flow of capitals. The GPI has been developed as an alternative of the GDP since it has important deficiencies as a measure of sustainable economic development. According to Clarke and Lawn (2008) the GDP is a poor indicator of community wellbeing because of the following problems:

1. GDP fails to make the distinction between economic activities and transactions that increase welfare and those that reduce it. In other word the GDP treats all regrettable expenditures (i.e. cost of cleaning of oil spills, automobile accidents, cost of divorce and cost of commuting) as an addition to welfare.

2. GDP ignores the value of non-monetary activities and transactions such as the value of household work and parenting, the value of volunteer work.

3. GDP doesn't account for the cost of non-renewable resource depletion (depreciation). The reason for this is because GDP is "gross" and doesn't include the capital depreciated during production of goods and services.

4. GDP ignores the income distribution and equity. It simply shows the total amount (value) of goods and services that have been produced by producers and doesn't 
contain any information about who consume these products and how it increases household's welfare.

The GPI (similar to the GDP) is based on the assumption that final personal consumption of produced goods and services is the main element of community welfare (and wellbeing), but (despite the GDP) it attempts to take into account all un-accounted costs and benefits, by adding or subtracting environmental and social (and economical) factors. Therefore GPI is GDP minus the environmental costs ( i.e. cost of resource depletion, ozone depletion, air pollution, water pollution, noise pollution, loss of farmland and loss of wetlands) and the social costs (i.e. cost of crime, family breakdown, commuting, automobile accident, loss leisure time) (Stiglitz et al., 2009). GDP and GPI can be represented as:

$$
\mathrm{GDP}=\mathrm{C}+\mathrm{I}+\mathrm{G}+(\mathrm{X}-\mathrm{M})
$$

Where, $\mathrm{C}$ is personal (household) consumption, $\mathrm{I}$ is capital investment by producers (i.e. purchase of machinery and equipment for a factory), $\mathrm{G}$ is government expenditures and (X-M) is value of exports minus imports.

$$
\begin{gathered}
\mathrm{GPI}=(\mathrm{C}-\mathrm{D})+(\mathrm{Sd}+\mathrm{Sg}+\mathrm{Su})+\mathrm{NCI}-\mathrm{HS}-\mathrm{NE}-\mathrm{F} \\
\mathrm{NCI}=(\mathrm{I}-\mathrm{CFC})+(\mathrm{X}-\mathrm{M})
\end{gathered}
$$

Where, $\mathrm{C}$ is personal consumption (durables and non-durables), $\mathrm{D}$ is expenditures on consumer durables, $\mathrm{Sd}$ is services generated by the exiting stock of consumer durables, $\mathrm{Sg}$ is services of government expenditures on public infrastructure (highways and streets), $\mathrm{Su}$ is value of unaccounted social and ecological services (e.g., household labor, volunteer work, ecosystem services), NCI is net investment (by producers) in fixed capital (I - CFC) and net change in 
international position (X-M), CFC is consumption of fixed capital (depreciation), HS is cost of decline of human capital and social degradation (e.g., cost of crime, family breakdown, lost leisure time, automobile accident), NE is cost of depletion of natural capital and environmental degradation, and $\mathrm{F}$ is net foreign borrowing. By substituting the equations 24 and 26 in the equation 25 (the government expenditure was added and then subtracted from the equation), we will have:

$$
\mathrm{GPI}=(\mathrm{GDP}-\mathrm{CFC}-\mathrm{F})+(\mathrm{Sd}-\mathrm{D})+(\mathrm{Sg}-\mathrm{G})+(\mathrm{Su}-\mathrm{NE}-\mathrm{HS})
$$

The standard form of GPI that contains more than twenty indicators as shown in Table 3.1. In this table some GPI indicators are more relevant to the environmental aspects of sustainability, while others fall into the social or economic domains (also some indicators could be assigned to the multiple domains). This table (as well as the equation 27) also shows that depletion/decline (or addition) of all types of capitals are included in the GPI index and a constant or increasing GPI over time simply means that the stock of capital will be at least as great for the future generation while decreasing GPI implies unsustainable development (Talberth et al., 2007). In other word, change in GPI must be equal or greater than zero in order to meet urban sustainability criteria (Equation 28).

$$
\Delta G P I \geq 0
$$

Where, $\triangle G P I$ is the change in the GPI value before and after a change. 
Table 3.1

Standard list of GPI indicators

\begin{tabular}{|c|c|c|c|}
\hline GPI indicators & $\begin{array}{l}\text { Welfare } \\
\text { Impact }\end{array}$ & Domain & Capital form \\
\hline $\begin{array}{c}\text { Personal consumption (non-durables and } \\
\text { durables) }\end{array}$ & + & Economic & - \\
\hline Government expenditure & + & Economic & $\begin{array}{l}\text { Physical capital } \\
\text { (\& other forms) }\end{array}$ \\
\hline Net capital investment & "+/-" & Economic & $\begin{array}{l}\text { Physical capital } \\
\text { (\& other forms) }\end{array}$ \\
\hline Net foreign borrowing & "+/-" & Economic & - \\
\hline Income distribution index & "+/-" & $\begin{array}{c}\text { Social } \\
(\& \text { Economic })\end{array}$ & - \\
\hline $\begin{array}{c}\text { Services of government expenditure on } \\
\text { public infrastructure (highways and streets) }\end{array}$ & + & Economic & $\begin{array}{l}\text { Physical capital } \\
\text { (\& other forms) }\end{array}$ \\
\hline $\begin{array}{l}\text { Services of household expenditure on } \\
\text { durables (i.e. vehicle, appliance,...) }\end{array}$ & + & Economic & $\begin{array}{l}\text { Physical capital } \\
\text { (\& other forms) }\end{array}$ \\
\hline Government expenditure & - & Economic & $\begin{array}{l}\text { Physical capital } \\
\text { (\& other forms) }\end{array}$ \\
\hline $\begin{array}{l}\text { Household expenditure on consumer } \\
\text { durables (vehicle, appliance,...) }\end{array}$ & - & Economic & $\begin{array}{l}\text { Physical capital } \\
\text { (\& other forms) }\end{array}$ \\
\hline Value of household work and parenting & + & $\begin{array}{c}\text { Social } \\
(\& \text { Economic })\end{array}$ & Human capital \\
\hline Value of volunteer work & + & $\begin{array}{c}\text { Social } \\
\text { (\& Economic) }\end{array}$ & Human capital \\
\hline Value of higher education & + & $\begin{array}{l}\text { Social }(\& \\
\text { Economic) }\end{array}$ & Human capital \\
\hline Cost of automobile accidents & - & Social & Human capital \\
\hline Loss of leisure time & - & Social & Human capital \\
\hline Cost of commuting & - & Social & Human capital \\
\hline Cost of underemployment & - & Social & Social capital \\
\hline Cost of crime & - & Social & Social capital \\
\hline Cost of family breakdown & - & Social & Social capital \\
\hline
\end{tabular}


Cost of household pollution abatement (air filters, water filters...)

Cost of air pollution

Carbon dioxide emissions damage

Cost of ozone depletion

Cost of water pollution

Cost of noise pollution

Depletion of nonrenewable energy resources

Loss of wetlands

Loss of farmland

Loss of primary forests
Environmental

(\& Social)

- Environmental Natural capital

- Environmental Natural capital

- Environmental Natural capital

- Environmental Natural capital

- Environmental Natural capital

- Environmental Natural capital

- Environmental Natural capital

- Environmental Natural capital

- Environmental Natural capital

Note $^{1}$ : adapted from Anielski (2001), Talberth, Cobb and Slattery (2007), and Costanza et al. (2004)

An important point to notice is that some GPI indicators are directly or indirectly related to "distance" and transportation (transport related indicators). Therefore, we can link the changes in value of GPI indicators to the changes in pattern of urban spatial structure within our modeling framework. This idea was first proposed by Yevdokimov and Mao (2004; 2002). They used GPI for measuring the changes in level of sustainability due to changes in transportation state (Zegras, 2005, 2006). The following formula is adapted from Yevdomikov and Mao's equation to measure changes in sustainability level:

$$
\Delta G P I=\Delta G D P \pm \sum_{i=1}^{N} \Delta E_{i} \geq 0
$$

Where, $\triangle G P I$ is the change in the GPI value due to the changes in spatial structure (morphology), $\triangle G D P$ is the change in GDP, and $\Delta E_{i}$ is the change in $\mathrm{i}$-th positive or negative economic, environmental and social effect not included in the GDP.

\footnotetext{
${ }^{1}$ The standard GPI table is consistent with equation 25 and doesn't include government expenditure, but in this table the government expenditure was added to the table (row B) and then subtracted from it (row H). This modification helps to be consistent with GPI formula in equation 27.
} 
This formulation clearly demonstrates the capability to link the urban spatial models with GPI index and interpret the model outputs in terms of sustainability. For example the social costs of commuting, automobile accident, and loss of leisure time can be expressed as a function of parameters such as vehicle miles traveled (VMT), Passenger Miles Traveled (PMT) or Average Travel Distance (ATD) which depend on the spatial characteristics of urban areas (size, shape, density, layout, etc.). All environmental indicators also could be derived from urban spatial pattern. Furthermore, depletion of non-renewable energy resources, cost of air pollution, carbon dioxide emissions damage and ozone depletion are correlated with automobile fuel consumption. Loss of wetland, farmland, and primary forest area are also direct results of replacement of natural land cover with man-made transportation infrastructure (such as highways, streets and parking). Finally, noise and water pollutions can be considered as consequences of traffic congestion. Another benefit of this approach is that it allows us to ignore those GPI indicators which don't depend on distance (i.e. cost of family breakdown, value of higher education), since their value doesn't change after modification of urban spatial structure.

Here it should be highlighted that most of the GPI indicators are difficult to measure, as we cannot quantify all effective factors due to lack of sufficient data (especially in urban scale). For example, the cost of noise pollution can depend not only on the amount of travel demand (VMT), but also on the type of vehicles and location of traffic. In addition, there is always a significant uncertainty in the economic valuation of natural assets (based on the ecosystem services they provide), since the majority of ecosystem services are non-market goods which do not have a market price. This uncertainty is more apparent when trying to monetize the social costs such as cost of automobile accidents or cost of commuting. Fortunately several studies have attempted to monetize the full costs and benefits of transport related indicators of 
sustainability. Among comprehensive examples are the studies conducted by MacKenzie et al. (1992) at the World Resource Institute, Kågeson (1993) at the European Federation for Transport and Environment, Delucchi (1997) at the Institute of Transportation Studies (Davis) and Litman (2009) at the Victoria Transport Policy Institute (VTPI).

The latter is among best-known efforts to assess the sustainability of a transportation system through quantifying the full internal and external costs of various transportation modes. The importance of this particular study lies in the fact that urban land-use and transportation pattern can increase the automobile dependency which can contribute to unsustainable development (Litman, 1996). Figure 3.8 shows the monetized estimates of various transportation cost categories for passengers of an average car in urban area, calculated by the VTPI. 2007 U.S. dollars per passenger miles traveled has been chosen as unit of measure. These cost categories can be converted to GPI indicators (see Table 3.2).

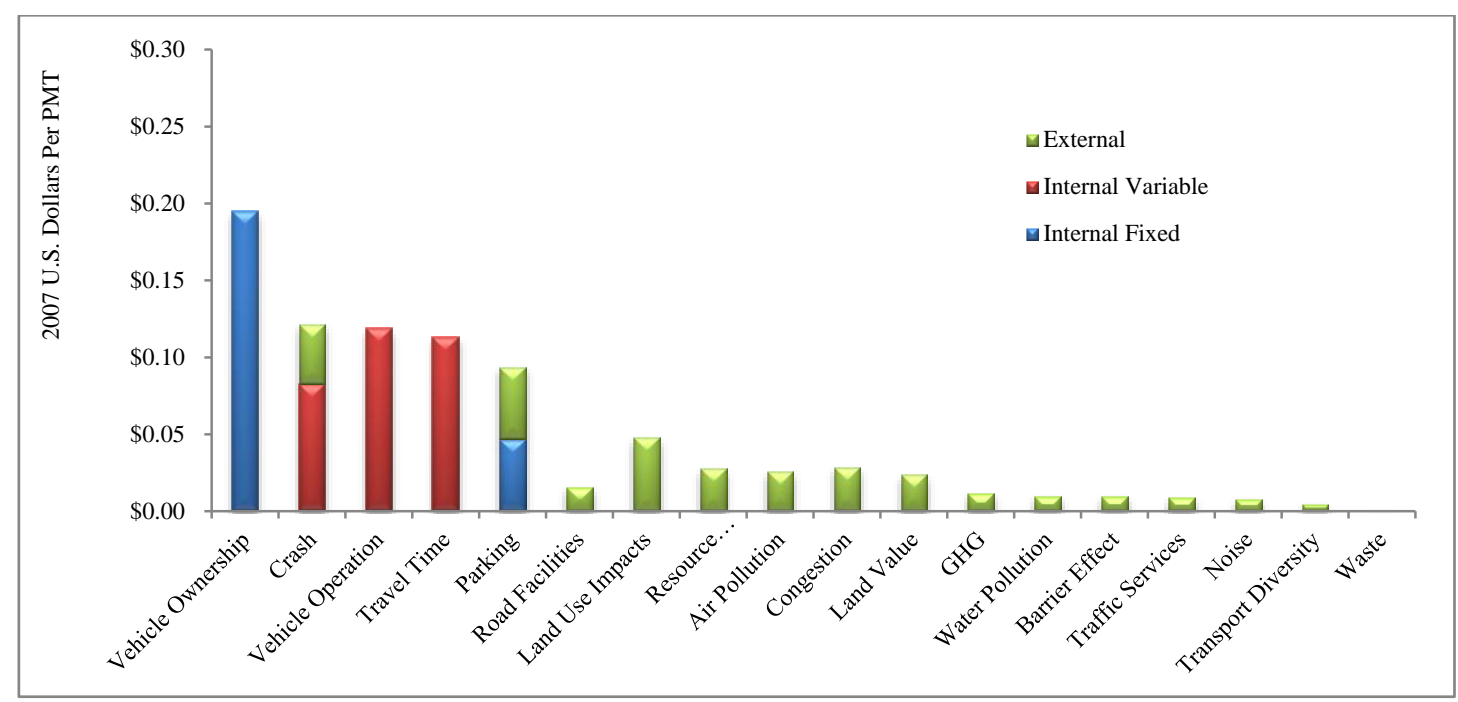

Figure 3.8 Monetized estimates of transportation costs for passengers of an average car in urban area

Source: Reproduced from (Litman, 2009) 
Savelson et al. (2006; 2008) used the VTPI cost estimates (see Figure 3.8) for calculation of GPI indicators in GPI Atlantic study. The GPI Atlantic is a comprehensive sustainability study for transportation system of Halifax Regional Municipality and Nova Scotia regions in Canada, used various transportation cost categories for Genuine Progress Index (GPI) transportation account (Savelson et al., 2006; Savelson et al., 2008). The GPI Atlantic approach is very useful because it uses the vehicle travel (Vehicle- Kilometer Traveled or Passenger-Kilometer Traveled) as the key indicator of calculation which is same as output unit of proposed model in this dissertation. Using this approach, the full cost can be carried out by multiplying the optimal value of objective function (unit: PMT) and overall monetized estimate of transportation unit costs from Figure 3.8 (unit: \$ per PMT) and Table 3.2.

Table 3.2

Linking Litman's transportation costs estimation and standard GPI indicators

\begin{tabular}{ccc}
\hline GPI components & $\begin{array}{c}\text { Transport } \\
\text { related }\end{array}$ & $\begin{array}{c}\text { Relevant components } \\
\text { (from Figure 3.8) }\end{array}$ \\
\hline $\begin{array}{c}\text { Gross Domestic Production (GDP) } \\
\text { - Fixed Capital Consumption (CFC) }\end{array}$ & & \\
+/- Net foreign borrowing (F) & & \\
+/- Income distribution index & $\checkmark$ & Road Facilities + Parking + \\
+ Services of government expenditure on public \\
infrastructure (Sg) \\
+ Services of household expenditure on durables \\
(Sd)
\end{tabular}


+ Value of volunteer work $(\mathrm{Su})$

+ Value of higher education $(\mathrm{Su})$

- Cost of automobile accidents (HS)

- Loss of leisure time (HS)

- Cost of commuting (HS)

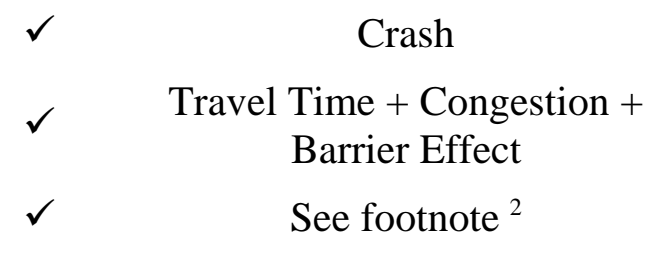

- Cost of underemployment (HS)

- Cost of crime (HS)

- Cost of family breakdown (HS)

- Cost of household pollution abatement (NE)

- Cost of air pollution (NE)

- Carbon dioxide emissions damage (NE)

- Cost of ozone depletion (NE)

- Cost of water pollution (NE)

- Cost of noise pollution (NE)

- Depletion of nonrenewable energy resources

$(\mathrm{NE})$

- Loss of wetlands (NE)

- Loss of farmland (NE)

- Loss of primary forests (NE)

$\begin{array}{cc}\checkmark & \text { Waste } \\ \checkmark & \text { Air Pollution } \\ \checkmark & \text { GHG } \\ \checkmark & \text { GHG } \\ \checkmark & \text { Water Pollution } \\ \checkmark & \text { Noise } \\ \checkmark & \text { Resource consumption } \\ & \text { Land Value + Land Use } \\ \checkmark & \text { Impacts } \\ & \text { Land Value + Land Use } \\ \checkmark & \text { Impacts } \\ & \text { Land Value + Land Use }\end{array}$

Finally transport-related benefits (services) can be estimated by using the theory of consumer's surplus or Marshallian surplus (Hayward \& Atlantic, 2004). Using this theory, consumer's surplus is defined as the difference between the maximum price a consumer is willing to pay for a product and the actual price. According to this theory, the net benefit to consumers (the consumer's surplus) of transportation service is equal to the area under the

\footnotetext{
${ }^{2}$ This indicator could include the value of all other transportation related indicators, but just for the commuting portion of total travel demand. We suggest omitting this item and including its value into the other transportation related indicators.
} 
demand curve and above a horizontal line at the actual (equilibrium) price (Greene $\&$ Jones, 1997). This area is represented in Figure 3.9 as area of the triangle ACG. The consumer's surplus will decrease by increasing the cost (distance). In this situation the reduced consumer's surplus is equal to area of triangle $\mathrm{AC}^{\prime} \mathrm{G}^{\prime}$.

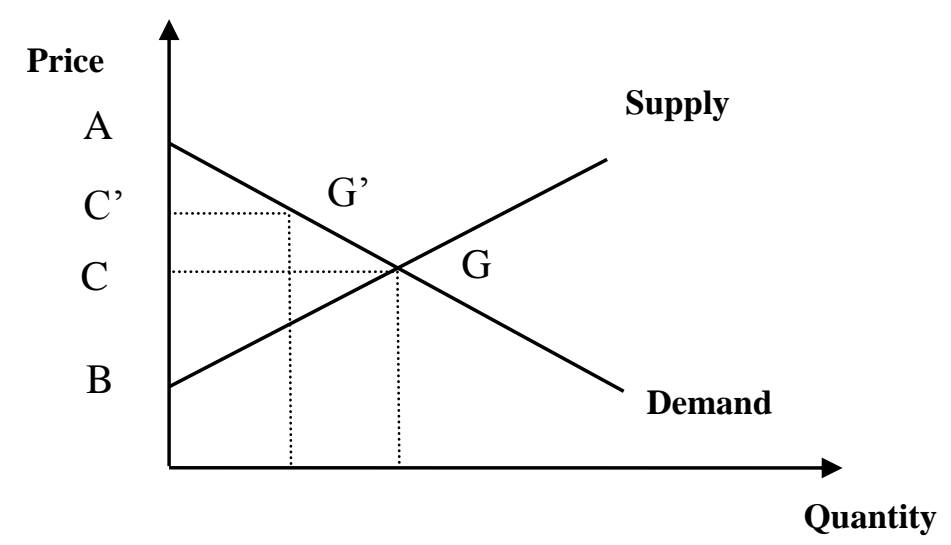

Figure 3.9 Relationship between supply, demand, price and consumer's surplus (welfare)

In case of variable trip frequency (referring to the Reinhardt's and Bacon's equation), the mathematical form of consumer's surplus is equal to:

$$
\mathrm{TB}=\int_{0}^{x_{i}}\left(P b-r . X_{i}\right) d X_{i}-P_{j}^{X} . X_{i}-f_{i} \times 2 \times d_{i j} \times c_{i j}-\frac{1}{2} \times \frac{s_{i}}{f_{i}} \times X_{i}
$$

In this equation the amount of two unknown parameters of $f_{i}$ and $X_{i}$ can be determined by solving two simultaneous equations of 21 and 23. 


$$
\left\{\begin{array}{l}
f_{i}=1 / 2 \sqrt{\frac{s_{i} \cdot X_{i}}{d_{i j} \cdot c_{i j}}} \\
P_{b}-r \times X_{i}=P_{j}^{*}+\frac{2 \cdot f_{i} \cdot d_{i j} \cdot c_{i j}}{X_{i}}+\frac{1}{2} \cdot \frac{S_{i}}{f_{i}}
\end{array}\right.
$$

The proposed modeling framework was applied to the study area of Morgantown, WV in Chapter IV. The results can help policy makers/decision makers to predict the environmental, economic and social impacts of changes in location and spatial configuration of selected urban facilities (food and beverage store) and choose the most sustainable scenario. 


\section{CHAPTER IV}

\section{Results and Analysis}

This chapter first introduces the city of Morgantown West Virginia as the case study area of this research. This description addresses main characteristics of the city, including its geographical location, socioeconomic attribute and remarkable physical characteristics, particularly its land use and transportation network pattern. The goal of this part is to provide the necessary information about the city's spatial structure and the geographical information layers used for the purpose of spatial modeling. The second part of this chapter presents the results of the model. The aim of this part is to simulate the environmental, economic and social impacts of the changes in the spatial configuration of the selected urban facility. These results could help us to answer the research question: to what extent the urban spatial structure can affect the pattern of urban sustainable development? The interpretation of the model's output in terms of sustainability has also been discussed in the next chapter.

\section{IV.1 Case study area: The city of Morgantown, WV}

Morgantown is a city in Monongalia County, West Virginia. The city is situated along the east bank of the Monongahela River at $39^{\circ} 38^{\prime} \mathrm{N}$ and $79^{\circ} 57^{\prime} \mathrm{W}$ and 947 feet above sea level. Morgantown with population of approximately 31000 and a land area of 10.17 square miles (26.34 km2) is the largest city in North-Central West Virginia (U.S. Census Bureau, 2012).The Morgantown Metropolitan Statistical area with a population of 129,709 includes surrounding cities of Westover, Granville, Star City, Brookhaven, Cassville, Cheat Lake, Masontown. The nearest large city with a population over 50,000 is Pittsburgh, Pennsylvania.

Figure 4.1 presents the official municipal map of Morgantown, providing a clear image of city boundary as well as developed and undeveloped lands within the city limits. Most of the 
city area has been devoted to developed urban lands. Morgantown Municipal Airport and WVU's agriculture farm are located in the north-east part of Morgantown city area. This map was selected as the case study area of this research and used to determine the extent of spatial objects and collect spatial data in geographic information system.

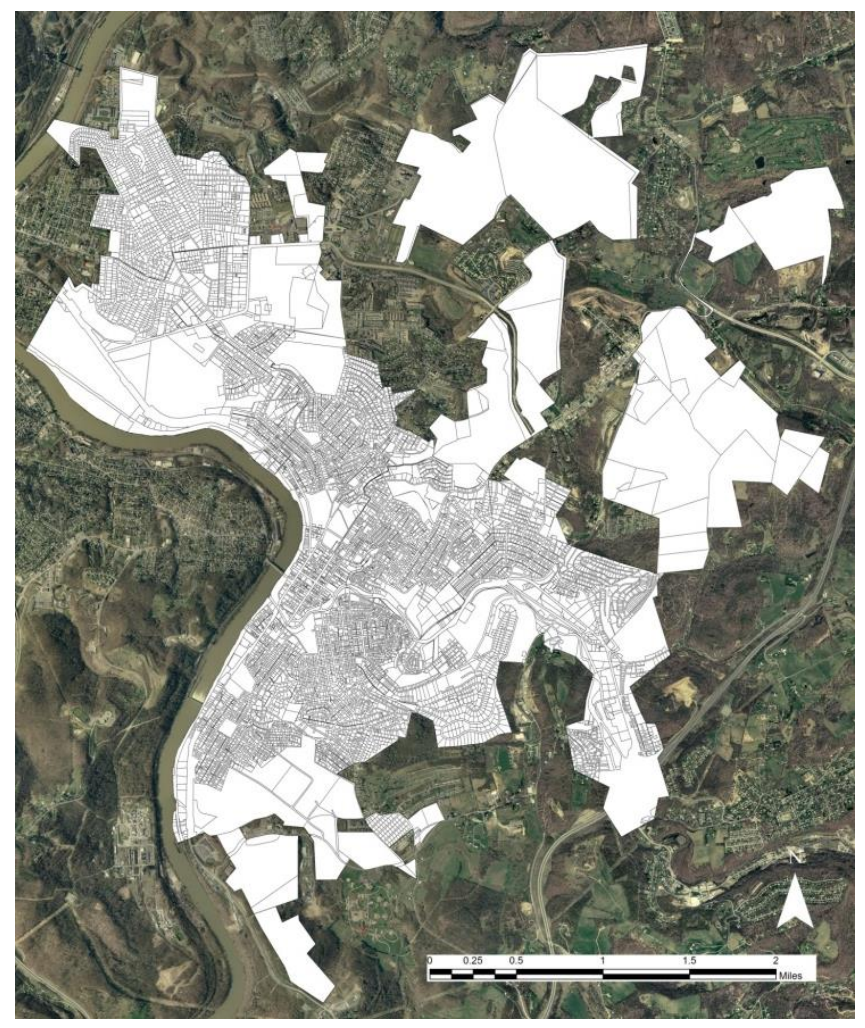

Figure 4.1 Official Municipal map of Morgantown

\section{IV.1.1 Socioeconomic characteristics}

According to US Census Bureau, in 2010 there were 11701 households and 3827 families in Morgantown residing in 12664 housing units with the median value of 166100 dollars. Morgantown also has a population density of 2917 person per square mile making it one of most dense cities within West Virginia (U.S. Census Bureau, 2010). This city which is well known as 
the home of West Virginia University is among the most educated places in the state, since 46.6 percent of population has Bachelor's or higher degree. The median age of Morgantown's residents is 22.6 years; which makes it one of the youngest cities in state; while the median age of West Virginia state is 43.4 years (U.S. Census Bureau, 2007-2011).

Another notable socioeconomic characteristic of Morgantown is its low unemployment rate which was 4.4 percent in August 2013. According to the American Community Survey 5Year Estimates (2007-2011) the median household income was also equal to 25948 dollars per year. Educational services (26 percent), accommodation and food services (17 percent), retail trade (11 percent), health care and social assistance (8 percent), professional, scientific, and technical services ( 7 percent), manufacturing ( 7 percent), and construction ( 7 percent) are the most common industries in Morgantown.

\section{IV.1.2 Physical characteristics and spatial structure attributes}

The available data and information sources and relevant comprehensive plan reports were reviewed to collect the physical characteristics of the city of Morgantown, Morgantown Metropolitan Statistical Area (MSA), and Monongalia County. The city of Morgantown's Comprehensive Plan and the regional Long Range Transportation Plan for the Morgantown Monongalia Metropolitan Planning Organization (MMMPO) are two comprehensive studies that contain a variety of useful information about different types of land- use, city's transportation infrastructure, housing condition, community facilities and other physical attributes of the city. Using the urban spatial structure metrics which were introduced in Chapter II, the key spatial characteristics of the city are defined as follows: 
Overall size: Morgantown is considered as a small city in terms of "overall size", the city has experienced significant socioeconomic changes during the last decades resulting in unforeseen physical growth of the city and its surrounding areas. This growth was mainly due to the expansion of West Virginia University as the engine of regional development. This rapid growth has pressured city's infrastructure such as transportation network as well as its housing stock.

Overall shape: Morgantown has complicated spatial pattern; its "overall shape" is mostly a mixture of grid and linear forms. The city core, which is generally defined as Downtown Morgantown, as well as most of the neighborhoods has grid or modified grid pattern. Being situated along the Monongahela River, the growth pattern of the city has largely been influenced by the Monongahela river. It should be noted that the rapid expansion of the city in recent years, is dramatically changing the current form of the city.

Density: Using the definition of density by Galster et al. (2001), the average residential density of Morgantown is 1245 dwelling per square miles. By excluding non-residential lands from calculation, the city residential density is almost equal to 4150 dwelling per net square miles. This density is in "low density" range based on definition proposed by Ellis (2004).

Equity of spatial distribution (entropy): As mentioned in Chapter II, "equity of spatial distribution" is a useful spatial structure indicator indicating how much urban system components such as population, buildings or activities are uniformly distributed within a city. According to the Comprehensive Plan of Morgantown (2013), topographic constraint is a major obstacle to construction. This issue has resulted to unequal distribution of buildings and population density within the city area. Other factors such as distance to downtown, distance to 
WVU's Campus, and distance to major roads also contribute to increased inequity. As a result, the core area of the city (Downtown Morgantown) and neighborhoods surrounding the downtown and WVU's campus (i.e. North Willey Street / Richwood Avenue Area) as well as urban corridors (i.e. Beechurst Avenue) have much higher density than other areas. It should be noted that the precise amount of equity of spatial distribution is usually calculated by Shannon's entropy index, which is not subject of this research.

Centrality: While the major commercial land uses have clustered around Morgantown's central business district (downtown), the residential lands have clustered around numerous focal points representing a poly-centric development pattern for the city. These focal points include Downtown, Evansdale, Health Science and Law School campuses which house most of the city's residents comprised of WVU's students and employees.

Sprawl: City is in early stages of urban sprawl and continues to expand toward lands outside of city limits, particularly toward the north and east parts of highway 705 adjacent to WVU's agriculture farm and Morgantown Municipal Airport such as Suncrest Town Center. Development of new commercial nodes and corridors such as Mountaineer Mall, University Town Center, and Sabraton commercial corridor are also a sign of 'leapfrogging' sprawl.

Diversity: Diversity of land use, amenities and building types is a useful metric of urban spatial structure. According to the city's Comprehensive Plan “Morgantown's diverse neighborhoods are among its most valuable assets" (Morgantown Planning Commission, 2013, p. 6). This diversity is mostly related to residential building types (single-family and multifamily, detached and attached, etc.) and their price level. Unfortunately the diversity of land-use (mixed land-use) and diversity of amenities is relatively poor in Morgantown (see Figure 4.3). 
Most of the neighborhoods have limited access to basic community services, civic facilities and amenities such as shopping centers, grocery stores, park space, public recreation centers, high schools and public transportation.

These deficits have been discussed in the Comprehensive Plan report in detail. This report emphasizes the importance of supportive strategies to expand family-friendly amenities such as community recreation centers and park space in the city. For example, two strategies of CF 2.3 and CF 3.2 are about finding suitable sites for developing new community recreational center and assisting Monongalia County Schools to find appropriate sites for new schools. The comprehensive plan also gives priority to infill and redevelopment of vacant, underutilized areas or deteriorating sites within the city limits over growth in green-field areas at the city edges and outside of city boundaries (Morgantown Planning Commission, 2013) . This type of development is more sustainable for the following reasons:

- It would reduce the consumption and replacement of natural land cover (green fields) with man-made surfaces.

- It facilitates the development of areas within the city limits which already served by existing infrastructure.

- It could reduce urban trip length through increasing urban density and reducing urban sprawl.

- It also provides better access to urban amenities for city residents.

The direct and indirect effects of the above benefits on stock of natural, physical and human capitals have been discussed in detail in previous chapters (see Chapter I and II). 


\section{IV.2 Geographic information database}

The GIS-based spatial database constructed for the study helped to represent the objects on the map, organize the spatial objects, conduct the spatial relationships, and analyze different types of information layers (point, line, polygon and grid). The basic GIS layers used for this research included Morgantown's boundary, land use (at parcel level), road and street network, elevation data, and demographic layers. Other GIS layers (i.e. distance to road and streets, slope and visibility) were constructed and reclassified by using those basic layers. Universal Transverse Mercator (UTM) projected coordinate system and the North American Datum of 1983 (NAD83) were applied for all GIS layers in this research.

\section{IV.2.1 Morgantown boundary}

Morgantown boundary layer was first generated in 2006 by the City of Morgantown's Planning Department as a guidance for Morgantown's official municipal boundary and zoning map. In this research, Morgantown boundary layer was used to determine the extent of other spatial objects (lands, road networks, etc.) within city limits. In other word, all other GIS layers have been clipped by the Morgantown boundary layer in order to have a common planning and analysis geographic framework.

\section{IV.2.2 Land use}

The first land use map of Morgantown was prepared by the City of Morgantown in 1999 as a part of the Comprehensive plan (year 1999) based on the Tax Assessors records and TIGER files from the Bureau of Census, US Department of commerce. The land use map provided basic information but it was not as detail as to provide data at parcel level, and to the best of our knowledge was not available in GIS format. Fortunately, the Development Service Department 
(Planning Division) of Morgantown has prepared a new parcel-based shape file for existing land uses as a part of the City's recent Comprehensive Plan update project (year 2013). A copy of this GIS layer was received in September 2013 in order to use in this research. Figure 4.2 illustrates 17 class land use classification map of Morgantown at parcel level.

The percentage of land covered by each type of land use is shown in Figure 4.3. West Virginia University covering more than 32 percentages of city's lands has the highest rank. The second rank belongs to the residential-single-family land use with about 21 percent. However, by including two-family, multi-family, and mobile homes, the total share of residential use will increase up to 25 percent. 


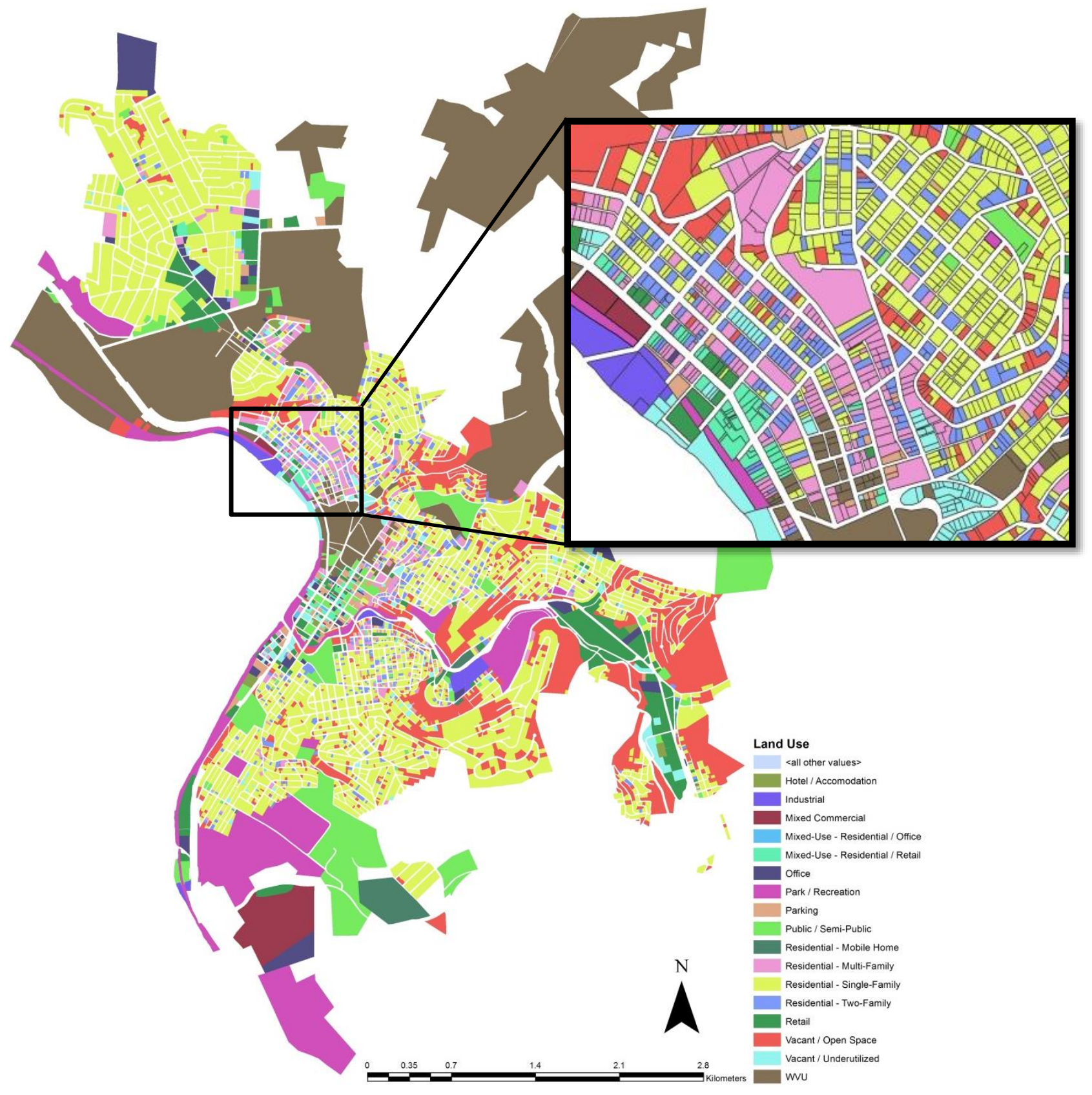

Figure 4.2 Parcel-based Land Use map of Morgantown

Source: Development Service Department (Planning Division) of Morgantown 
Less than 0.5 percent of city area has been occupied by the mixed-use (residential/office and residential/retail) lands which mostly located in Morgantown Downtown and Sunnyside (around Beechurst Avenue). This low percentage indicates that Morgantown is not a sustainable city in terms of land-use diversity.

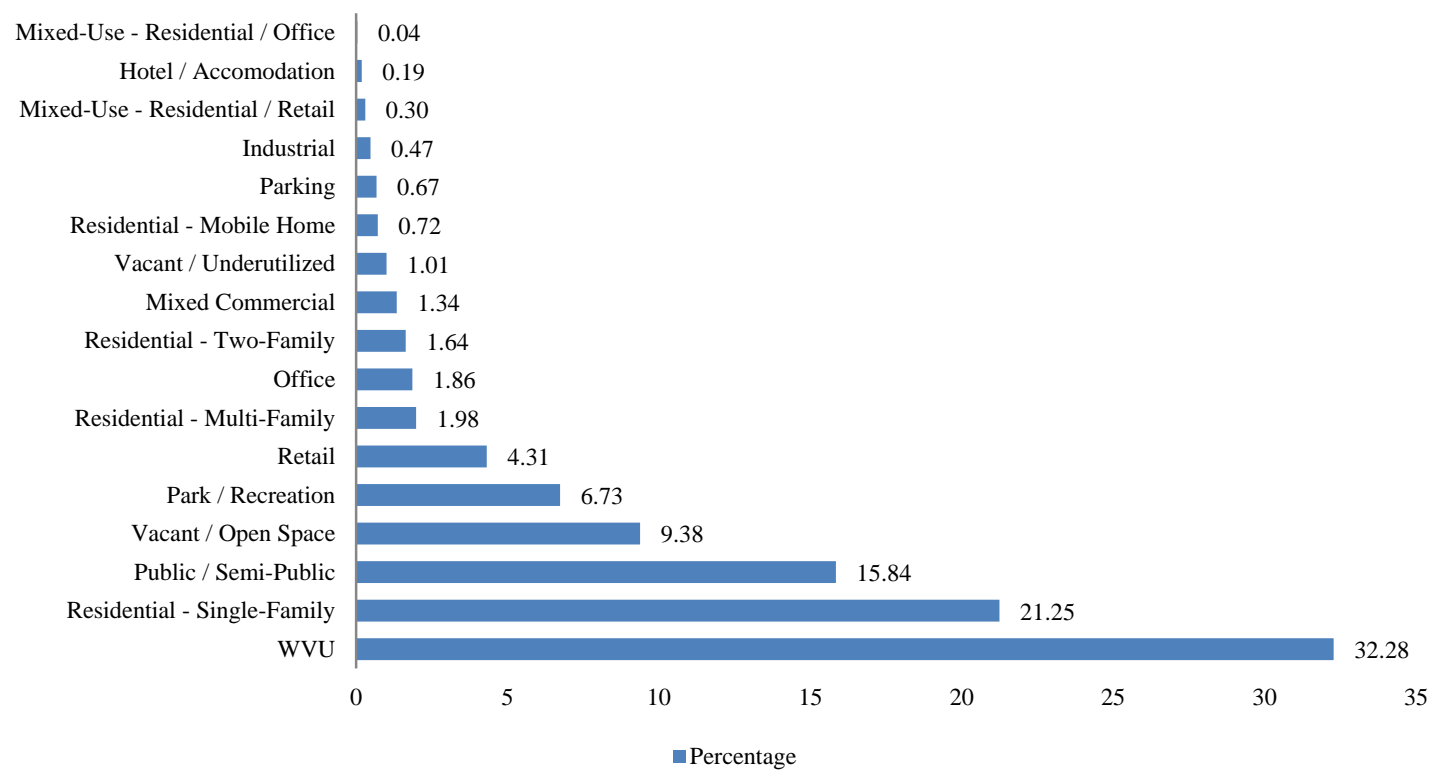

Figure 4.3 Percentage of land covered by each type of land use

This research uses the land use data layer as one of several inputs for land suitability analysis subcomponent of model. This GIS layer provides necessary land use data for determining favorable lands for infill or redevelopment. It also helps to exclude restricted lands (i.e. public lands, preserved lands, parks, etc.) from analysis.

\section{IV.2.3 Road network}

Four different road network layers were used in this research, including U.S. Interstates Highways, U.S. Routes, U.S. Highways, and Morgantown Streets. The first three layers, 
published by the U.S. Department of Transportation (Bureau of Transportation Statistic) as part of the National Transportation Atlas Database, are available on West Virginia GIS Technical Center website (http://wvgis.wvu.edu). Morgantown Streets layer was extracted from the U.S. Topologically Integrated Geographic Encoding and Referencing (TIGER) and Morgantown Comprehensive Plan (2013) database. Figure 4.4 depicts the road network of Morgantown.

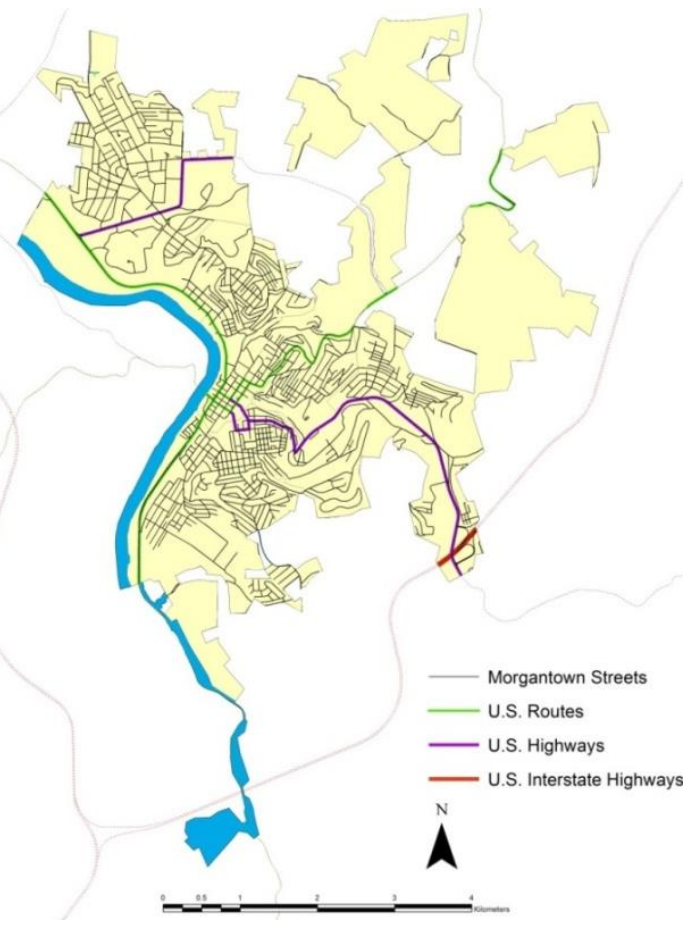

Figure 4.4 Road Network map of Morgantown

Source: U.S.DOT, TIGER, Morgantown Comprehensive Plan

In addition to the land use layer, road network layers were used as input for land suitability analysis in order to calculate the following parameters: 1) distance to major road network, 2) visibility from highway network, and 3) exposure to noise and highway pollution. First parameter expresses the importance of better access to road networks. For instance, a commercial developer or an owner of a grocery store prefers to choose lands with better access 
to highway and major streets in order to attract more customers. However, the benefits of better accessibility are not limited to economic attractiveness. It also improves social justice through the increasing citizen's ability to reach desired goods, services, and facilities, in particular public facilities such as schools, hospitals, recreational centers etc. Second parameter is also important as high level of visibility makes lands more desirable for development of public facilities.

Finally, due to the negative impacts resulting from highway noise and air pollution, the model's third criterion is set to avoid selecting lands adjacent to highways. Figure 4.5 depicts Euclidean Distance to streets and highways maps generated form road network map of Morgantown.
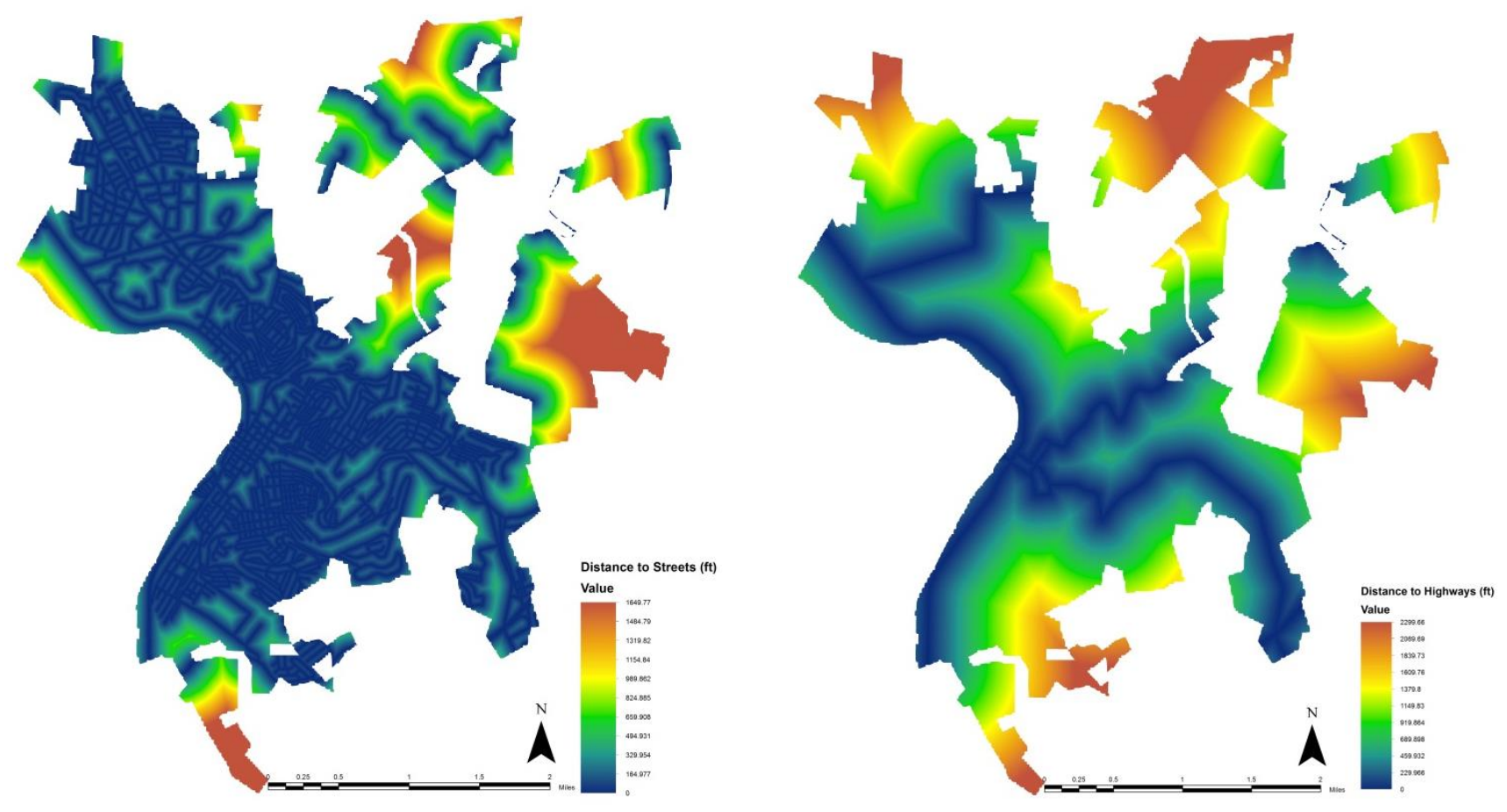

Figure 4.5 Distance to streets (left) and distance to highways (right) 
In addition, the Morgantown Street layer was used to calculate minimum distance matrix (dij) of initial candidate sites as an input for the proposed spatial optimization model.

\section{IV.2.4 Elevation data}

The National Elevation Dataset (NED), best available raster elevation data layer provided by the U.S. Geological Survey, was used for the purpose of generating Slope and Visibility layers (see Figure 4.6 and Figure 4.7). This layer contains elevation information for all United States territory at a resolution of 30 meters, while some areas have finer resolutions of 10 and evern 3 meters. Figure 4.6 shows digital elevation grid cropped by the Morganrown boundary layer.

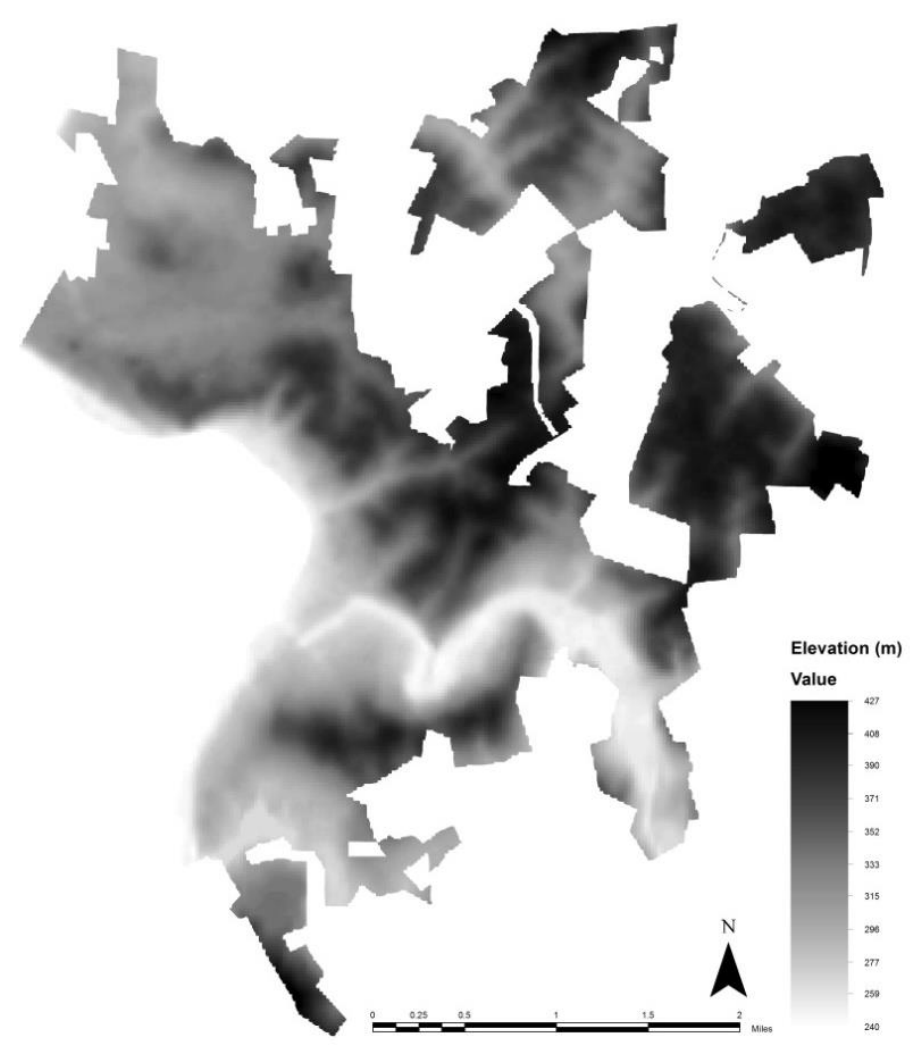

Figure 4.6 Morgantown's digital elevation map 
The Digital Elevation Dataset layer was converted to the slope layer, using the ArcGIS

Slope tool. The slope layer was then used to derive lands with slope less than 25 degrees that are considered suitable for development. Visibility layer was also created by entering the elevation layer (as input raster) and the highway network layers (as input poly-line observer feature) into the ArcGIS Viewshed tool.
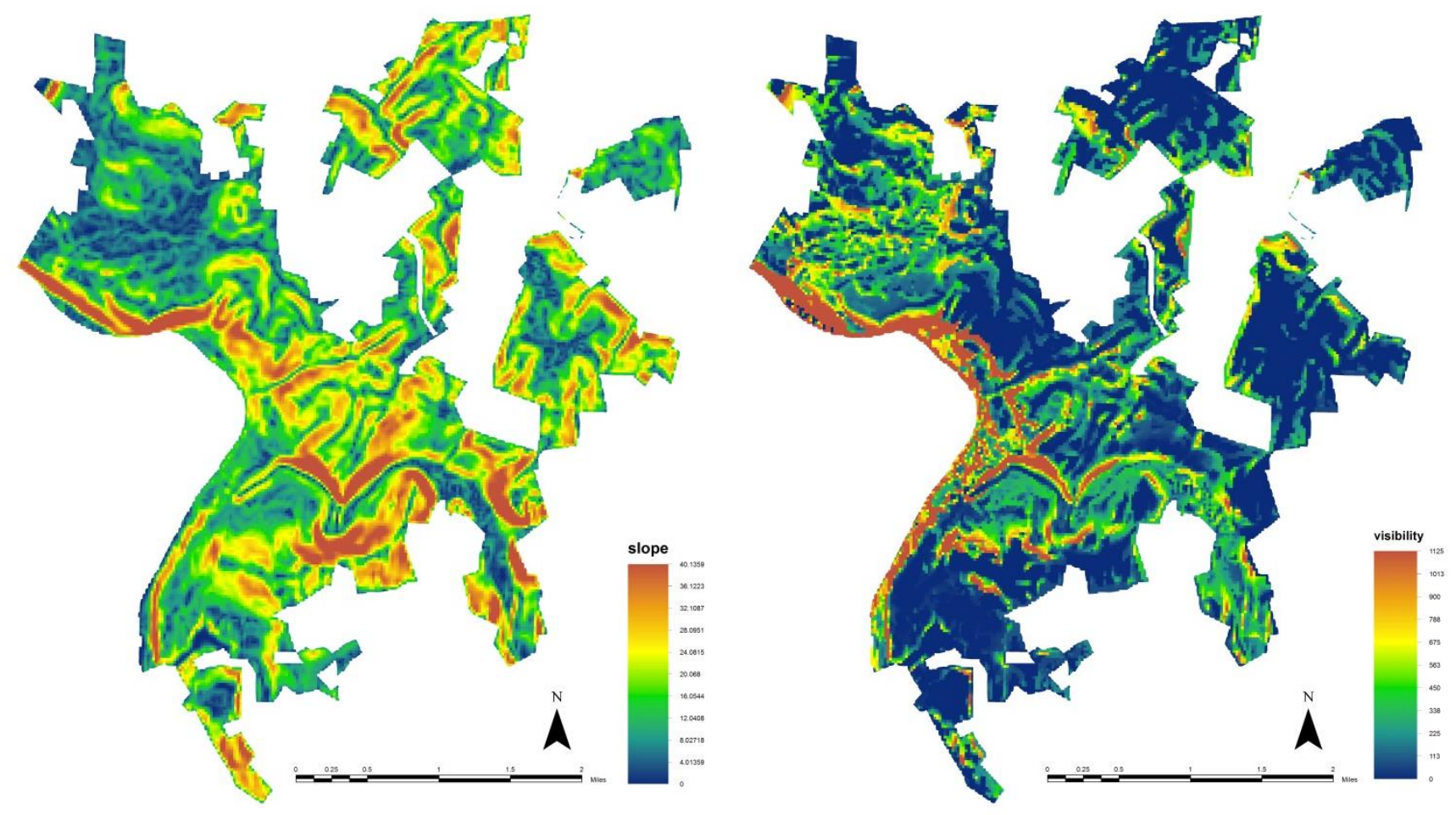

Figure 4.7 Slope (left) and visibility (right)

Morgantown's demographic GIS layer, downloaded from the West Virginia GIS

Technical Center website (http://wvgis.wvu.edu), contains the number of population in each census block for the year 2010. This layer has been originally constructed from TIGER's census block shape file and demographic attributes from U.S. Census Bureau American Fact Finder. 
Demographic GIS layer was used to calculate the number of generated trips in the optimal facility location model (equations 19). Figure 4.8 shows Morgantown's population GIS map.

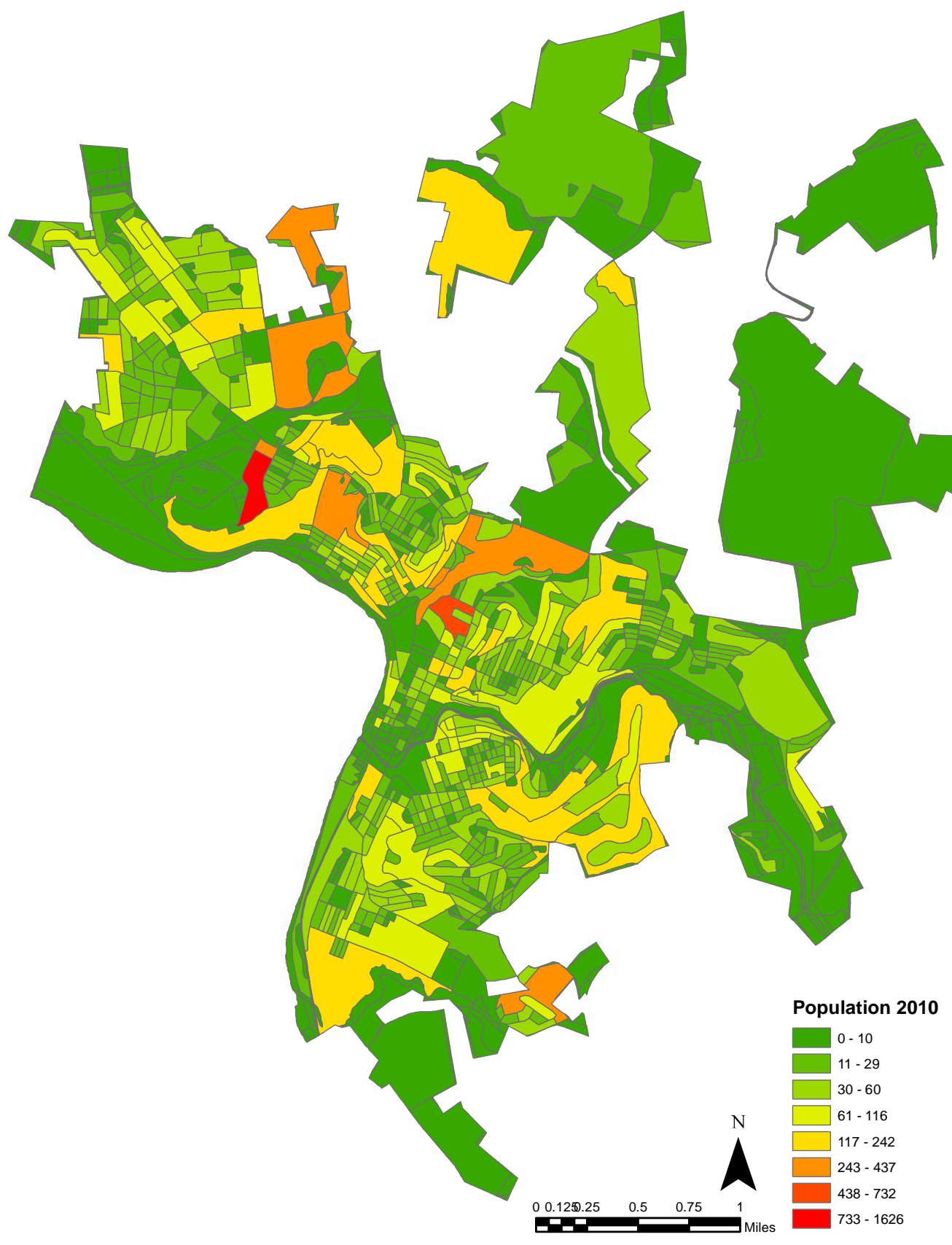

Figure 4.8 Morgantown's population by each census block (year 2010)

Source: U.S.DOT, TIGER, Morgantown Comprehensive Plan 


\section{IV.3 Subject of modeling (selected urban facility)}

In this research "food and beverage store (including supermarkets, grocery (except convenience) stores, specialty food stores and beer, wine, and liquor stores)" was selected as subjects of modeling. Food and beverage store was considered for modeling purposes since shopping activity is one of the main determinants of urban economic system. According to U.S. Census Bureau's Annual Retail Trade Survey (2013) the estimated U.S. per capita retail sale was about 15500 dollars in year 2012 and each person has spent 2012 dollars in food and beverage stores in this year (see Table 4.5), while American Community Survey 5-Year Estimates (20072011) shows that the median household income is about 26000 \$/year. The local statistics also show that retail trade is the third important industry in Morgantown. The total value of retail sale in Morgantown was equal to 561,833,000 dollars in year 2010. Also, the share of food and beverage store from the total retail sale in Morgantown was about $18 \%(\$ 102,551,000)$ which is higher than similar rates in West Virginia (12\%) and the United States (14\%) (CLRChoice, 2012). The significant share of shopping activity in urban economic system, indicates that shopping is an important parameter influencing the travel behavior in urban areas. As a result, the location and spatial layout of shopping destination (i.e. food and beverage stores) can play a key role in urban travel pattern and urban sustainability.

In addition, food and beverage store will be used as an example subject for the proposed spatial optimization model since shopping activity is an example of urban activity which has variable trip frequency rate. In other word consumer's shopping behavior (average size of the shopping basket and the shopping trip frequency) depends to the travel distance or travel time between the origin and destination points. This characteristic allows us to use trip frequency rate as an endogenous variable in the proposed spatial optimization model. 


\section{IV.4 Application of Land Suitability Analysis (LSA)}

In order to apply the land suitability analysis, all input datasets were entered into ArcGIS with the same coordinate system of NAD83 and then clipped by Morgantown's Boundary layer. The distance to streets, distance to highways, slope and visibility raster layers were created using the spatial analyst tool (Figures 4.5 and 4.7). The next step was to reclassify the inputs on the scale from 0 (unsuitable) to 5 (most suitable). The reclassification process was based on the following general evaluation criteria emphasizing that the candidate location of supply points must:

- $\quad$ Be on buildable grade (0-25 degree)

- Be close to streets, major roads and highways (better accessibility)

- Be far enough from highway (less exposure to noise and air pollution)

- Be on areas with high visibility from highway networks (better visibility)

- Be on favorite lands for infill and redevelopment such as vacant, under-utilized

- Not be on protected or restricted lands such as public/semipublic, park and recreation

Table 4.1 shows the utility scores assigned to different values of grid layers in order to covert theme to five point rating scale. The minimum and maximum values were used for linear rescaling of slope, distance to highway, distance to street and visibility criteria. The utility score of land use criterion was determined considering the recommendation of Comprehensive Plan of Morgantown (2013) for giving priority to infill and redevelopment of vacant, underutilized areas or deteriorating sites over growth in green-field areas. 
Table 4.1

Utility scores matrix used for reclassification

\begin{tabular}{|c|c|c|c|c|c|c|}
\hline & 5 & 4 & 3 & 2 & 1 & 0 \\
\hline Land use & $\begin{array}{c}\text { Vacant/ } \\
\text { Underutilized }\end{array}$ & $\begin{array}{c}\text { Industrial } \\
\text { Commercial } \\
\text { Office } \\
\text { Retail }\end{array}$ & $\begin{array}{l}\text { Mixed } \\
\text { Use }\end{array}$ & Residential & $\begin{array}{c}\text { Hotel/ } \\
\text { Accommodation }\end{array}$ & $\begin{array}{c}\text { Public/Semipublic } \\
\text { Park and } \\
\text { Recreation } \\
\text { Open Space } \\
\text { WVU } \\
\text { Parking }\end{array}$ \\
\hline Slope (degree) & $0-5$ & $5-10$ & $10-15$ & $15-20$ & $20-25$ & $>25$ \\
\hline Distance to Highway (m) & $10-362$ & 363- 673 & $674-985$ & $986-1297$ & $>1297$ & $<10$ \\
\hline Distance to Street (m) & $0-25$ & $25-50$ & $50-75$ & $75-100$ & $>100$ & - \\
\hline Visibility & $>8$ & $6-8$ & $4-6$ & $2-4$ & $0-2$ & - \\
\hline
\end{tabular}

It is notable that selection of appropriate evaluation criteria depends on the nature of decision, type of selected facility and availability of data in study area. For example, proximity to educational institutions may be determined as a specific evaluation criterion for the suitability analysis of a library, while a wind farm should be located on suitable facing slopes to capture dominant winds. Taking into consideration that in this research the LSA is used as a supplemental tool for finding an initial set of candidate sites for the spatial optimization model (main model), the complexity of suitability analysis- induced by the large number of criteriawas avoided by choosing the most important general criteria. Results of reclassification step have been depicted in Figures 4.9 and 4.10. 

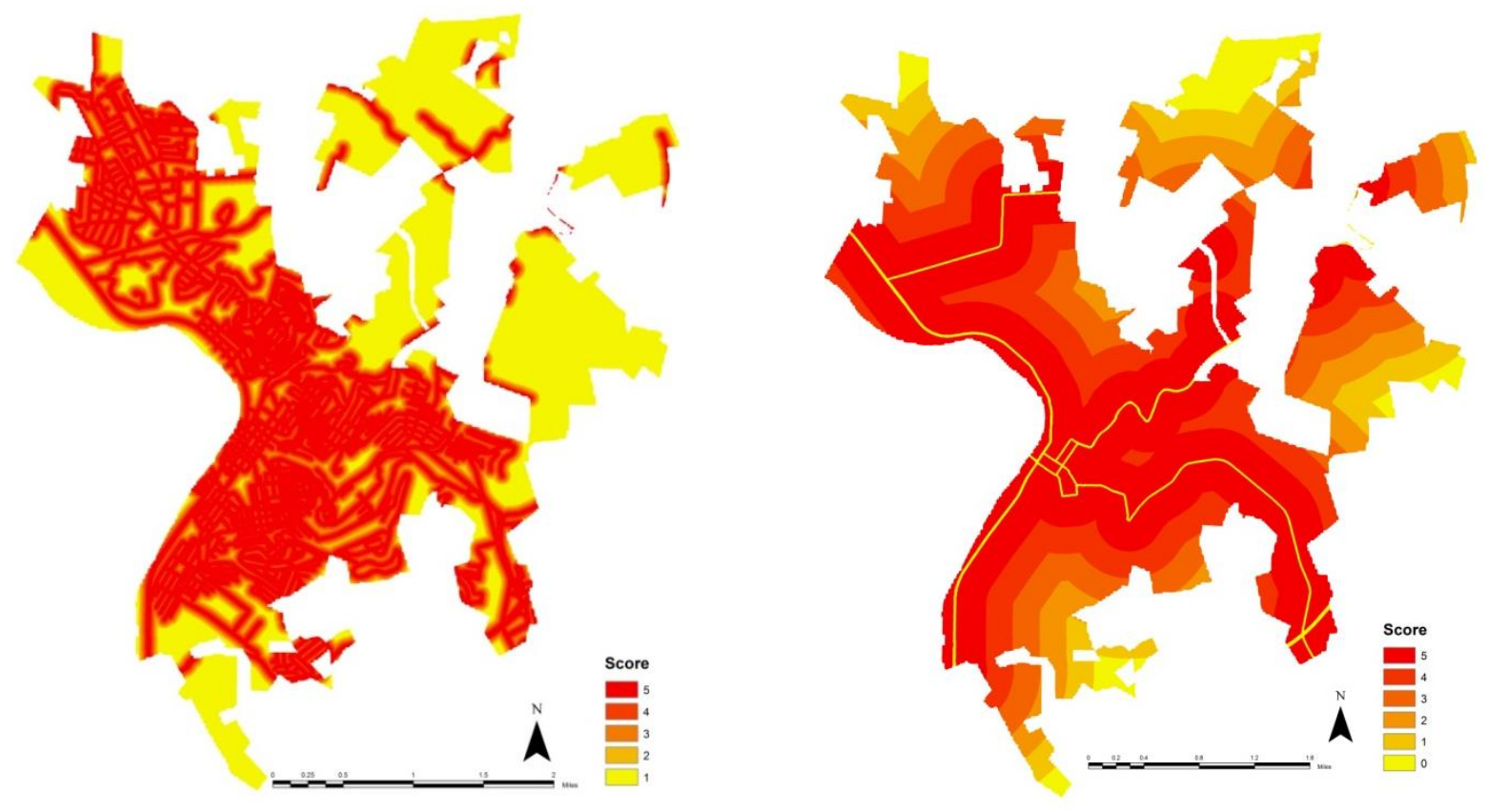

Figure 4.9 Reclassified distance to streets (left) and distance to highways (right)
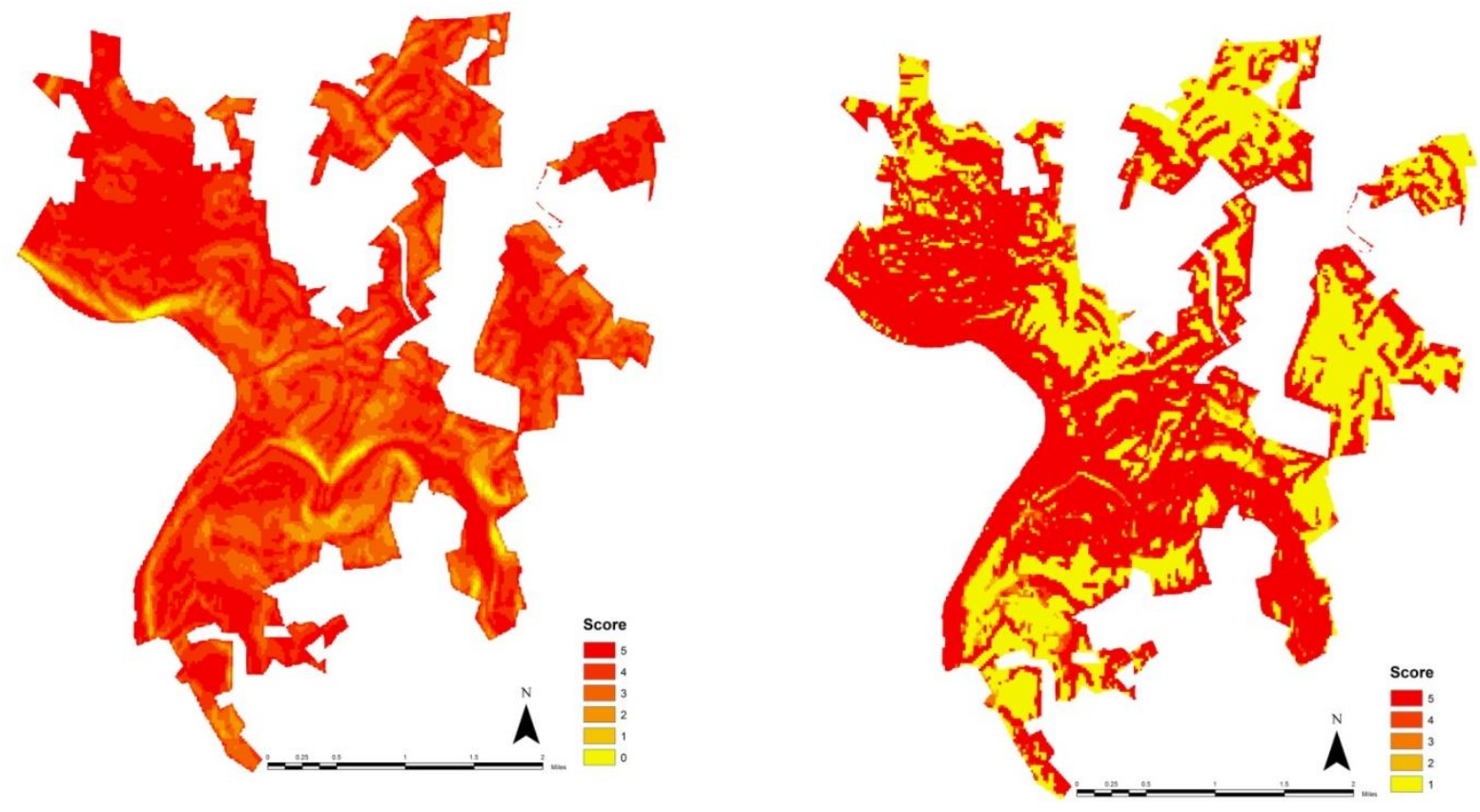

Figure 4.10 Reclassified slope (left) and visibility (right) 
At the next step, the reclassified (normalized) layers were integrated together using ArcGIS “Weighted Sum" tool, given the following preference weights for criteria:

Table 4.2

Preference weights

\begin{tabular}{cc}
\hline Criteria & Weight (\%) \\
\hline Land Use & 39.0 \\
Slope & 23.9 \\
Dist2Highway & 22.2 \\
Dist2street & 10.0 \\
Visibility & 4.8 \\
\hline
\end{tabular}

These preference weights were computed by applying the AHP technique to the comparison matrix of criteria which is shown in Table 4.3. The consistency of comparisons was also checked $(\lambda=5.14 ; \mathrm{CI}=0.04 ; \mathrm{CR}=0.03)$. Since the consistency ratio $(\mathrm{CR})$ is equal to 0.03 which is less than 0.10 then we can conclude that comparisons are consistent and preference weights are applicable for multi-criteria evaluation.

Table 4.3

AHP comparison matrix

\begin{tabular}{cccccc}
\hline Criteria & Land Use & Slope & Dist2Highway & Dist2street & Visibility \\
\hline Land Use & 1.00 & 2.00 & 2.00 & 3.00 & 8.00 \\
Slope & 0.50 & 1.00 & 1.00 & 4.00 & 4.00 \\
Dist2Highway & 0.50 & 1.00 & 1.00 & 3.00 & 4.00 \\
Dist2street & 0.33 & 0.25 & 0.33 & 1.00 & 3.00 \\
Visibility & 0.13 & 0.25 & 0.25 & 0.33 & 1.00 \\
\hline
\end{tabular}


Finally; in order to make more understandable results; the result map of suitability analysis was rescaled to 0-100 range. Then the Salt and Pepper pixels; which are very small pixels scored very high but are not connected or associated with anything else; have been removed from the final suitability map (Majority Filter tool).

All above steps were completed using the ArcGIS "Model Builder" tool which provides a visual and graphical representation of model process. This tool allows to change key parameters or input data layers and re-run the model. It also allows for more complex models to be stored and re-applied, saving time and effort in recreating the model. Figure 4.11 shows the model builder developed for land suitability analysis. It contains model inputs (blue), processes (yellow), and outputs (green). 


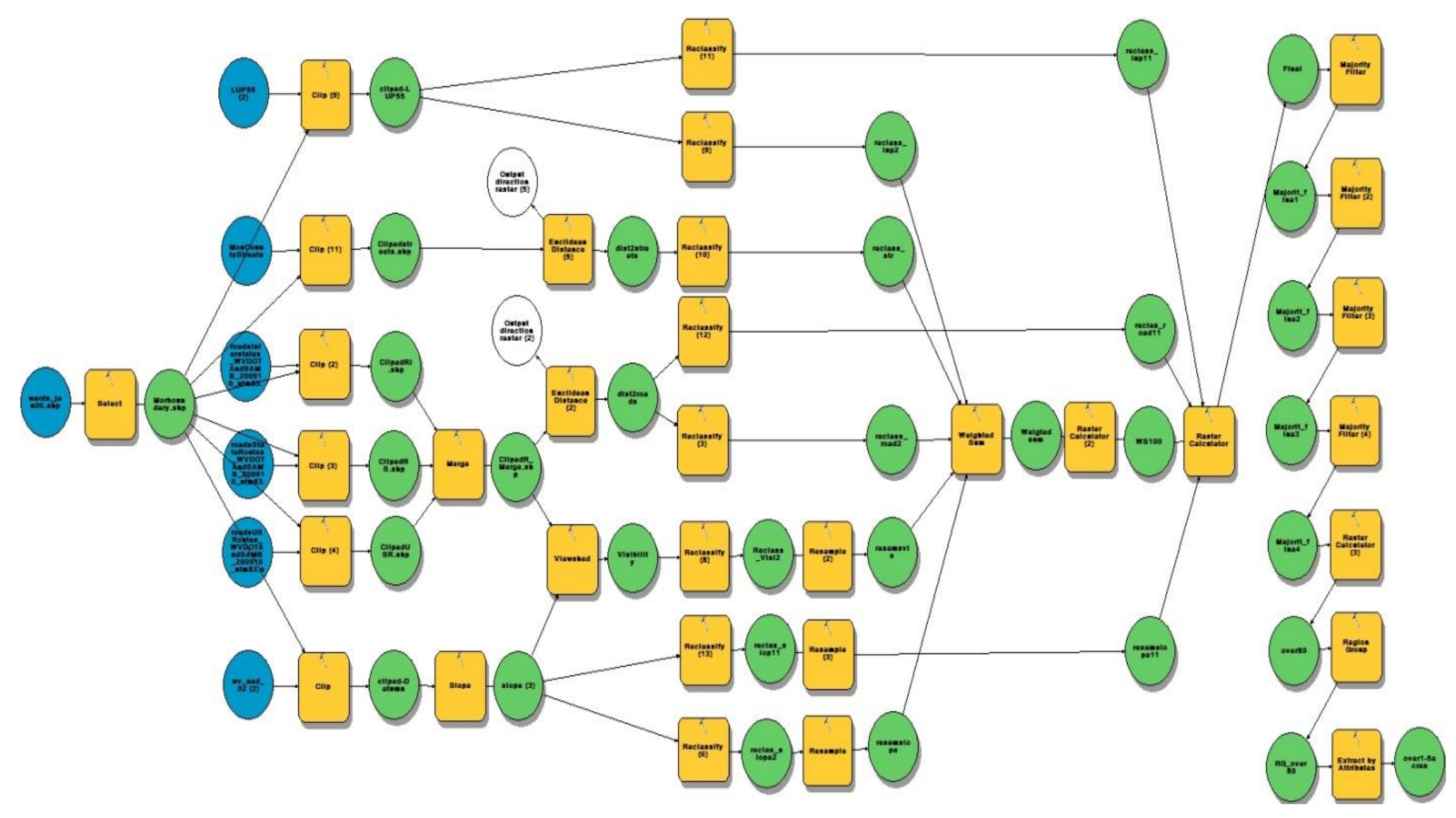

Figure 4.11 GIS model builder for land suitability analysis 
The final output of the LSA model is a colored map in which grid cells are ranked according to their overall suitability score (Figure 4.12). The higher ranked areas (score>80) are mainly clustered in seven recognizable locations. The largest location is located in Sabraton area (along Earl L. Core Road between Sabraton Avenue and Decker's Creek Boulevard). Other suitable locations are located in Downtown/Wharf District area (along High Street and University Avenue), Sunnyside area (along Beechurst Avenue), Waterfront corridor (along Don Knotts Boulevard), Suncrest area (along University Avenue), Van Voorhis Road corridor, and E Brockway Avenue area (between E Brockway Avenue and Deckers Creek Trail). These clusters are considered as a set of candidate supply points for using in the proposed spatial optimization model, described in next section. 


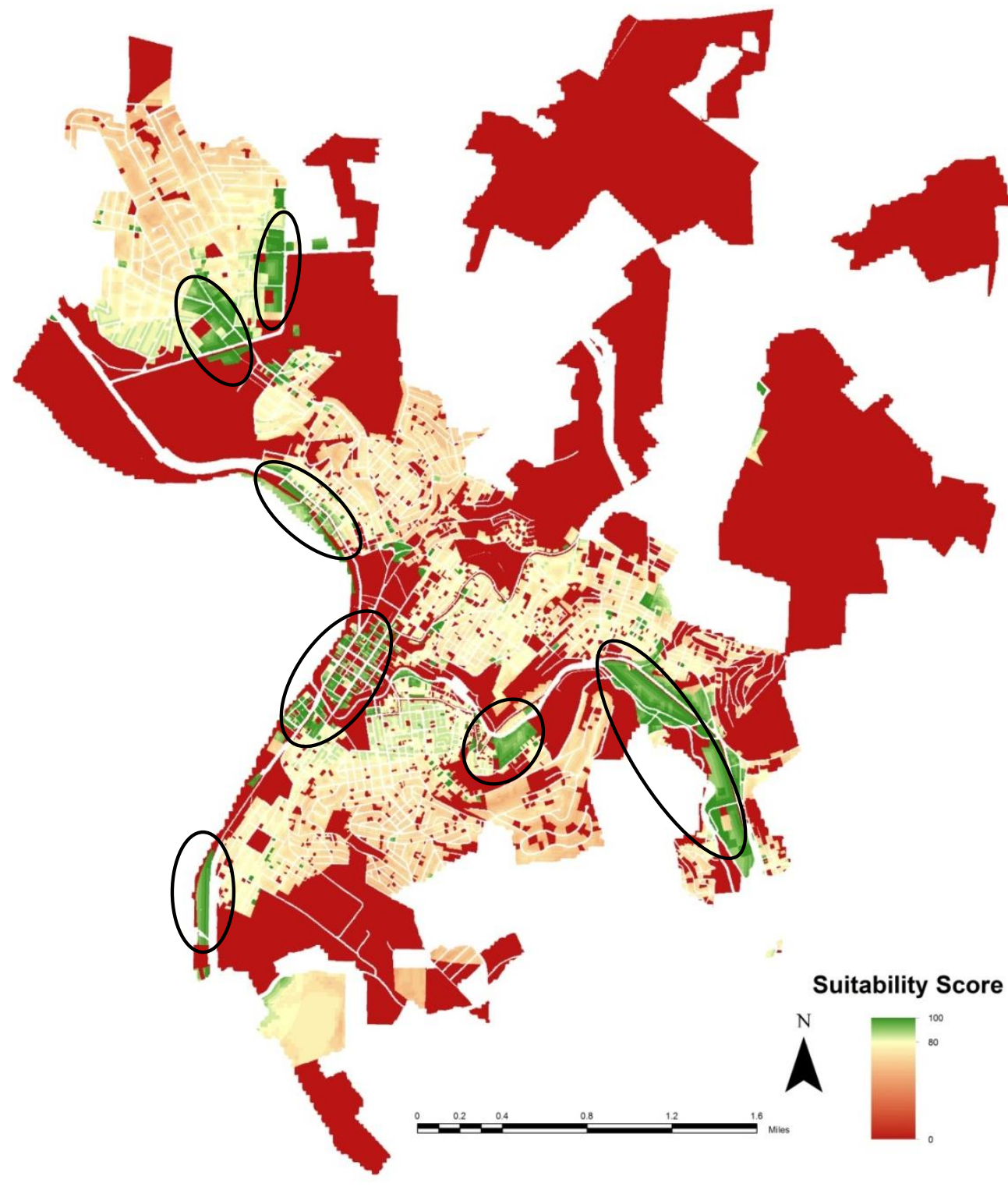

Figure 4.12 Overall suitability scores 


\section{IV.5 Application of spatial optimization model}

In this research the Microsoft Excel's LP/IP solver has been selected for simulation purpose, since it allows us to link two subcomponents of proposed spatial optimization model (optimal facility location model and optimal shopping frequency model). Model inputs can be divided into two groups. The first group consists of those inputs which are constructed using information from the spatial database (see Figure 3.5). It includes the population data and minimum distance matrix. The second group contains parameters such as trip rate, transportation unit cost, storage unit cost, sale price of shopping basket and price elasticity. These parameters are estimated using the available data sources. The final output of the spatial optimization model is a table in which values of objective function for various spatial configurations are represented in terms of daily passenger miles traveled (PMT/day). The following sections describe model inputs and outputs.

\section{IV.5.1 Inputs}

The input variables of spatial optimization model are as follows:

1. After determining the set of candidate points, the area of Morgantown was divided into 7 smaller zones using the Voronoi diagram. Voronoi diagram is a method of dividing an area into a number of polygons (called Voronoi cell) so that each polygon contains one generating point (called site). In this method every point within a given Voronoi cell is closer to its generating site than to any other sites. The result of zoning procedure is represented in Figure 4.13 where each of seven generating sites is represented by a polygon. 


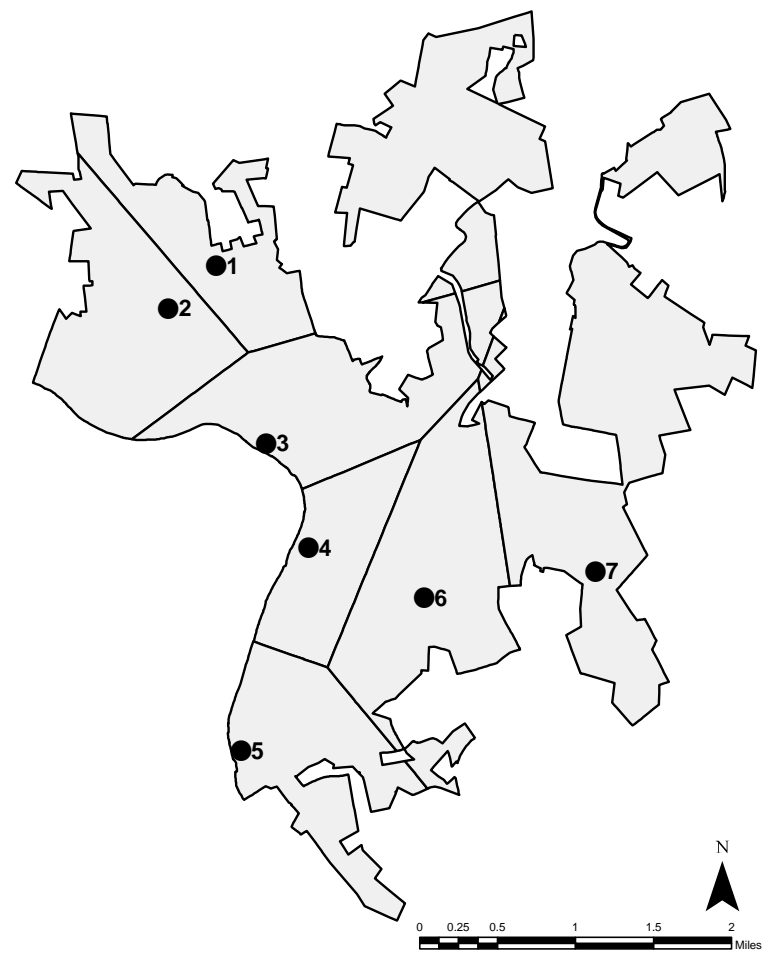

Figure 4.13 Proposed zoning map

Using this zoning system, one can argue that all people live in a given zone will firstly choose their generating site for shopping, since it is closer to them than all other generating sites (in other zones). In other word, the first choice of people live in zone $\mathrm{i}$ is site $\mathrm{i}$. The zoning system was utilized to assign population to each of seven candidate sites using the census block data (see Figure 4.8). The total number of people assigned to each zone is represented in Figure 4.14 . 


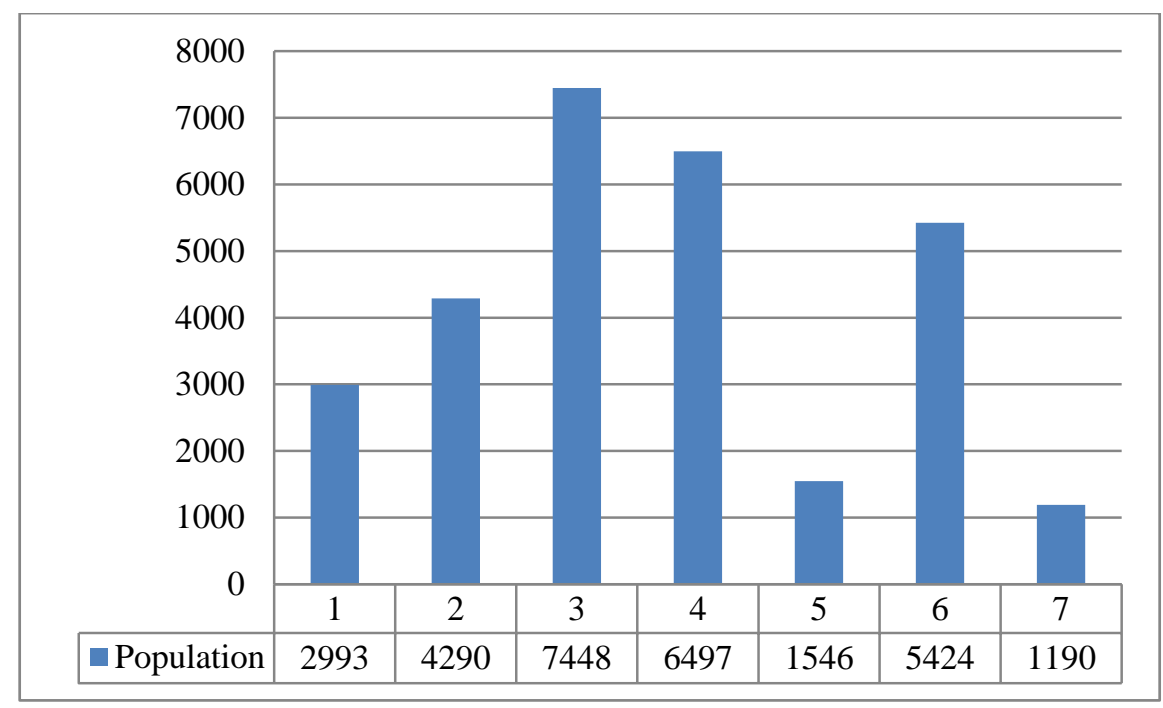

Figure 4.14 Total number of people by each zone

2. The distance matrix was calculated using Network Analyst tools of ArcGIS (Table 4.4). Each cell of matrix (dij) shows the average of the least-cost paths along the street network from centroid of all census blocks in origin zone $\mathrm{i}$ to the generating point of destination zone $\mathrm{j}$.

Table 4.4

Minimum distance matrix - Unit: Miles

\begin{tabular}{lccccccc}
\hline & Zone 1 & Zone 2 & Zone 3 & Zone 4 & Zone 5 & Zone 6 & Zone 7 \\
\hline Zone 1 & 1.31 & 1.55 & 2.19 & 2.82 & 4.18 & 3.61 & 4.12 \\
Zone 2 & 1.16 & 0.83 & 1.82 & 2.55 & 3.90 & 3.43 & 4.37 \\
Zone 3 & 1.56 & 1.43 & 0.72 & 1.20 & 2.56 & 2.03 & 2.80 \\
Zone 4 & 2.59 & 2.42 & 1.15 & 0.47 & 1.57 & 1.10 & 2.32 \\
Zone 5 & 3.82 & 3.65 & 2.35 & 1.49 & 0.81 & 2.06 & 3.09 \\
Zone 6 & 3.30 & 3.12 & 1.89 & 1.19 & 1.98 & 1.16 & 1.95 \\
Zone 7 & 3.92 & 3.89 & 2.97 & 2.59 & 3.68 & 1.89 & 1.09 \\
\hline
\end{tabular}


3. The precise value of trip rate depends on local socio-economic and physical parameters such as income level, car ownership rate, transportation network characteristics, topography, and type of food products. Here, in the absence of detailed local data, the Institute of Transportation Engineers (ITE) trip generation manual was used for rough estimation of initial value of trip frequency rate. According to ITE manual, the trip rate, afternoon PM peak hour, of a supermarket (code 850) is 9.48 trips per 1000 square feet of space. Using this rate and assuming 2.157 square feet per person as the average supermarket space per capita for typical American cities (Cotterill \& Franklin, 1995), the average trip rate for a food and beverage store $(f)$ is estimated to be equal to 0.3 trips per day per person. This value was used as the initial value of variable $f$ in equation 19 (The precise values are calculated by model).

4. Transportation cost per unit of distance $(c)$ is calculated by summation of internal transportation unit costs (vehicle ownership, vehicle operation, travel time, parking, road facilities and crash cost) in Figure 3.8. The estimated value is equal to 0.7 U.S \$ per Passenger Miles Traveled (PMT).

5. Storage cost $(S)$ was estimated to be 0.5 U.S \$ per shopping basket of food and beverage. A shopping basket was defined as basket of food and beverage purchase per person per day and its quantity is represented by $X$.

6. Sale price of a shopping basket $\left(P^{*}\right)$ was calculated based on the data from US Census Bureau's Annual Retail Trade Survey (US Census Bureau, 2013) (see Table 4.5). As can be seen each person has spent 2012 \$/year in food and beverage stores (NAICS code 445). Therefore we can assume that the sale price of a shopping basket is $5.5 \$$. 
Table 4.5

Estimated U.S. Per Capita Retail Sales by Kind of Business-Year 2012

\begin{tabular}{ccc}
\hline NAICS Code & Kind of business & Per capita spending \\
\hline 441 & Motor vehicle and parts dealers & 2,851 \\
442 & Furniture and home furnishings store & 302 \\
443 & Electronics and appliance stores & 328 \\
444 & Building mat. and garden equip. and supplies dealers & 939 \\
445 & Food and beverage stores & 2,012 \\
446 & Health and personal care stores & 878 \\
447 & Gasoline stations & 1,758 \\
448 & Clothing and clothing access. stores & 769 \\
451 & Sporting goods, hobby, book, and music stores & 271 \\
452 & General merchandise stores & 2,070 \\
453 & Miscellaneous store retailers & 360 \\
454 & Nonstore retailers & 1,301 \\
722 & Food services and drinking places & 1,672 \\
\hline
\end{tabular}

Note: From (US Census Bureau, 2013)

7. Finally we can generate the demand curve for a general food and beverage basket if we know one point (point $A_{0}$ ) on the line and slope (or price elasticity). The price elasticity was estimated based on the research conducted by Andreyeva et al. (2010). They have suggested the next table (Table 4.6) as the best approximation for mean price elasticity of 16 food and beverage groups. The average price elasticity is equal to 0.6 . In other word, with a $1 \%$ change in final price of shopping basket, the change in purchased quantity (basket size) will be $0.6 \%$. 
Table 4.6

US price elasticity estimates, by food and beverage category, from 1938 - 2007

\begin{tabular}{|c|c|}
\hline Food and Beverage Category & Absolute Value of Mean Price Elasticity Estimate (95\% CI) \\
\hline Food away from home & 0.81 \\
\hline Soft drinks & 0.79 \\
\hline Juice & 0.76 \\
\hline Beef & 0.75 \\
\hline Pork & 0.72 \\
\hline Fruit & 0.70 \\
\hline Poultry & 0.68 \\
\hline Dairy & 0.65 \\
\hline Cereals & 0.60 \\
\hline Milk & 0.59 \\
\hline Vegetables & 0.58 \\
\hline Fish & 0.50 \\
\hline Fats/oils & 0.48 \\
\hline Cheese & 0.44 \\
\hline Sweets/sugars & 0.34 \\
\hline Eggs & 0.27 \\
\hline Average & 0.60 \\
\hline
\end{tabular}

Note: Reproduced from (Andreyeva et al., 2010, p. 219)

Also, we have a known point on the demand line. The coordination of this point can be calculated by putting the following known parameters (average value of typical American cities) in the Reinhardt's equations:

$f_{0}=0.3 \mathrm{trip} / \mathrm{day} / \mathrm{person}$

$\mathrm{P}^{*}=5.5 \$$ (for a shopping basket)

$S=0.5$ U.S $\$$ per shopping basket 


\section{$C=0.7$ U.S \$ per PMT}

Using the above coefficients the estimated final price (summation of sale price, transportation cost, and storage cost) for one shopping basket $\left(X_{0}=1\right)$ is equal to 7.30 dollars $\left(P_{0}\right.$ $=7.30$ ). The estimated demand curve and demand function equation were shown in Figure 4.15 and equation 32 .

$$
P=19.5-12.2 X
$$

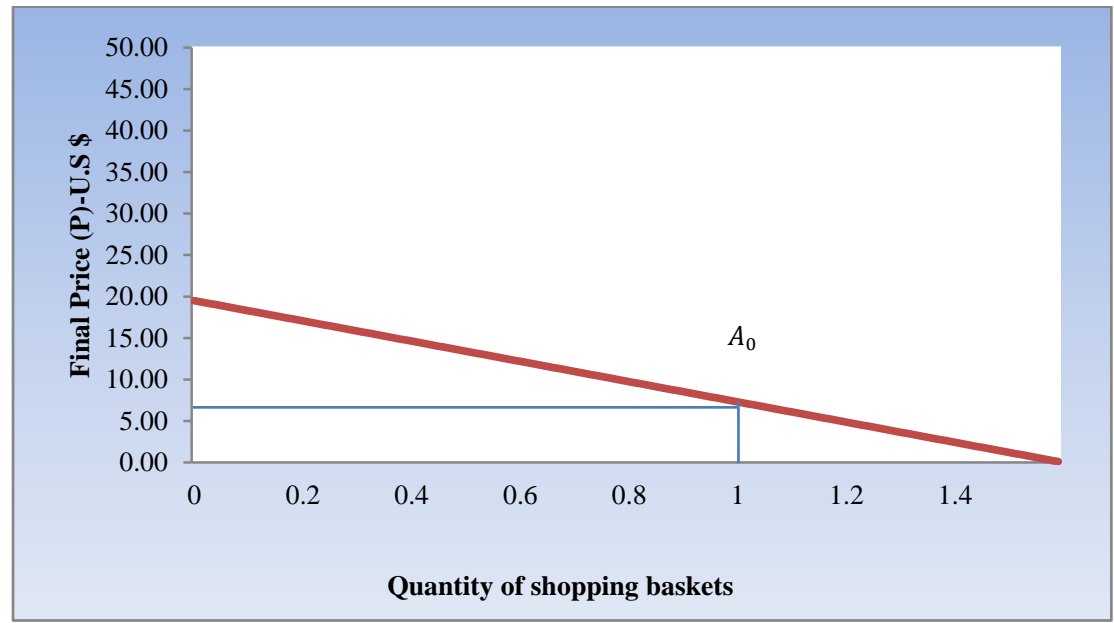

Figure 4.15 Estimated demand curve for food and beverage basket

\section{IV.5.2 Results of computer simulation (outputs)}

The results of applying the model for food and beverage stores in Morgantown are explained in this section. The simulation result begins with an output summary table for the monocentric pattern $(\mathrm{P}=1)$ which is the simplest scenario. In this scenario all stores are assumed to be located in one center and the proposed model finds the best center among candidates $(\mathrm{N}=7)$ for locating them. The value of the objective function (PMT/day) for each location has been 
presented in terms of daily passenger miles traveled. As can be seen center 4 is the optimum solution, since the value associated with its objective function is minimal. The next solutions were achieved and ranked by dropping out the previous optimum solutions and re-running the model. The precise value of trip frequency rates (trip/day) from demand points to selected supply points are also presented in Table 4.7.

Table 4.7

Summary of model output for monocentric pattern $(p=1)$

\begin{tabular}{cccccccccc}
\hline Center & Rank & $\begin{array}{c}\text { Objective } \\
\text { function }\end{array}$ & $f_{1}$ & $f_{2}$ & $f_{3}$ & $f_{4}$ & $f_{5}$ & $f_{6}$ & $f_{7}$ \\
\hline 1 & 5 & 36357 & 0.377 & 0.402 & 0.343 & 0.261 & 0.211 & 0.229 & 0.208 \\
2 & 4 & 35132 & 0.344 & 0.478 & 0.359 & 0.272 & 0.217 & 0.236 & 0.209 \\
3 & 2 & 30326 & 0.286 & 0.316 & 0.515 & 0.404 & 0.276 & 0.310 & 0.243 \\
4 & 1 & 29238 & 0.249 & 0.263 & 0.393 & 0.641 & 0.351 & 0.395 & 0.261 \\
5 & 6 & 38580 & 0.200 & 0.209 & 0.263 & 0.342 & 0.483 & 0.302 & 0.216 \\
6 & 3 & 34543 & 0.218 & 0.224 & 0.298 & 0.413 & 0.296 & 0.402 & 0.310 \\
7 & 7 & 40916 & 0.203 & 0.196 & 0.250 & 0.277 & 0.237 & 0.304 & 0.415 \\
\hline
\end{tabular}

As can be seen Downtown/Wharf District (along High Street and University Avenue) is the best spot and Suncrest area (along University Avenue), Sunnyside area (along Beechurst Avenue), Sabraton area (along Earl L. Core Road between Sabraton Avenue and Decker's Creek Boulevard), Waterfront corridor (along Don Knotts Boulevard), Van Voorhis Road corridor and E Brockway Avenue area (between E Brockway Avenue and Deckers Creek Trail) are respectively ranked in lower positions. Figure 4.16 illustrates an interpolated ranking map of monocentric scenario which was generated using Inverse Distance Weighted (IDW) technique. 
The IDW interpolation technique is based on the assumption that cells are close to one another are more alike than those are farther apart.

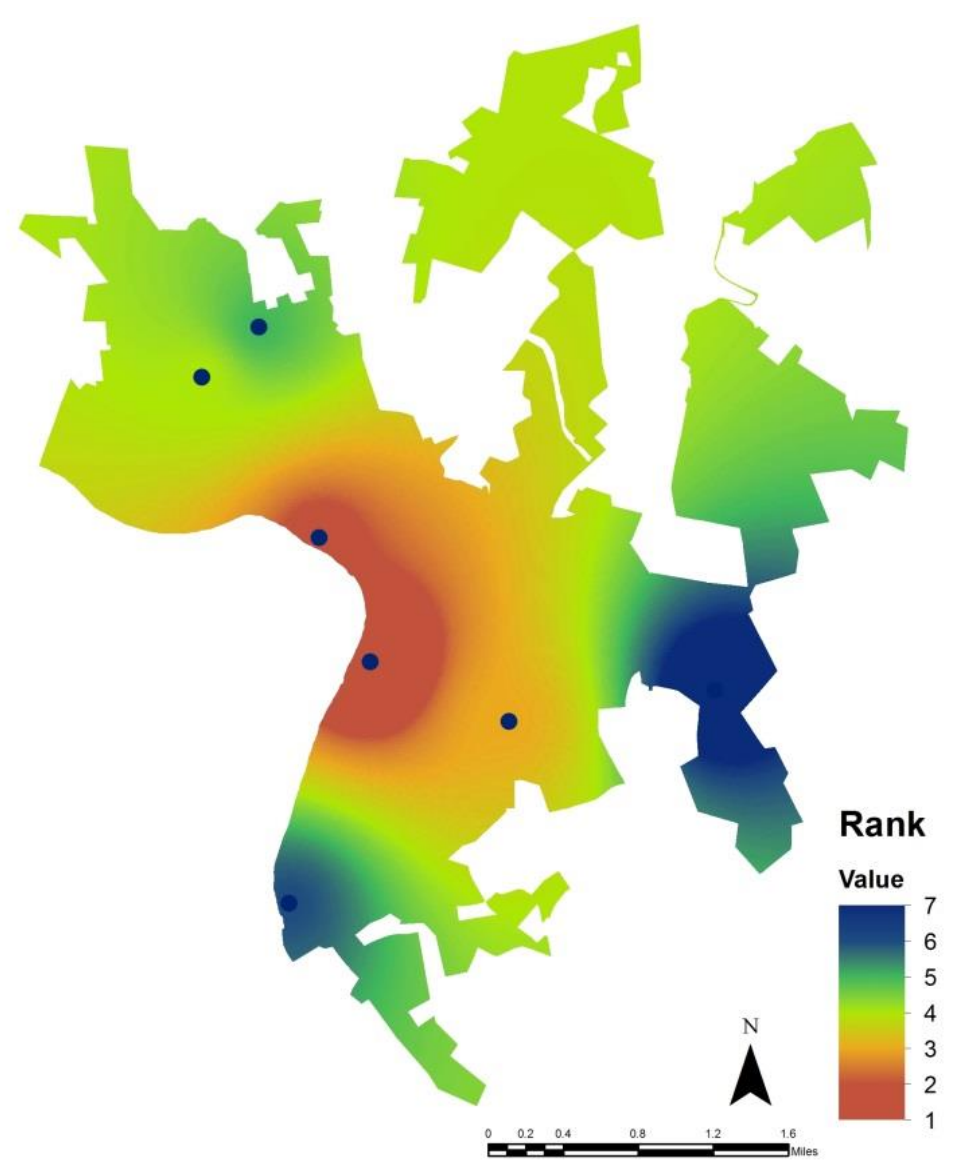

Figure 4.16 Interpolated ranking map of monocentric scenario

The polycentric pattern scenarios $(\mathrm{P}=2 \ldots \mathrm{N})$ are also simulated and the optimal spatial configuration for each scenario is in Table 4.8. The total number of possible spatial configurations in each scenario is equal to $\mathrm{C}(\mathrm{N}, \mathrm{P})=\mathrm{N}$ ! / $\mathrm{P} !(\mathrm{N}-\mathrm{P})$ !. 
Table 4.8

Summary of model output for polycentric patterns $(p=2 \ldots 7)$

\begin{tabular}{ccccccccccc}
\hline Scenario & $\begin{array}{c}\text { Possible } \\
\text { spatial } \\
\text { configurations }\end{array}$ & $\begin{array}{c}\text { Optimal } \\
\text { Spatial } \\
\text { Configuration }\end{array}$ & $\begin{array}{c}\text { Objective } \\
\text { function }\end{array}$ & $f_{1}$ & $f_{2}$ & $f_{3}$ & $f_{4}$ & $f_{5}$ & $f_{6}$ & $f_{7}$ \\
\hline $\mathrm{P}=2$ & 21 & $2 \& 4$ & 25870 & 0.344 & 0.478 & 0.393 & 0.641 & 0.351 & 0.395 & 0.261 \\
$\mathrm{P}=3$ & 35 & $2 \& 3 \& 4$ & 24362 & 0.344 & 0.478 & 0.515 & 0.641 & 0.351 & 0.395 & 0.261 \\
$\mathrm{P}=4$ & 35 & $2 \& 3 \& 4 \& 7$ & 23828 & 0.344 & 0.478 & 0.515 & 0.641 & 0.351 & 0.395 & 0.415 \\
$\mathrm{P}=5$ & 21 & $2 \& 3 \& 4 \& 5 \& 7$ & 23420 & 0.344 & 0.478 & 0.515 & 0.641 & 0.483 & 0.395 & 0.415 \\
$\mathrm{P}=6$ & 7 & $1 \& 2 \& 3 \& 4 \& 5 \& 7$ & 23176 & 0.377 & 0.478 & 0.515 & 0.641 & 0.483 & 0.395 & 0.415 \\
$\mathrm{P}=7$ & 1 & $1 \& 2 \& 3 \& 4 \& 5 \& 6 \& 7$ & 23136 & 0.377 & 0.478 & 0.515 & 0.641 & 0.483 & 0.402 & 0.415 \\
\hline
\end{tabular}

The simulation results are depicted in Figure 4.17. The blue points show the value of the objective function for the optimal spatial configuration (optimal solutions) in each scenario $(\mathrm{p}=1 \ldots 7)$ and the red points show the maximum value of the objective function for first $(\mathrm{P}=1)$ and last scenarios $(\mathrm{P}=7)$. This figure is used to analyze the simulation results in terms of urban sustainability in the next section. The maximum objective function value belongs to the worst spatial configuration (pessimal solution) in the monocentric scenario which is equal to 40916 PMT/day and this value dramatically drops to 23136 PMT/day in the optimal spatial configuration of the polycentric scenarios. 


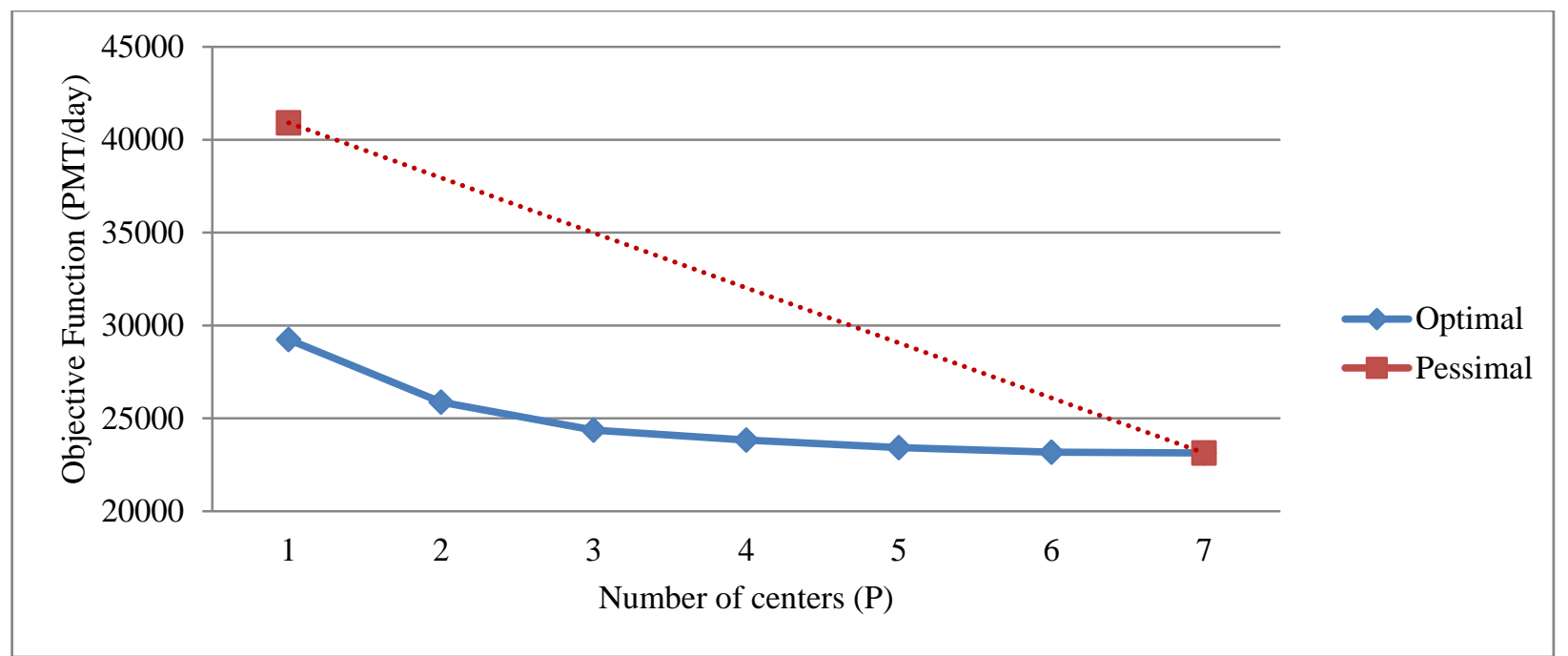

Figure 4.17 Value of objective function for different spatial configurations

\section{IV.6 Sustainability assessment}

This section presents the estimate of changes in the GPI due to the changes in the spatial arrangement of food and beverage stores in the city of Morgantown by using equation 33 (see Chapter III for details).

$$
\Delta G P I=\Delta G D P \pm \sum_{i=1}^{N} \Delta E_{i}
$$

The right hand side of this equation has two parts. The first shows the change in GDP, which is assumed to be zero in the short run. The second part represents the change (depletion or addition) in the environmental, economic and social state of the city as a function of travel demand. The travel demand is also assumed to be a function of changes in the spatial configuration of the selected urban facility determined by the estimated value of the objective functions in the proposed spatial optimization model (see Chapter III for details). As mentioned earlier the monetary unit value of the negative environmental, economic and social effects are adopted from VTPI study findings (see Figure 3.8; Table 3.1; and Table 3.2 for more detail). 
Figure 4.18 shows the negative effects for the best and the worst spatial configurations. In this figure the green items are those effects that are relevant to the natural capital (non-renewable resource depletion and environmental degradation) and blue and red items respectively show the human capital and physical capital categories.

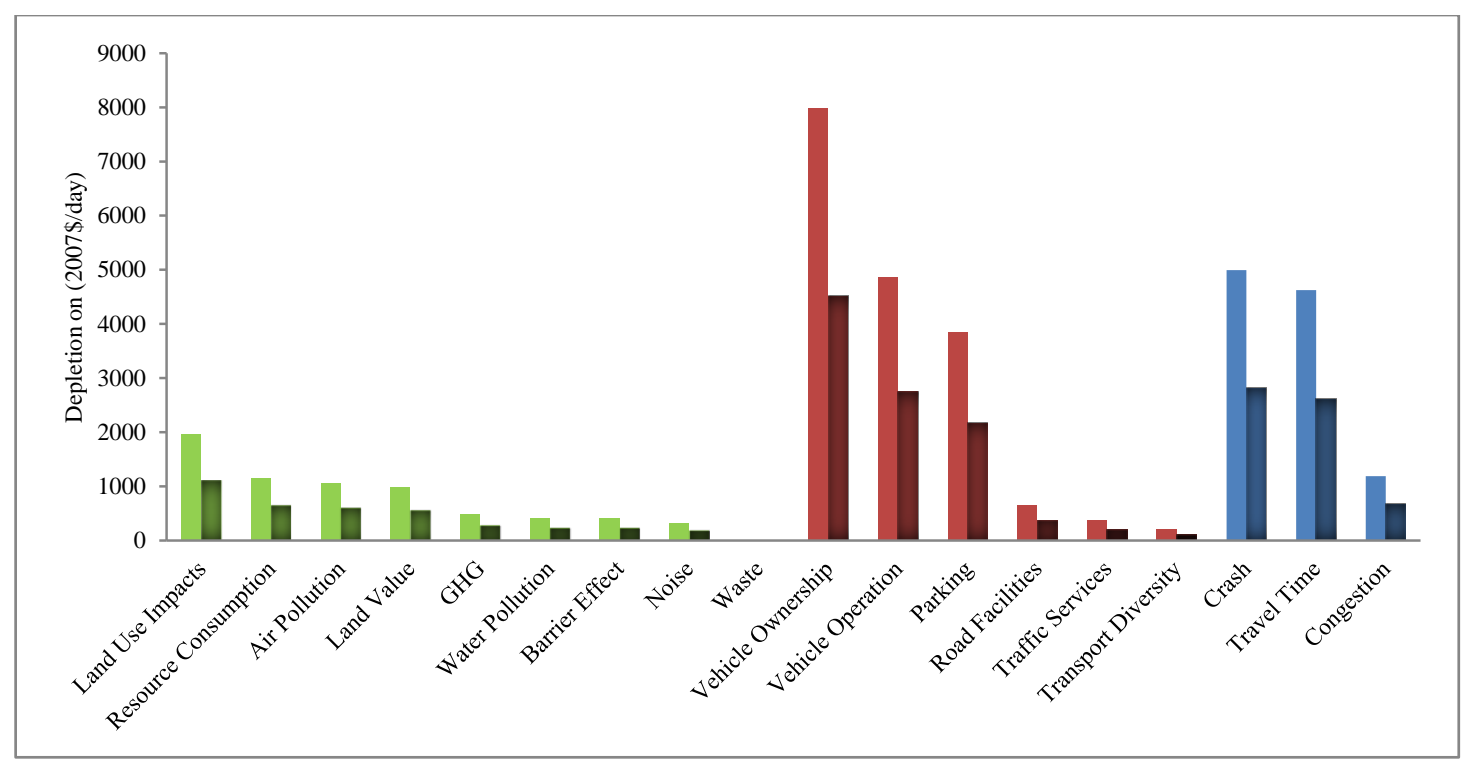

Figure 4.18 Comparison of negative effects (best and worst cases)

As discussed earlier these cost categories are also very similar to GPI indicators and can easily be converted and consolidated into the relevant components of GPI table (see Table 3.2). The following figure shows the difference between the value of GPI components in the best and worst cases. It includes the changes in government expenditure (G), household expenditure on consumer durables (D), depletion of natural capital and environmental degradation (NE), and decline of human capital and social degradation (HS), Sd (services generated by the existing stock of consumer durables) and Sg (services of government expenditures on highways and streets). It's noteworthy that first four components are calculated by using monetized estimates of transportation costs in Figure 3.8 and two last components are estimated by using the theory 
of consumer's surplus (see equations 30 and 31). Other GPI components (GDP, CFC, F, and Su) are assumed to be the same in all scenarios since these components are not sensitive to distance (at least in the short term). The last bar also shows the overall change in GPI level $(\triangle G P I)$ which is equal to 29631 \$day.

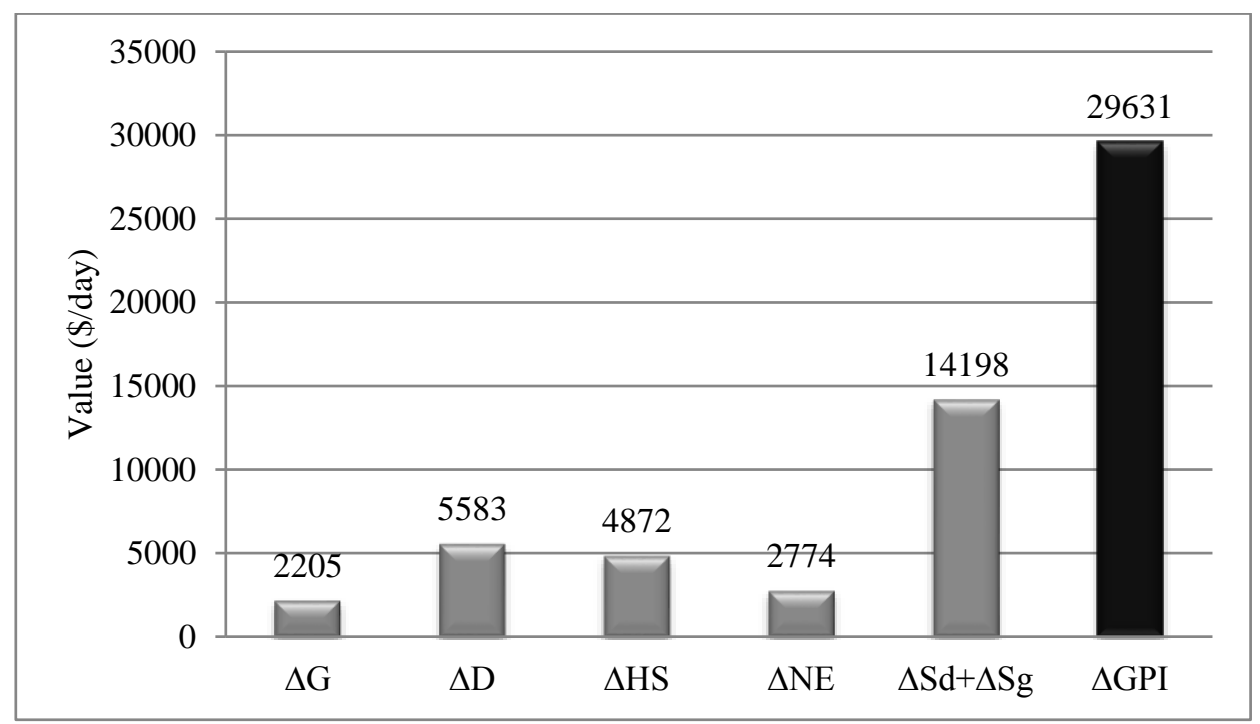

Figure 4.19 Changes in GPI and GPI components (best and worst cases)

Finally, the changes in GPI level has been categorized into four categories of reduction in natural, physical and human capital depletion/decline and increase of consumer surplus in the following chart. 


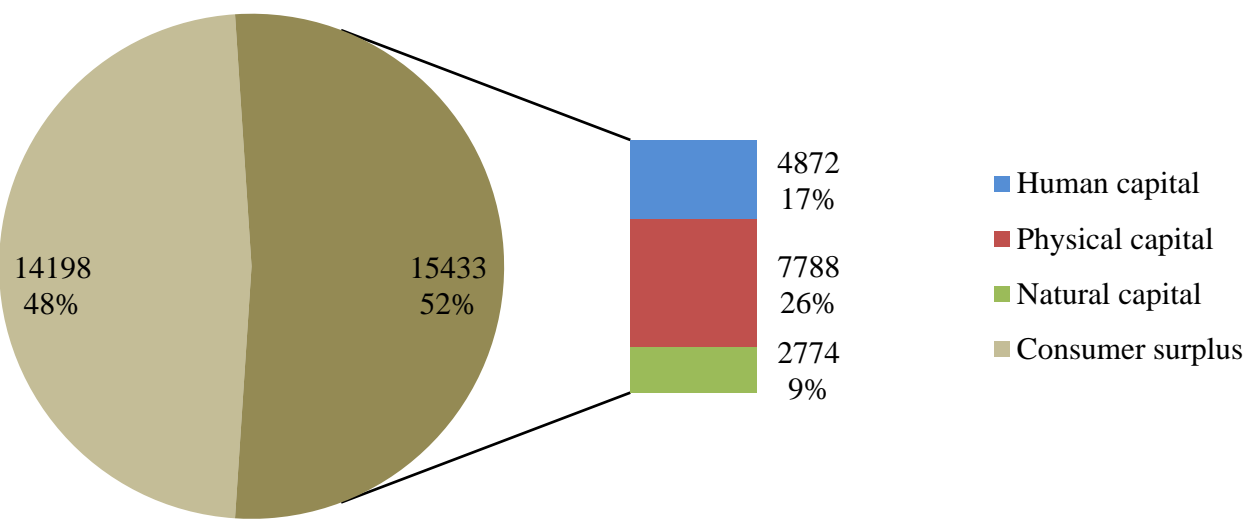

Figure 4.20 Changes in depletion/decline of capital stock and addition to consumer surplusUnit: \$day

The sustainability assessment indicates that by changing the spatial arrangement of the selected urban facility, the GPI level can dramatically rise or drop. The monetary value of the maximum increase is about $30000 \$ /$ day (or 10 million $\$ /$ year). About one-half of it comes from an addition to consumer welfare and the other half is because of reduced depletion/decline of capital stocks. A deeper discussion is given in the next chapter. 


\section{CHAPTER V}

\section{Discussion and Conclusion}

The purpose of this chapter is firstly to provide a more in-depth discussion of the findings from chapter IV, and secondly to provide a general conclusion on the impact of urban spatial structure on sustainable development, in particular the relationship between centrality and sustainability. For the first aim, the simulation results are demonstrated as a spectrum of monocentric, polycentric and hybrid forms and direction and magnitude of changes in components of GPI index for each scenario are interpreted. The methodological and data limitations as well as suggestions for future studies are discussed in the second section. Chapter IV closes with a conclusion section.

\section{V.1 Discussion}

In this section, a deeper analysis is carried out to interpret the results of simulation. Looking at the simulation result (Figure 4.17) we can interpret the results as follow:

- Optimal solution value has an inverse relationship with the number of supply centers (negative slope).The higher the number of centers, the lower the optimal solution value. Using this fact we can generally argue that the optimal polycentric spatial structures are more effective than the optimal monocentric pattern. The simulation result clearly indicates that the optimal polycentric scenarios can reduce the travel demand (in terms of PMT/day) up to 20 percent compared to the optimal monocentric scenario. This improvement is more than 40 percent when we compare the worst case of the monocentric scenario with the best case of the polycentric scenarios. 
- The equation of the optimal solution curve is nonlinear and shows a gradual decrease in slope as number of centers is increased. In other word, the simulation plot shows a gradual decrease along with the value of $\mathrm{p}$, but no more significant decrease beyond a certain point. This fact can help us to generalize the simulation findings to higher values of $\mathrm{P}$. As a result one can argue that decentralized pattern of activities is even better than polycentric pattern, but the difference is negligible.

- However the optimal solution value of the polycentric scenarios is lower than the optimal solution value of the monocentric, but we cannot conclude that the value of other feasible solutions of the polycentric scenarios are similarly lower than the value of other feasible solutions of monocentric. This fact can be seen in Figure 5.1. As a result, we cannot aver that all polycentric spatial configurations are necessarily better than monocentric spatial configurations.

- The polycentricity and decentralization of shopping activities results in two opposite effects. First, the travel distance between customers and suppliers tends to be shorter, since decentralization can bring the shopping centers (food and beverage stores) closer to residential areas. It's remarkable that this argument is exclusively applicable for activities such as shopping and we cannot generalize it to other trip purposes. In fact, this argument is based on the assumption that people travel to the closest center for shopping. This assumption is not valid for work trip purpose, since travel distance or travel time is not a main criterion for choosing the destination for work. In this case, employment and job opportunities can attract people from any residential areas (not closest) and origin and destinations are almost random (Bertaud, 2004). Consequently; despite the shopping trips, the work trip distance in polycentric 
structure may tend to be longer than monocentric. This point has been noticed by Gordon and Richardson (1996). They argue that "if metropolitan spatial structure is largely the result of the interaction between transportation and land use, a sub-centre anchored on a suburban mall may have more significance than one based on an industrial park, even if the latter generates more jobs" (Gordon \& Richardson, 1996, p. 290). The second effect of decentralization is related to trip frequency rate. The shopping frequency tends to be higher when the residential areas become closer to stores. The combination of these two opposite effects determines the overall value of travel demand (objective function of spatial optimization model).

- A diagram of conceptual urban spatial structure in relation to monocentric and polycentric patterns is represented in Figure 5.1. Using this diagram, the findings of this research can be generalized to the conceptual spatial structures proposed by Bertaud (2004) and Tsai (2005). In this framework the number of centers can be demonstrated as a spectrum of monocentric, polycentric and hybrid forms. Bertaud introduced his monocentric, mono-polycentric (hybrid), urban-village polycentric, and random-movement polycentric models to display the schematic representation of trip patterns within a metropolitan area. The compact monocentric, compact polycentric and decentralized models were also developed by Tsai to represent the centrality of spatial structure using the concept of clustering (see Figure 2.11 for detail). In Figure 5.1, the Bertaud's monocentric model and Tsai's compact monocentric model are located on the left end of the spectrum (point A), while the right extreme shows Bertaud's urban-village and random-movement polycentric model as well as the decentralized model of Tsai (points C and D). The hybrid 
structures such as mono-polycentric and compact polycentric models are located between these two extremes (point B). It's notable that urban-village polycentric model is a better model for shopping activities, while random-movement polycentric model is more appropriate for other type of activities such as work and business. The difference between these activities was explained earlier.

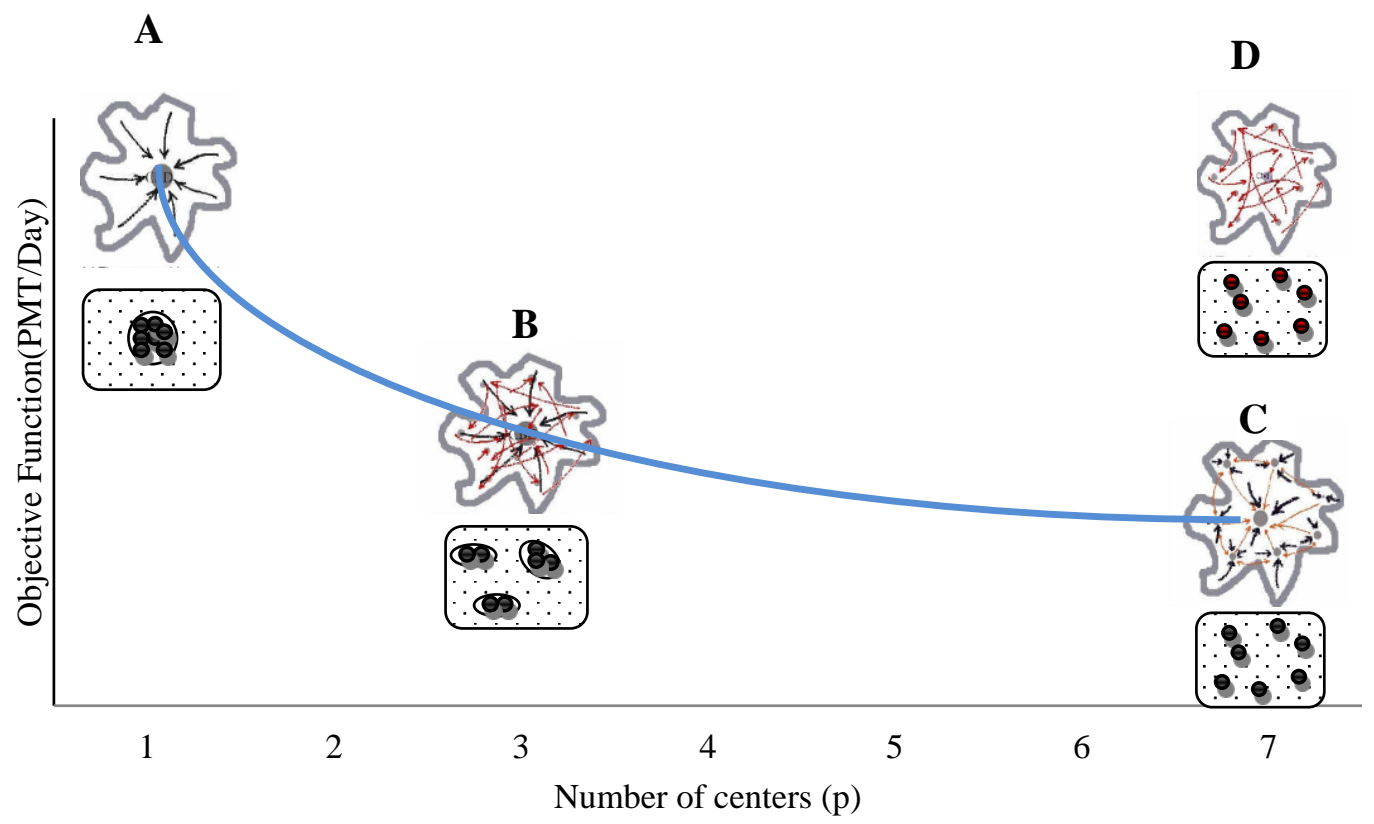

Figure 5.1 Conceptual models of urban spatial structure and simulation result

Source: The irregular polygons are from (Bertaud, 2004, p. 8) 
- In the context of sustainability, the simulation result answers to the main question of this research: polycentricity (or decentralization) of urban facilities is a better planning solution for achieving urban sustainability. However, as mentioned before, this conclusion is conditional and depends on type of urban facility and optimality of decentralization. The sustainability assessment shows how decentralization of food and beverage stores in Morgantown would result in a considerable increase in GPI index. The monetary value of the maximum increase is about $30000 \$ /$ day (or 10 million \$/year). About one-half of it comes from an addition to consumer welfare and the other half is because of reduced depletion/decline of capital stocks. Also, almost half of this reduction relates to physical capital, while reductions in the depletion of natural capital and decline of human capital are orderly equal to 17 and 33 percent (see Figure 4.20).

\section{V.2 Limitations and future works}

Although the proposed framework provides a useful tool for measuring the effects of urban spatial structure on sustainable development, there are still barrier and limitations to implement this framework. These can be categorized as methodology and data limitations. The methodological limitations are those that may restrict the ability of the model to simulate the real world and replicate it for all situations.

The first methodological limitation is rooted in the assumption that people always select the nearest urban facility to travel. This assumption is a typical assumption of p-median location models. Drezner (2007) explained that this assumption might be incorrect in many situations and proposed to use gravity p-median model to overcome this problem. As mentioned earlier, this assumption is valid for certain types of activities such as general shopping and it is not 
necessarily true for other activity types such as work and business. Even high-end shopping activities don't obey this rule. Analysis of other activity types is out of the scope of this research and we cannot generalize the results to all other urban facilities. Another reality is that shopping activity is no longer all about travel to physical stores. Today, the online shopping (or home shopping) forms a considerable part of trade and this fact can bias the result of optimal facility location and optimal shopping frequency models. Further studies can take advantage of these research findings and expand the simulation framework to include other types of urban activitiessuch as high end shopping, online shopping, work and business.

The second methodological limitation is related to the nature of urban trips. In this research the proposed model only captures single purpose shopping trips, while some researchers claim that the multipurpose shopping is an important aspect of shopping behavior. They argue that there is still a lack of a methodology for evaluating the relationship between shopping demand and the number and type of retail, supermarkets and shopping centers (Arentze, Oppewal, \& Timmermans, 2005; Popkowski Leszczyc, Sinha, \& Sahgal, 2004). More research is needed to measure the effects of urban spatial structure on consumer shopping behavior (choice of shopping trip purpose and destination).

Another important limitation is about the role of public transit and walking in shopping trips. However, share of walking and public transit mode in shopping trips are significantly smaller than other types of trip, especially in long distances, but still they can play an unavoidable role in access to the grocery stores, shopping centers and supermarkets (Daniels \& Mulley, 2011; Litman, 2013). Some planners also encourage smart growth policies through building stores near public transit stations in order to increase the share of public transportation 
in shopping activities. The current research doesn't cover these kinds of trips due to the lack of local data. A more detailed analysis is expected in future studies.

In addition, as the focus of the proposed spatial optimization model is to maximize the public sector benefits and consumer welfare, the model result may not maximize the producer surplus or private sector profits. This issue is challenging since there is usually a conflict between the interests and benefits of producers and consumer welfare. The multi-objective facility location model can be useful to overcome this challenge in future works.

The possible relationship between urban spatial structure and GPI's social sub-indicators is another opportunity for future studies. GPI has 25 sub-indicators (Table 3.1) among which 9 sub-indicators are directly related to human and social capital forms; these include value of household work and parenting, value of volunteer work, value of higher education, loss of leisure time, cost of commuting, cost of automobile accident, cost of underemployment, cost of crime, and cost of family breakdown. The focus of these sub-indicators in GPI accounting system is to deduct the regrettable costs to human and social capitals from GDP. These costs are treated as a positive factor in GDP accounting system since they increase the monetary exchanges in the marketplace. For instance, GDP counts household's expenditure on divorce lawyers or car accident fees as an addition to economic welfare. It is clear that these regrettable costs have negative effect on household's welfare, quality of life, and human and social well-being. Several GPI studies have used proxies to measure these social sub-indicators. For example Anielski and Rowe (1999) and Costanza et al. (2004) used cost of divorce and cost of television watching as two main proxies for cost of family breakdown. They assumed that the lack of time spent with family members due to television watching is one of the main reasons for decline in household's well-being and increase in divorce possibility. It is also clear that the recent popularization of 
social networks technology (such as Facebook and Instagram), beside the television watching, can intensify the possibility of divorce and increase the cost of family breakdown - and consequently reduce the overall GPI level. A number of GPI studies have emphasized measuring the cost of crime, illegal gambling, and other social costs that are not correctly measured by GDP; examples include Talberth, Cobb, \& Slattery (2007) and Hayward (2004). In this research, the proposed modeling framework captures the changes in only three human and social GPI subindicators - cost of automobile accident, loss of leisure time and cost of commuting - due to the changes in the pattern of urban spatial structure. These sub-indicators are clearly dependent on the geographical distance between locations of the selected urban facilities. Other social GPI sub-indicators are assumed to be constant before and after any changes in spatial configuration of the selected urban facilities. Therefore, these factors do not affect the overall change in GPI level $(\triangle G P I)$. More research is required to explore the possible relationship between urban centrality and these sub-indicators. We also assumed that monocentricity or polycentricity does not influence the income distribution of residents and wage gap between different social classes. Future studies might reject this basic assumption and change the outcome of the model.

Data limitation involves common issues of access to reliable data and information. In particular, data accessibility is very limited at the local level. One data issue is related to the input variables of the spatial optimization model, including trip generation rate, transportation unit cost, sale price, and price elasticity for food and beverage goods. Another data problem is associated with the estimation of GPI indicators at an urban scale. GPI is mainly applied for national level studies and their implications and applications for measuring sustainable development at urban and regional scale is one of the recent and hotly debated issues in academic literature (Bagstad \& Shammin, 2012; Clarke \& Lawn, 2008; S. M. Posner \& 
Costanza, 2011). Clarke and Lawn (2008) hold that lack of universal agreement about GPI subindicators and lack of uniformity in sub-national statistics are two main constraints for application of GPI at sub-national level. They argue that these issues become more challenging as the spatial unit becomes smaller from state to county to neighborhood. They also propose to substitute the proxy data for those that are not available by using any number of assumptions. The same approach was implemented in this research as previously described.

Finally, it's noteworthy that GPI includes a comprehensive set of environmental, economic, and social sub-indicators that contribute to quality of life and allows us in "separating out those things that we consume that make us "happier" and those that don't or even make us less happy" (Dietz \& Neumayer, 2006, p. 190) but still it is not a perfect measure of human and social well-being. This imperfection has many reasons which have been discussed by several researchers. For example see Bagstad and Shammin (2012) and Clarke and Lawn (2008). One of the main reasons is that "GPI is a consumption-based indicator" (S. Posner, 2010, p. 30). This research used GPI as the main metric for sustainability assessment, using other sustainability metrics in future researches may better reflect the changes in human and social well-being.

\section{V.3 Conclusion}

This dissertation contributed to understanding the mechanism through which the spatial structure of an urban area could affect the urban sustainability. In order to achieve the research goals -after reviewing relevant literature on sustainable development, urban spatial structure and their interrelationship- the analytical techniques and models were explored and an appropriate methodological framework was proposed based on this literature. The proposed framework allows us to simulate this mechanism, find the direction and measure the magnitude of changes in the urban sustainability level due to the changes in the spatial configuration of urban facilities. 
The changes in spatial configuration were modeled using a combination of optimal facility location model and optimal shopping frequency model. This framework was then applied to the study area of Morgantown, WV, using a set of scenarios for spatial distribution of food and beverage stores. These scenarios were demonstrated as a spectrum of monocentric, polycentric and hybrid forms. A sustainability assessment then conducted to evaluate the modeling results, using the Genuine Progress indicator (GPI). The findings were represented in terms of changes in components of GPI index, depletion/decline (or addition) of capital stock (natural, physical and human capital) and consumer surplus (welfare).

From a theoretical point of view, this dissertation provides a better insight on how the concepts of urban spatial structure, sustainable development, and wealth are related together. The quantitative relationship between these concepts has not been deeply analyzed in the academic literature, and therefore the proposed quantitative methodology and simulation framework can help to fill out this important research gap. The reasons for this research gap are many. The first reason is related to the lack of quantitative theories to analyze the contribution of urban spatial structure to sustainable development. This deficit was discussed in Chapter I. This gap becomes more remarkable, for instance, when we attempt to take into consideration all significant environmental, economic and social impacts of urban spatial structure (Fallström et al., 2009; Jabareen, 2006; S Salat, 2007).

Another reason is that the idea of using inclusive wealth - one that contains all forms of capital- as a key explanatory factor in sustainable development literature is relatively new. However, the capital approach could help significantly in assessing the urban spatial structure scenarios and enhance the ability to interpret the environmental, social and economic impacts in terms of sustainability but the estimation (quantification and valuation) of capital stock in the 
urban and regional level is very challenging (Bagstad \& Shammin, 2012; Clarke \& Lawn, 2008; S. M. Posner \& Costanza, 2011). To tackle this problem, this dissertation focused on measuring the changes of capital flow instead of measuring the changes in the stock of capital. The novelty of this approach is that the value of the total capital stock is not required for estimating and comparing various spatial configuration scenarios to find the most sustainable urban form. Instead, we just need to calculate the changes in the value of those capital flow components that are sensitive to distance. This allows us to narrow down the sustainability assessment to comparison of distance-based components of capital flow and ignore irrelevant variables. The GPI index was used as sustainability metric, since it measures the flow of capital and includes more than twenty five environmental, social and economic indicators; at least seventeen of them are directly or indirectly related to distance and transportation. Thus, GPI is a powerful quantitative tool to deal with urban spatial structure problems

From the practical point of view, the findings allow us to answer the main question of this research: to what extent the urban spatial structure can affect the pattern of urban sustainable development? The application of the proposed simulation framework for the selected urban facility (food and beverage stores) in the study area of Morgantown reveals that polycentric and decentralized spatial structures would result in a considerable increase in the GPI index (compare to the mono-centric structure). This finding supports those previous studies indicating that polycentric cities have stronger claims to sustainability than cities with monocentric spatial structure. However, the findings also indicate that this inference is not a general principle and would depend on the type of urban facility (land use) and optimality of decentralization (see Section V.1 for details). 
This research also does not claim that the findings are universally true for all urban scales, since polycentricity (decentralized development) and monocentricity (centralized development) are scale dependent phenomena (Hall \& Pain, 2006; Parr, 2004; Tsai, 2001). This fact (scale dependency) may explain the difference or contrast between the result of this research and those studies which claim that monocentric pattern, would be more efficient spatial structure when compared with polycentric and decentralized patterns. For example see the work of Bertaud (2004) and Tsai (2001). Instead, this research provides an integrated analytical framework which is applicable for various geographical scales and urban facilities. This framework is also an appropriate tool for simulating various morphological patterns of urban areas (other than polycentric and monocentric patterns) and measuring their effects on urban sustainable development.

The overall conclusion is that the urban spatial structure is one of the key builtenvironment factors that might have significant impacts on pattern of urban sustainable development. The proposed framework of this research can help planners, designers and decision makers to better understand the relationship between urban spatial structure, wealth, capital, welfare and sustainability and consequently they can better evaluate the environmental, social and economic advantage/disadvantages of their decisions. 


\section{REFRENCES}

Abdala, P. R. Z., \& MOCELLIN, A. (2010). Ecovillages and Permaculture: a Reference Model for Sustainable Consumption? Encontro da ANPAD, 34.

Akouayri, H. (2012). Air Pollution. StudyMode.com Retrieved 12, 2012, from http://www.studymode.com/essays/Air-Pollution-1263043.html

Alberti, M. (2000). Urban form and ecosystem dynamics: Empirical evidence and practical implications. Achieving sustainable urban form, 84-96.

Alberti, M. (2008). Modeling the urban ecosystem: a conceptual framework Urban Ecology (pp. 623-646): Springer.

Alonso, W. (1960). A theory of the urban land market. Papers in Regional Science, 6(1), 149157.

Alonso, W. (1964). Location and land use. Toward a general theory of land rent. London: Harvard University Press.

Anas, A. (1983). Discrete choice theory, information theory and the multinomial logit and gravity models. Transportation Research Part B: Methodological, 17(1), 13-23.

Anas, A. (1987). Modeling in urban and regional economics: Taylor \& Francis.

Anas, A., Arnott, R., \& Small, K. A. (1998). Urban spatial structure. Journal of economic literature, 1426-1464.

Anderson, W. P., Kanaroglou, P. S., \& Miller, E. J. (1996). Urban form, energy and the environment: a review of issues, evidence and policy. Urban Studies, 33(1), 7-35.

Andreyeva, T., Long, M. W., \& Brownell, K. D. (2010). The impact of food prices on consumption: a systematic review of research on the price elasticity of demand for food. American journal of public health, 100(2), 216.

Anielski, M. (2001). The Alberta GPI Blueprint. Pembina Institute for Appropriate Development, Drayton Valley, Alberta. Available at http://www. pembina. org/pdf/publications/gpi_blueprint. pdf [viewed 18 March 2003].

Anielski, M., \& Rowe, J. (1999). The Genuine Progress Indicator-1998 Update. Redefining Progress. San Francisco, CA.

Apparicio, P., Abdelmajid, M., Riva, M., \& Shearmur, R. (2008). Comparing alternative approaches to measuring the geographical accessibility of urban health services: Distance types and aggregation-error issues. International Journal of Health Geographics, 7(1), 7.

Arcosanti. (2014). Arcology Design.

Arentze, T. A., Oppewal, H., \& Timmermans, H. J. (2005). A multipurpose shopping trip model to assess retail agglomeration effects. Journal of Marketing Research, 42(1), 109-115.

Atkinson, G. (2008). Sustainability, the capital approach and the built environment. Building Research \& Information, 36(3), 241-247.

Aurand, A. G. (2007). Is Smart Growth Smart for Low-Income Households: A Study of the Impact of Four Smart Growth Principles on the Supply of Affordable Housing: ProQuest.

Bacon, R. W. (1984). Consumer spatial behaviour: a model of purchasing decisions over space and time: Clarendon Press Oxford.

Bacon, R. W. (1992). The travel to shop behaviour of consumers in equilibrium market areas. Journal of Transport Economics and Policy, 283-298.

Bagstad, K. J., \& Shammin, M. R. (2012). Can the Genuine Progress Indicator better inform sustainable regional progress?-A case study for Northeast Ohio. Ecological indicators, $18,330-341$. 
Bang, J. M. (2005). Ecovillages: A practical guide to sustainable communities: New Society Publishers.

Barbey, B. (1985). MOROCCO. Fez. Aerial view. The medina. .

Beckmann, M. J., \& Miksch, L. (1968). Location theory: Random House New York.

Bell, S., \& Morse, S. (2012). Measuring sustainability: learning from doing: Routledge.

Berechman, J., \& Small, K. A. (1988). Research policy and review 25. Modeling land use and transportation: an interpretive review for growth areas. Environment and Planning A, 20(10), 1285-1309.

Berry, B. J. L., \& Ginsburg, N. (1967). Geography of market centers and retail distribution: Prentice-Hall Englewood Cliffs, NJ.

Bertaud, A. (2001). Metropolis: A measure of the spatial organization of 7 large cities. Unpublished Working Paper, 1-22.

Bertaud, A. (2004). The spatial organization of cities: deliberate outcome or unforeseen consequence? IURD Working Paper Series. Berkeley: Institute of Urban and Regional Development.

Bertaud, A., \& Poole, R. (2007). Density in Atlanta: implications for traffic and transit. Policy Brief No. 61, Reason Foundation.

Birch, E. L. (1980). Radburn and the American planning movement: the persistence of an idea Journal of the American Planning Association, 46, 424-439.

Birch, E. L., \& Lynch, A. (2012). Measuring US Sustainable Urban Development State of the World 2012 (pp. 77-86): Springer.

Blériot, J. (2010). Vauban: a pioneering sustainable community in Germany, from http://www.ellenmacarthurfoundation.org/circular-economy/explore-more/initiativesaround-the-world/vauban-a-pioneering-sustainable-community-in-germany

Boyce, D. E., \& Southworth, F. (1979). Quasi-dynamic urban-location models with endogenously determined travel costs. Environment and Planning A, 11(5), 575-584.

Briassoulis, H. (2000). Analysis of land use change: theoretical and modeling approaches, from http://www.rri.wvu.edu/WebBook/Briassoulis/contents.htm

Brotchie, J. F., Dickey, J. W., \& Sharpe, R. (1980). TOPAZ-General planning technique and its applications at the regional, urban, and facility planning levels: Springer.

Brundtland, G. H., \& World Commission on Environment and Development. (1987). Our common future (Vol. 383): Oxford University Press Oxford.

Burger, A. (2012). Malaysia's Smart Eco-Village Includes 4-Level Aquaculture System, 3/15/2013, from http://www.triplepundit.com/2012/07/malaysias-smart-eco-villageincludes-4-level-aquaculture-system/

Burton, E. (1996). The compact city: a sustainable urban form? : Routledge.

Burton, E. (2000). The compact city: just or just compact? A preliminary analysis. Urban Studies, 37(11), 1969-2006.

Campbell, J. F. (1996). Hub location and the p-hub median problem. Operations Research, 44(6), 923-935.

Carbon Footprint. (2014). Merriam-Webster.com Retrieved 11, 2014, from http://www.merriam-webster.com/dictionary/carbon\%20footprint

Carey, H. C. (1859). Principles of social science (Vol. 3): JB Lippincott \& Company.

Carley, M., \& Christie, I. (2000). Managing Sustainable Development. London: Earthscan. 
Center for International Earth Science Information Network (Cartographer). (2005). Gridded Population of the World, Version 3 (GPWv3) Data Collection [raster digital data, map]. Retrieved from http://sedac.ciesin.columbia.edu/gpw/index.jsp

Cervero, R., \& Duncan, M. (2003). Walking, bicycling, and urban landscapes: evidence from the San Francisco Bay Area. Journal Information, 93(9).

Chan, Y. (2005). Location, transport and land-use: modelling spatial-temporal information: Springer.

Christaller, W. (1933). Die zentralen Orte in Suddeutschland. Translated by Carlisle W. Baskin, 1966, as Central Places in Southern Germany: Prentice Hall, Englewood Cliffs, NJ.

Clarke, M., \& Lawn, P. (2008). Is measuring genuine progress at the sub-national level useful? Ecological indicators, 8(5), 573-581.

Clough, R. H., Sears, G. A., \& Sears, S. K. (2005). Construction contracting: A practical guide to company management: J. Wiley.

CLRChoice. (2012). Morgantown Retail Sales Statistics Retrieved 2/15, 2015, from http://www.clrsearch.com/Morgantown-Demographics/WV/Retail-Sales-Statistics

Cobb, C., Halstead, T., \& Rowe, J. (1995). If the GDP is up, why is America down? ATLANTICBOSTON, 276, 59-79.

Colemanm, M. (2011). What would be the result of every country having same number of cars as the U.S has? Retrieved 11, 2014, from http://www.auto-types.com/autonews/whatwould-be-the-results-of-every-country-having-same-number-of-cars-as-the-us-has7993.html

Collins, M. G., Steiner, F. R., \& Rushman, M. J. (2001). Land-use suitability analysis in the United States: historical development and promising technological achievements. Environmental Management, 28(5), 611-621.

Cookson, A. (2012). Prosperity, Poverty or Extinction?: Humanity's Choices: Xlibris Corporation.

Corbusier, L. (1987). The city of to-morrow and its planning: Dover Publications.

Cornelissen, A. M. G., Berg, J., Koops, W., Grossman, M., \& Udo, H. (2000). Assessment of sustainable development: a novel approach using fuzzy set theory. Agriculture, Ecosystems \& Environment, 86(2), 173-185.

Costanza, R., Erickson, J., Fligger, K., Adams, A., Adams, C., Altschuler, B., . . Kelly, J. (2004). Estimates of the genuine progress indicator (GPI) for Vermont, Chittenden County and Burlington, from 1950 to 2000. Ecological economics, 51(1), 139-155.

Cotterill, R., \& Franklin, A. The Urban Grocery Store Gap. Storrs: Food Marketing Policy Center, University of Connecticut. 1995. Food Marketing Policy Issue Paper(8).

Cotterill, R., \& Franklin, A. (1995). The Urban Grocery Store Gap Food Marketing Policy Issue Paper(8).

Daly, H. E. (1990). Toward some operational principles of sustainable development. Ecological economics, 2(1), 1-6.

Daniels, R., \& Mulley, C. (2011). Explaining walking distance to public transport: the dominance of public transport supply. World, 28, 30.

Davidson, D. (1994). Corporate Amenities, Trip Chaining and Transportation Demand Management: Federal Transit Administration, Office of Technical Assistance and Safety.

Davis, D. L., \& Saldiva, P. H. N. (1999). Urban air pollution risks to children: a global environmental health indicator: World Resources Institute, Health, Environment and Development Program. 
De La Barra, T. (1989). Integrated land use and transport modelling. Decision chains and hierarchies: Cambridge University Press

Delucchi, M. A. (1997). The Annualized Social Cost of Motor-Vehicle Use in the US, 19901991: Summary of Theory, Data, Methods, and Results Social Costs and Sustainability (pp. 380-417): Springer Berlin Heidelberg.

Dempsey, N., Brown, C., Raman, S., Porta, S., Jenks, M., Jones, C., \& Bramley, G. (2010). Elements of urban form Dimensions of the sustainable city (pp. 21-51): Springer.

Dietz, S., \& Neumayer, E. (2006). Some constructive criticisms of the Index of Sustainable Economic Welfare: Edward Elgar.

DiPasquale, D., \& Wheaton, W. C. (1996). Urban economics and real estate markets: Prentice Hall Englewood Cliffs, NJ.

Downton, P. F. (2008). Ecopolis: architecture and cities for a changing climate (Vol. 1): Springer.

Dresner, S. (2008). The principles of sustainability: Routledge.

Drezner, T., \& Drezner, Z. (2007). The gravity p-median model. European Journal of Operational Research, 179(3), 1239-1251.

DS World's Lands. (2013). ACQUAINTANCE TO CURITIBA, from http://dslands.com/photo/cities/curitiba/02/

Eastman, J., Jin, W., Keym, P., \& Toledano, J. (1995). Raster procedures for multicreteria/multi-objective decisions. Photogrammetric Engineering and Remote Sensing, 61(5), 539-547.

Echenique, M., Crowther, D., \& Lindsay, W. (1969). A spatial model of urban stock and activity. Regional Studies, 3(3), 281-312.

Ellis, J. G. (2004). Explaining Residential Density [Research \& Debate]. Places, 16(2).

Eppli, M., \& Shilling, J. (1996). How critical is a good location to a regional shopping center? Journal of Real Estate Research, 12(2), 459-468.

European Space Agency. (2012). VOLGOGRAD BY NIGHT, from http://spaceinimages.esa.int/Images/2012/04/Volgograd_by_night

EUROSTAT. (2011). Sustainable Development in the European Union: 2011 Monitoring Report of the EU Sustainable Development Strategy: Publications office of the European Union.

Ewing, R. (1997). Is Los Angeles-style sprawl desirable? Journal of the American Planning Association, 63(1), 107-126.

Fallström, B., Marcus, L., \& Ström, P. (2009). Urban Form and Urban Capital. Paper presented at the 7th International Space Syntax Symposium, Stockholm.

Freedman, J. (1975). Crowding and Behavior: The Psychology of High-Density Living. New York: Viking Adult.

Fulton, W. (1995). Beyond Sprawl: New Patterns of Growth to Fit the New California. San Francisco: Bank of America.

Fulton, W. B., Pendall, R., Nguyen, M., \& Harrison, A. (2001). Who sprawls most?: How growth patterns differ across the US: Brookings Institution, Center on Urban and Metropolitan Policy Washington, DC.

Galster, G., Hanson, R., Ratcliffe, M. R., Wolman, H., Coleman, S., \& Freihage, J. (2001). Wrestling sprawl to the ground: defining and measuring an elusive concept. Housing policy debate, 12(4), 681-717.

Garnier, T., \& Mariani, R. (1990). Une cité industrielle: Rizzoli.

Gatti, R. F. Radburn;The town for motor age, from http://www.radburn.org/geninfo/history.html 
Gerster, G. (1977). Overview of Yazd, the world's biggest adobe city.

Gerster, G. (2013). The Ancient City of Firuzabad, from http://www.independent.co.uk/artsentertainment/art/features/paradise-lost-persia-from-above2261928.html?action $=$ gallery \&ino $=5$

Gilman, R. (1991). The eco-village challenge. Context, 29(10).

Girardet, H. (2004). Cities people planet: liveable cities for a sustainable world: WileyAcademy Chichester, UK.

Global Ecovillage Network. WHAT IS AN ECOVILLAGE? , from http://gen.ecovillage.org/ecovillages.html

Gordon, P., \& Richardson, H. W. (1996). Beyond polycentricity: the dispersed metropolis, Los Angeles, 1970-1990. Journal of the American Planning Association, 62(3), 289-295.

Gordon, P., \& Richardson, H. W. (1997). Are compact cities a desirable planning goal? Journal of the American Planning Association, 63(1), 95-106.

Government of Singapore. (2013). TIANJIN Eco-city, A Model For Sustainable Development. Retrieved from http://www.tianjinecocity.gov.sg/

Greene, D. L., \& Jones, D. W. (1997). The full costs and benefits of transportation: conceptual and theoretical issues. New York: Springer.

Hakimi, S. (1965). Optimum distribution of switching centers in a communication network and some related graph theoretic problems. Operations Research, 13(3), 462-475.

Hakimi, S. L. (1964). Optimum locations of switching centers and the absolute centers and medians of a graph. Operations Research, 12(3), 450-459.

Hall, P. G., \& Pain, K. (2006). The polycentric metropolis: learning from mega-city regions in Europe: Routledge.

Hamilton, K. (1994). Green adjustments to GDP. Resources Policy, 20(3), 155-168.

Hamilton, K. (2000). Genuine saving as a sustainability indicator. OECD Proceedings: Frameworks to Measure Sustainable Development, 65-78.

Hamilton, K., \& Clemens, M. (1999). Genuine savings rates in developing countries. The World Bank Economic Review, 13(2), 333-356.

Handy, S., Paterson, R. G., \& Butler, K. (2003). Planning for street connectivity: getting from here to there.

Hansen, W. G. (1959). How accessibility shapes land use. Journal of the American Institute of Planners, 25(2), 73-76.

Hardoy, J. E., Mitlin, D., \& Satterthwaite, D. (2001). Environmental problems in an urbanizing world: Earthscan.

Hart, M. (1995). Guide to sustainable community indicators: QLF/Atlantic Center for the Environment.

Hart, M. (2010). Sustainable Measures. http://www.sustainablemeasures.com/node/42 Retrieved 11,2014

Hayward, K., \& Atlantic, G. (2004). Costs and Benefits of Gaming: A Literature Review with Emphasis on Nova Scotia: GPI AAtlantic.

Herbert, J. D., \& Stevens, B. H. (1960). A Model for the Distribution of Residential Activity in Urban Areas. Journal of Regional Science, 2(2), 21-36.

Hicks, J. R. (1946). Value and capital (Vol. 2): Clarendon Press Oxford.

Hillier, B. (2009). Spatial sustainability in cities: Organic patterns and sustainable forms. Paper presented at the 7th International Space Syntax Symposium, Stockholm. 
HOLMGREN, D. (2007). Os Fundamentos da Permacultura. Traduzido por: Alexandre Van Parys e Amantino Ramos de Freitas. Austrália: Ecossistemas.

Holtgard, E. (2009). Framework for self sustaining eco-village. University of South Florida. Hotelling, H. (1929). Stability in competition. Economic Journal, 30, 41-57.

Howard, E., \& Osborn, F. J. (1965). Garden cities of to-morrow (Vol. 23): The MIT Press. Hunt, J. D. (2003). Design and application of the PECAS land use modelling system. Paper presented at the 8th International Conference on Computers in Urban Panning and Urban Management, Sendai, Japan.

Hunt, J. D., Kriger, D. S., \& Miller, E. J. (2005). Current operational urban land-use-transport modelling frameworks: A review. Transport Reviews, 25(3), 329-376.

IISD. (2013). Sustainability Indicator Systems, from http://www.iisd.org/foresightgroup/sis.aspx International Institute for Sustainable Development. (2007). Dashboard of Sustainability, from http://www.iisd.org/cgsdi/dashboard.asp

Irrgang, B. (2005). A study of the efficiency and potential of the eco-village as an alternative urban model. Stellenbosch: University of Stellenbosch.

Jabareen, Y. R. (2006). Sustainable Urban Forms Their Typologies, Models, and Concepts. Journal of Planning Education and Research, 26(1), 38-52.

Jackson, R. (2004). The ecovillage movement. Permaculture magazine, 40, 25-30.

Jacobs, J. (1961). The death and life of great American cities: Vintage.

Jacobs, J. (1992). The death and life of great American cities: Vintage.

Jiang-Ping, W., \& Qun, T. (2009). Urban planning decision using multi-objective optimization algorithm. Paper presented at the Computing, Communication, Control, and Management, 2009. CCCM 2009. ISECS International Colloquium on.

Joerin, F., Thériault, M., \& Musy, A. (2001). Using GIS and outranking multicriteria analysis for land-use suitability assessment. International Journal of Geographical Information Science, 15(2), 153-174.

Johnston, R. A., \& McCoy, M. C. (2006). Assessment of integrated transportation/land use models: Information Center for the Environment, Department of Environmental Science and Policy, University of California Davis.

Jonna, R., Neff, J., Livingston, G., Giles, E., \& Stutzman, D. (2005). Ecovillages and Urban Change in the US: A comparison of urban and suburban ecovillages. University of Oregon. Retrieved from http://design.uoregon.edu/nywc/arch/studio/arch484/2006/ecovil-papers/LAEV_EVIfinal.pdf

Joss, S., Tomozeiu, D., \& Cowley, R. (2011). Eco-Cities: A Global Survey 2011 (Eco-City Profiles): London: University of Westminster.

Kågeson, P. (1993). Getting the Price Right: A European Scheme for Making Transport Pay its True Costs. Stockholm and Brussels.

Kaiser, E. J., Godschalk, D. R., \& Chapin, F. S. (1995). Urban land use planning (Vol. 4): University of Illinois Press Urbana, IL.

Kannfinch. (2011). Masdar City Cetre, from http://www.kannfinch.com/\#/projects/masdar-citycentre

Kasper, D. (2008). Redefining community in the ecovillage. Human Ecology Review, 15(1), 1224.

Keirstead, J., \& Shah, N. (2013). The Changing Role of Optimization in Urban Planning Optimization, Simulation, and Control (pp. 175-193): Springer. 
Kenworthy, J., \& Laube, F. (2001). The Millennium Cities Database for Sustainable Transport.Database.

Kenworthy, J., Laube, F. B., Newman, P., Barter, P., Raad, T., Poboon, C., \& Guia Jr, B. (1999). An international sourcebook of automobile dependence in cities 1960-1990.

Kenworthy, J., Laube, F. B., Newman, P., Barter, P., Raad, T., Poboon, C., \& Guia Jr, B. (2000). An international sourcebook of automobile dependence in cities 1960-1990: University Press of Colorado.

Kenworthy, J. R., Laube, F. B., Newman, P., Barter, P., Raad, T., Poboon, C., \& Guia Jr, B. (2000). An international sourcebook of automobile dependence in cities 1960-1990: University Press of Colorado.

Khisty, C. J., \& Lall, K. (1990). Transportation Engineering: An Introduction: Prentice Hall, Englewood Cliffs, New Jersey.

Kirby, A. (2004). Domestic Protest: The Ecovillage Movement as a Space of Resistance, from http://bad.eserver.org/issues/2004/65/kirby.html

Koomen, E., \& Stillwell, J. (2007). Modelling land-use change: Springer.

Krugman, P. R. (1991). Geography and trade: MIT press.

Kulash, W., Anglin, J., \& Marks, D. (1990). Traditional neighborhood development: will the traffic work?

Kuzmyak, J. R., Pratt, R. H., Douglas, G. B., \& Spielberg, F. (2003). Traveler Response to Transportation System Changes. Chapter 15-LAnd Use and Site Design: transportation Research Board.

Landis, J., \& Zhang, M. (1998). The second generation of the California urban futures model. Part 1: Model logic and theory. Environment and Planning B, 25, 657-666.

Lautso, K. (2004). The Propolis Approach to Urban Sustainability - Theory and Results From Seven European Case Cities. Paper presented at the European Transport Conference 2004, Strasbourg, France.

Lautso, K., Spiekermann, K., Wegener, M., Sheppard, I., Steadman, P., Martino, A., . . . Echenique, M. E. P. M. (2004). Planning and research of policies for land use and transport for increasing urban sustainability Final report. Dortmund: Institute of Spatial Planning (IRPUD).

Lautso, K., \& Toivanen, S. (1999). SPARTACUS system for analyzing urban sustainability. Transportation Research Record: Journal of the Transportation Research Board, 1670(1), 35-46.

Litman, T. (1996). Transportation cost analysis for sustainability: Victoria Transport Policy Institute.

Litman, T. (2009). Transportation cost and benefit analysis: Victoria Transport Policy Institute.

Litman, T. (2013). Evaluating Active Transport Benefits and Costs: Guide to Valuing Walking and Cycling Improvements and Encouragement Programs.

Lösch, A., Woglom, W. H., \& Stolper, W. F. (1954). The economics of location (Vol. 1940): Yale University Press New Haven.

Lowry, I. S. (1964). A model of metropolis $R M-4035-R C$. Santa Monica, CA: Rand Corporation.

Lynch, K. (1981). Good city form: The MIT Press.

MacKenzie, J. J., Dower, R. C., \& Chen, D. D. (1992). The going rate: what it really costs to drive: World Resources Institute Washington, DC.

Malczewski, J. (2004). GIS-based land-use suitability analysis: a critical overview. Progress in Planning, 62(1), 3-65. 
Maoh, H., \& Kanaroglou, P. (2009). A tool for evaluating urban sustainability via integrated transportation and land use simulation models. Environnement Urbain, 3.

Mavin, D. (2010). Hong Kong Air Quality 'Severe' Retrieved 2/18/2014, from http://blogs.wsj.com/chinarealtime/2010/03/23/hong-kong-air-quality-severe/

Maxwell, I. E. (2009). Managing sustainable innovation: the driver for global growth: Springer.

McFadden, D. (1974). Conditional logit analysis of qualitative choice behavior. In P. Zarembka (Ed.), Frontiers of Econometrics. ConditioNew York, NY: Academic Press.

Metcalf, R. (2008). Mesa del Sol Reshapes Region, from http://nreionline.com/news/areas/forest_citys_mesa_delsol_0301

Meurs, H., \& Haaijer, R. (2001). Spatial structure and mobility. Transportation Research Part D: Transport and Environment, 6(6), 429-446.

Mobaraki, O., Mohammadi, J., \& Zarabi, A. (2012). Urban form and sustainable development: The case of Urmia City. Journal of Geography and Geology, 4(2), p1.

Moffatt, S., Suzuki, H., \& Iizuka, R. Eco² Cities Guide: World Bank.

Morgantown Planning Commission. (2013). Comprehensive Plan, City of Morgantown. Morgantown.

Morris, A. E. J., \& Morris, A. (1994). History of urban form: before the industrial revolutions: Longman scientific \& technical Essex.

Muller, N. Z., Mendelsohn, R., \& Nordhaus, W. (2011). Environmental accounting for pollution in the United States economy. The American Economic Review, 101(5), 1649-1675.

Mumford, L. (1961). The city in history: Its origins, its transformations, and its prospects (Vol. 67): Houghton Mifflin Harcourt.

Nantulya, V. M., \& Reich, M. R. (2002). The neglected epidemic: road traffic injuries in developing countries. BMJ: British Medical Journal, 324(7346), 1139.

Neebe, A. W. (1978). A branch and bound algorithm for the p-median transportation problem. Journal of the Operational Research Society, 989-995.

Nelson, A. C., \& Duncan, J. B. (1995). Growth management principles and practices: American Planning Association.

Neuman, M. (2005). The compact city fallacy. Journal of Planning Education and Research, 25(1), 11-26.

Newman, P. (2006). The environmental impact of cities. Environment and Urbanization, 18(2), 275-295.

Newman, P. G. (2006). The environmental impact of cities. Environment and Urbanization, 18(2), 275-295.

Newman, P. G., \& Kenworthy, J. R. (1989). Cities and automobile dependence: an international sourcebook.

NJ Transit. (1994). Planning for transit-friendly land use: A handbook for New Jersey communities. Trenton, NJ: NJ Transit.

Norton, M. G. (2007). Japan's Eco-towns-Industrial clusters or Local Innovation Systems? Paper presented at the Proceedings of the 51st Annual Meeting of the International Society for the Systems Sciences(ISSS).

Olsén, A. (2014). Stockholm, from http://contemporarycity.org/2014/04/stockholm/

Oryani, K., \& Harris, B. (1997). Review of Land Use Models: Theory and Application. Paper presented at the Sixth Transportation Research Board Conference on the Application of Transportation Planning Methods. 
Ottensmann, J. R. (1977). Urban sprawl, land values and the density of development. Land economics, 53(4), 389-400.

Papacostas, C. S., \& Prevedouros, P. D. (1993). Transportation engineering and planning: Prentice Hall.

Park, R. E. (1915). The city: Suggestions for the investigation of human behavior in the city environment. The American Journal of Sociology, 20(5), 577-612.

Park, R. E., \& Burgess, E. W. (1984). The city: University of Chicago Press.

Parr, J. (2004). The polycentric urban region: a closer inspection. Regional Studies, 38(3), 231240.

Pearce, D., \& Atkinson, G. (1998). The concept of sustainable development: An evaluation of its usefulness ten years after Brundtland. Revue Suisse d Economie Politique et de Statistique, 134, 251-270.

Pearce, D. W., \& Atkinson, G. D. (1993). Capital theory and the measurement of sustainable development: an indicator of "weak" sustainability. Ecological economics, 8(2), 103-108.

Peden, M., Scurfield, R., Sleet, D., Mohan, D., Hyder, A. A., Jarawan, E., \& Mathers, C. D. (2004). World report on road traffic injury prevention: World Health Organization Geneva.

Perry, C. (1929). The neighborhood unit. The Urban Design Reader, 54-65.

Petersen, R. (2002). Land-use Planning and Urban Transport. Sustainable Transport: A Sourcebook for Policy-makers in Developing Countries Module 2a. Robdorf, Germany: Deutsche Gesellschaft für Technische Zusammenarbeit (GTZ) GmbH.

Popkowski Leszczyc, P. T., Sinha, A., \& Sahgal, A. (2004). The effect of multi-purpose shopping on pricing and location strategy for grocery stores. Journal of Retailing, 80(2), 85-99.

Posner, S. (2010). Estimating the Genuine Progress Indicator (GPI) for Baltimore, MD.

Posner, S. M., \& Costanza, R. (2011). A summary of ISEW and GPI studies at multiple scales and new estimates for Baltimore City, Baltimore County, and the State of Maryland. Ecological economics, 70(11), 1972-1980.

Pourasghar, S. F., Salehi, E., \& Masnavi, M. (2010). An Analytical-comparative Study on Measurement Methods of Sustainable Development. Environmental Research, 1(1), 6782.

Prastacos, P. (1986). An integrated land-use-transportation model for the San Francisco Region: 1. Design and mathematical structure. Environment and Planning A, 18(3), 307-322.

Putman, S. H. (1983). Integrated urban models: policy analysis of transportation and land use. Oxford, UK. : Routledge.

Qiang, M. (2009). Eco-city and eco-planning in China: taking an example for Caofeidian ecocity. Paper presented at the 4th International Conference of the International Forum on Urbanism Amsterdam,Delft.

Ravenstein, E. G. (1885). The laws of migration. Journal of the Statistical Society of London, 48(2), 167-235.

Rees, W. E. (1992). Ecological footprints and appropriated carrying capacity: what urban economics leaves out. Environment and Urbanization, 4(2), 121-130.

Reilly, W. J. (1931). The law of retail gravitation. New York: Knickerbocker Press.

Reinhardt, P. G. (1973). A Theory of Household Grocery Inventory Holdings. Kyklos, 26(3), 497-511. 
ReVelle, C. S., \& Swain, R. W. (1970). Central facilities location. Geographical Analysis, 2(1), 30-42.

Richard, R. (1987). Ecocity Berkeley: building cities for a healthy future: North Atlantic Books, Berkeley.

Rodrigue, J.-P. (2014). The Geography of Transport System Retrieved 11, 2014, from http://people.hofstra.edu/geotrans/eng/methods/reillylaw.html

Rodrigue, J.-P., Comtois, C., \& Slack, B. (2009). The geography of transport systems: Routledge.

Rushton, G. (1969). Analysis of spatial behavior by revealed space preference. Annals of the Association of American Geographers, 59(2), 391-400.

Saaty, T. L. (1977). A scaling method for priorities in hierarchical structures. Journal of mathematical psychology, 15(3), 234-281.

Salat, S. (2007). Energy and Bioclimatic Efficiency of Urban Morphologies: A Comparative Analysis of Asian and European Cities. Paper presented at the Proceedings of the International Conference on Sustainable Building South East Asia.

Salat, S., Bourdic, L., \& Nowacki, C. (2010). Assessing urban complexity. International Journal of Sustainable Building Technology and Urban Development, 1(2), 160-167.

Sassen, S. (1994). Cities in a world economy: Pine Forge.

Savelson, A., Colman, R., Litman, T., Walker, S., \& Parmenter, R. (2006). The GPI Transportation Accounts-Sustainable Transportation in Nova Scotia: GPI Atlantic.

Savelson, A., Colman, R., \& Martin, W. (2008). The GPI Transportation Accounts: Sustainable Transportation in Halifax Regional Municipality: GPI Atlantic.

Schneider, M. (1959). Gravity models and trip distribution theory. Papers in Regional Science, 5(1), 51-56.

Schrank, D., Eisele, B., \& Lomax, T. (2012). TTI's 2012 URBAN MOBILITY REPORT: Texas A\&M Transportation Institute. The Texas A\&M University System.

Shaw, R. (2007). Eco-towns and the next 60 years of planning. Town \& Country Planning Tomorrow Series Paper, 9.

Singh, R. K., Murty, H., Gupta, S., \& Dikshit, A. (2009). An overview of sustainability assessment methodologies. Ecological indicators, 9(2), 189-212.

Smithsonian Channel's Aerial America. (2010-2012). AERIAL AMERICA: NEW YORK.

Solow, R. M. (1986). On the intergenerational allocation of natural resources. The Scandinavian Journal of Economics, 141-149.

Southworth, F. (1995). A Technical Review of Urban Land Use--Transportation Models as Tools for Evaluating Vehicle Travel Reduction Strategies: U.S. department of Energy: the Office of Environmental Analysis and Sustainable Development

Stahl, K. (1987). Theories of urban business location. In E. S. Mills (Ed.), Handbook of regional and urban economics (Vol. 2, pp. 759-820).

Stewart, J. Q. (1947). Empirical mathematical rules concerning the distribution and equilibrium of population. Geographical Review, 37(3), 461-485.

Stiglitz, J. E., Sen, A., \& Fitoussi, J.-P. (2009). Report by the commission on the measurement of economic performance and social progress. Paris: Commission on the Measurement of Economic Performance and Social Progress.

Stouffer, S. A. (1960). Intervening opportunities and competing migrants. Journal of Regional Science, 2(1), 1-26.

Streissguth, T. (1999). Utopian Visionaries (Vol. 29): The Oliver Press, Inc. 
Suzuki, H., Dastur, A., Moffatt, S., Yabuki, N., \& Maruyama, H. (2010). Eco2 Cities: Ecological cities as economic cities: World Bank Publications.

Sycamore Springs EcoVillage. (2013). Mission and Long-term Goals, from http://www.ecovillages.com/visit_mission.php

Systematics, C., \& Deakin, H. (1994). The Effects of Land Use and Travel Demand Management Strategies on Commuting Behavior: Final Report: US Department of Transportation.

Talberth, J., Cobb, C., \& Slattery, N. (2007). The Genuine Progress Indicator 2006. Oakland, CA: Redefining Progress, 26.

The Economist Online. (2012, Jan 18th 2012). Going to town Retrieved 11, 2014, from http://www.economist.com/blogs/graphicdetail/2012/01/daily-chart-6

Timmermans, H. (2003). The saga of integrated land use-transport modeling: how many more dreams before we wake up? Paper presented at the Keynote paper, Moving through nets: The Physical and social dimension of travel, 10th International Conference on Travel Behaviour Research, Lucerne, www. ivt. baug. ethz. ch/allgemein/pdf/timmermans. pdf.

Tinsley, S., \& George, H. (2006). Ecological footprint of the Findhorn foundation and community: HIE Moray

Torrens, P. M. (2000). How land-use-transportation models work (Working paper). London, UK: Centre for Advanced Spatial Analysis (UCL).

Tsai, Y.-h. (2001). Travel efficient urban form: a nationwide study of small metropolitan areas.

Tsai, Y.-H. (2005). Quantifying urban form: compactness versus' sprawl'. Urban Studies, 42(1), 141-161.

U.S. Census Bureau. (2007-2011). State \& County QuickFacts: Morgantown, WV Retrieved November 23, 2012, from http://quickfacts.census.gov/

U.S. Census Bureau. (2010). State \& County QuickFacts: Morgantown, WV Retrieved November 23, 2012, from http://quickfacts.census.gov/

U.S. Census Bureau. (2012). State \& County QuickFacts: Morgantown , WV Retrieved November 23, 2012, from http://quickfacts.census.gov/

U.S. EPA. (2001). Our Built and Natural Environments: A Technical Review of the Interactions between Land Use, Transportation, and Environmental Quality Washington, D.C.: U.S. EPA Retrieved from http://www.epa.gov/dced/pdf/built.pdf.

UN-HABITAT. (1996). An Urbanizing World, Global Report on Human Settlements: UN Human Settlements Programme.

UN-HABITAT. (2008). State of the World's Cities 2008/2009: Harmonious Cities. London • Sterling, VA: UN-HABITAT.

UNCTAD, U. (2008). Creative Economy. Report 2008. The Challenge of Assessing the Creative Economy: towards informed Policy-making. New York: United Nation.

UNEP. (2011). Keeping Track of Our Changing Environment: From Rio to Rio+20 (1992-2012). Nairobi: Division of Early Warning and Assessment (DEWA), United Nations Environment Programme (UNEP).

United Nations. Dept. of Economic and Social Affairs. (2001). Indicators of sustainable development: Guidelines and methodologies: United Nations, Economic \& Social Affairs.

UNU-IHDP, \& UNEP. (2012). Inclusive Wealth Report 2012: Measuring progress toward sustainability. Cambridge: Cambridge University Press.

Urban Times. (2012). The Beauty of Urban Planning from Space, from http://sustainablecitiescollective.com/node/98151 
US Census Bureau. (2013). Estimated U.S. Per Capita Retail Sales by Selected Kind of Business: 1992 Through 2012 Retrieved 11, 2014, from http://www2.census.gov/retail/releases/current/arts/percap.xls

Victor, P. A. (1991). Indicators of sustainable development: some lessons from capital theory. Ecological economics, 4(3), 191-213.

Victoria Transport Policy Institute. (2011). Accessibility Retrieved 11, 2014, from http://www.vtpi.org/tdm/tdm84.htm

Victoria Transport Policy Institute. (2014). Roadway Connectivity: Creating More Connected Roadway and Pathway Networks Retrieved 11, 2014, from http://www.vtpi.org/tdm/tdm116.htm

Waddell, P. (1998). The Oregon prototype metropolitan land use model. Paper presented at the 1998 ASCE Conference on Transportation, Land Use and Air Quality: Making the Connection.

Wang, X., \& Vom Hofe, R. (2007). Research methods in urban and regional planning: Springer. Weber, A. (1909). Über den Standort der Industrien: JCB Mohr.

Wegener, M. (2004). Overview of land-use transport models. Handbook of transport geography and spatial systems, 5, 127-146.

Wheaton, W. C. (1974). Linear programming and locational equilibrium: the Herbert-Stevens model revisited. Journal of Urban Economics, 1(3), 278-287.

Wikipedia. (2013a). Champlain, Quebec, from http://en.wikipedia.org/wiki/Champlain,_Quebec Wikipedia. (2013b). Paolo Soleri, from http://en.wikipedia.org/wiki/Paolo_Soleri

Williams, K., Burton, E., Jenks, M., Williams, K., Burton, E., \& Jenks, M. (2000). Achieving sustainable urban form: an introduction. Achieving sustainable urban form, 1-5.

Williams, K., Jenks, M., \& Burton, E. (2000). Achieving sustainable urban form: Routledge.

Wilson, A. (1967). A statistical theory of spatial distribution models. Transportation research, 1(3), 253-269.

Woodhouse, P., Howlett, D., \& Rigby, D. (2000). Sustainability indicators for natural resource management \& policy: A framework for research on sustainability indicators for agriculture and rural livelihoods (working paper). Department for International Development Research Project No. R7076CA.

World Bank. (1997). Expanding the measure of wealth: indicators of environmentally sustainable development Environmentally Sustainable Development Studies and Monographs Series (World Bank). Washington, DC.

World Bank. (2006). Where is the Wealth of Nations? Measuring Capital for the 21st Century. Washington, D.C.

World Health Organization. (2011). Air quality and health, from http://www.who.int/mediacentre/factsheets/fs313/en/index.html

Wright, F. L. (1935). Broadacre City: A new community plan. Architectural Record, 77(4), 243254.

Yevdokimov, Y. (2004). Sustainable Transportation in Canada. Draft Paper: Departments of Economics and Civil Engineering, University of New Brunswick, Canada.

Yevdokimov, Y., \& Mao, H. (2002). Modeling Sustainable Transportation Systems.

Yu, B., Yang, Z., \& Cheng, C. (2007). Optimizing the distribution of shopping centers with parallel genetic algorithm. Engineering Applications of Artificial Intelligence, 20(2), 215223. 
Zegras, C. (2005). Sustainable urban mobility: exploring the role of the built environment. Massachusetts Institute of Technology.

Zegras, C. (2006). Sustainable transport indicators and assessment methodologies. Paper presented at the Biannual Conference and Exhibit of the Clean Air Initiative for Latin American Cities.

Zhang, W.-B. (2002). An Economic Theory of Cities: Spatial Models with Capital, Knowledge, and Structures (Vol. 512): Springer.

Zipf, K. G. (1949). Human behavior and the principle of least effort: Addison-Wesley. 